\title{
High performance of simple organic phosphorescence host-guest materials
}

Yunsheng Wang,"\#, Heqi Gao ${ }^{2, \#}$, Jie Yang ${ }^{1 *}$, Manman Fang ${ }^{1}$, Dan Ding ${ }^{2 *}$, Ben Zhong Tang ${ }^{1,4 *}$ and Zhen $\mathrm{Li}^{1,3,5 *}$

${ }^{1}$ Tianjin Key Laboratory of Molecular Optoelectronic Sciences, Department of Chemistry, Institute of Molecular Aggregation Science, Tianjin University, Tianjin 300072, China

${ }^{2}$ Collaborative Innovation Center of Chemical Science and Engineering, Nankai University, Tianjin 300071, China

${ }^{3}$ Department of Chemistry, Sauvage Center for Molecular Sciences, Wuhan University, Wuhan 430072, China ${ }^{4}$ Department of Chemistry, The Hong Kong University of Science \& Technology, Clear Water Bay, Kowloon, Hong Kong

${ }^{5}$ Joint School of National University of Singapore, Tianjin University, International Campus of Tianjin University, Binhai New City, Fuzhou 350207, China

\#These authors contributed equally to this work

*E-mail: jieyang2018@tju.edu.cn; dingd@nankai.edu.cn; tangbz@ust.hk; lizhen@whu.edu.cn.

The study of purely organic room-temperature phosphorescence (RTP) has drawn increasing attention because of its considerable theoretical research and practical application value. Currently, organic RTP materials with both high efficiency $\left(\Phi_{P}>20 \%\right)$ and a long lifetime $\left(\tau_{\mathrm{P}}>\mathbf{1 0} \mathrm{s}\right)$ in air are still scarce due to the lack of related design guidance. Here, we report a new strategy to increase the phosphorescence performance of organic materials by integrating the RTP host and RTP guest in one doping system to form a triplet 
exciplex. With these materials, the high-contrast labelling of tumours in living mice and encrypted patterns in thermal printing are both successfully realized for the first time by taking advantage of both the long afterglow time (up to $25 \mathrm{~min}$ in aqueous media) and high phosphorescence efficiency $(43 \%)$.

Room-temperature phosphorescence (RTP) has attracted much attention because of its potential applications in bio-imaging, anticounterfeiting and OLEDs thanks to its long emission lifetime and high exciton utilization. ${ }^{1-2}$ Most RTP materials are based on inorganic or organometallic complexes, which might suffer from a series of intrinsic problems, such as potential toxicity, high cost, and inferior stability in aqueous environments. ${ }^{3}$

In recent years, purely organic RTP materials have been discovered and quickly become a research hotspot, as they could overcome most of the problems encountered in inorganic or organometallic RTP systems. A variety of RTP systems have been developed based on host-guest interactions, $H$-aggregation, heavy-atom effects, intermolecular electronic coupling, intermolecular $\pi-\pi$ or hydrogen bond interactions, etc. ${ }^{4-10}$ However, organic RTP materials with both high efficiency $\left(\Phi_{\mathrm{P}}>20 \%\right)$ and a long lifetime $\left(\tau_{\mathrm{P}}>10 \mathrm{~s}\right)$ in air are still scarce, as the efficiency and lifetime are in competition with each other in theory, similar to the impossibility of having your cake and eating it too. Partially due to the limited performance of organic RTP materials, progress in their corresponding applications is not sufficient, especially for time-resolved bio-imaging (Chart S1) ${ }^{8,11-20}$ 


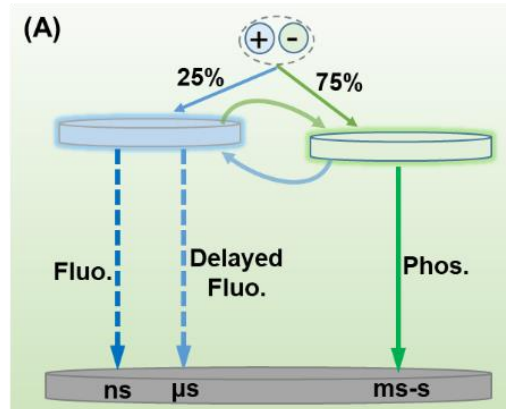

(B)

(C)

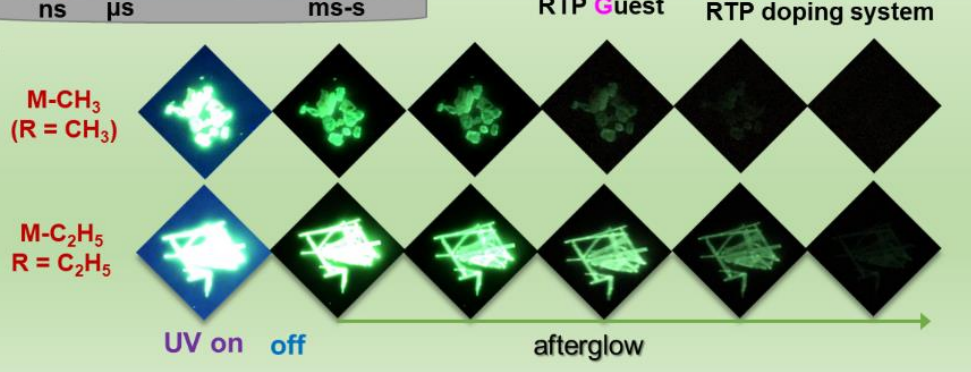

Fig. 1 The construction of RTP systems and their corresponding performance. (A) Schematic diagram of room-temperature phosphorescence, which shows the characteristics of a long emission lifetime and high exciton utilization efficiency. (B) The strategy used to develop efficient RTP materials with an RTP host and RTP guest to construct a doping system. (C) The RTP behaviours of the host-guest doping systems based on $\mathrm{M}-\mathrm{CH}_{3}$ and $\mathrm{M}-\mathrm{C}_{2} \mathrm{H}_{5}$.

\section{RTP behaviours}

In this work, a series of organic RTP materials with both high efficiency and long lifetimes were successfully developed by intelligently integrating the RTP host and RTP guest into one doping system. As shown in Fig. 1, two phenothiazine derivatives $\left(\mathrm{CzS}-\mathrm{CH}_{3}\right.$ and $\left.\mathrm{CzS}-\mathrm{C}_{2} \mathrm{H}_{5}\right)$ were selected as guests, and their corresponding dioxide derivatives $\left(\mathrm{CS}-\mathrm{CH}_{3}\right.$ and $\left.\mathrm{CS}-\mathrm{C}_{2} \mathrm{H}_{5}\right)$ were selected as hosts to yield the host-guest systems of $\mathrm{M}-\mathrm{CH}_{3}$ and $\mathrm{M}-\mathrm{C}_{2} \mathrm{H}_{5}$, respectively, since they were found to show moderate RTP effects and matched energy levels in our previous works. ${ }^{15,21}$ Upon co-crystallization, grinding or heating stimulus of the mixed samples of RTP hosts and guests, bright RTP emission was achieved with a phosphorescence efficiency of up to $20 \%$ and $43 \%$ 
for $\mathrm{M}-\mathrm{CH}_{3}$ and $\mathrm{M}-\mathrm{C}_{2} \mathrm{H}_{5}$, respectively. Notably, their long persistent luminescence lasting for 25 min could be monitored even in aqueous environments. After carefully investigating their photophysical properties, coupled with theoretical calculations, it was found that the formation of a triplet exciplex played a significant role in the outstanding RTP performance of these materials. Accordingly, the applications of time-resolved bio-imaging and encrypted thermal printing were explored. Ultimately, the high-contrast and high-selectivity labelling of tumours in living mice and clear patterns in thermal printing were both successfully realized for the first time.

The photoluminescence (PL) behaviours of the hosts, guests and their corresponding doping systems through co-crystal are shown in Fig. 2A and Figs. S1-S4. Taking the methyl-substituted system of $\mathrm{M}-\mathrm{CH}_{3}$ as an example, $\mathrm{CS}-\mathrm{CH}_{3}$ and $\mathrm{CzS}-\mathrm{CH}_{3}$ present moderate RTP performance with phosphorescence lifetimes of $245 / 1.01 \mathrm{~ms}$ and quantum yields of approximately $1 \%$, while the corresponding fluorescence emissions are dominant (Fig. 2A). Once mixed together at a mass ratio of 100:1 to form a co-crystal, significant changes occurred. $\mathrm{M}-\mathrm{CH}_{3}$ showed a pure RTP emission with a considerable increase in the phosphorescence efficiency to $20 \%$. Furthermore, the afterglow, in which two components exist, was also largely prolonged (Fig. S2). One component was bright and relatively short $(39 \mathrm{~ms})$, while the other could last for tens of min, with a lifetime of $17 \mathrm{~s}$ with relatively weak emission (Fig. 2A). Similar phenomena were observed for the $\mathrm{M}-\mathrm{C}_{2} \mathrm{H}_{5}$ system based on $\mathrm{CS}-\mathrm{C}_{2} \mathrm{H}_{5}$ and $\mathrm{CzS}-\mathrm{C}_{2} \mathrm{H}_{5}$ (Fig. S3-S4), while much inferior RTP performance was observed for the systems based on $\mathrm{CS}-\mathrm{CH}_{3} / \mathrm{CzS}-\mathrm{C}_{2} \mathrm{H}_{5}$ or $\mathrm{CS}-\mathrm{C}_{2} \mathrm{H}_{5} / \mathrm{CzS}-\mathrm{CH}_{3}$. Excitingly, the RTP efficiency of $\mathrm{M}-\mathrm{C}_{2} \mathrm{H}_{5}$ increased to as high as $43 \%$, which is among the highest values for organic persistent RTP materials. ${ }^{1-2}$ Thus, both high RTP efficiency and a long lifetime were achieved in these two systems. 

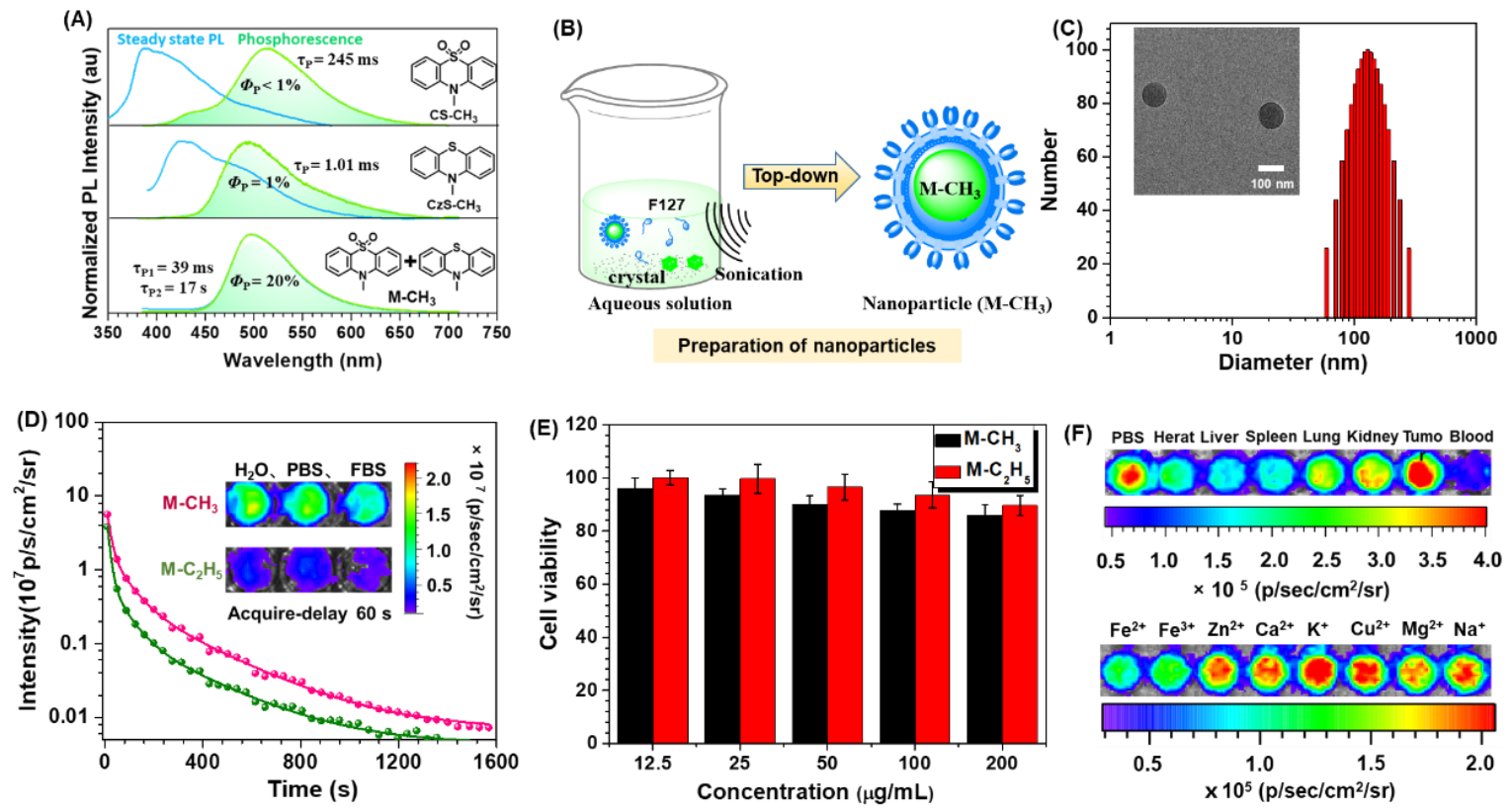

Fig. 2 Photophysical properties of $\mathbf{M}-\mathrm{CH}_{3}$. (A) The steady-state PL and RTP spectra of $\mathrm{CS}_{-} \mathrm{CH}_{3}, \mathrm{CzS}_{3}-\mathrm{CH}_{3}$ and their co-crystal $\left(\mathrm{M}-\mathrm{CH}_{3}\right)$ with a mass ratio of $100: 1$; (B) Schematic diagram of the preparation of nanocrystals via a top-down route; (C) Size distribution of $\mathrm{M}-\mathrm{CH}_{3}$ nanocrystals. Inset: TEM image. (D) Time-dependent luminescence decay of ultralong phosphorescence of nanocrystals based on $\mathrm{M}-\mathrm{CH}_{3}$ and M- $\mathrm{C}_{2} \mathrm{H}_{5}$ recorded after turning off the light irradiation, acquired by an IVIS ${ }$ instrument in bioluminescent mode. Inset: Phosphorescent images of nanocrystals in different aqueous media acquired at $60 \mathrm{~s}$ after stopping light excitation; (E) Cytotoxicities of $\mathrm{M}-\mathrm{CH}_{3}$ and $\mathrm{M}-\mathrm{C}_{2} \mathrm{H}_{5}$ nanocrystals against HeLa cancer cells. The HeLa cells were incubated with nanocrystals at various concentrations for $24 \mathrm{~h}$. (F) Phosphorescent images of M-CH nanocrystals after incubation with various metal ions and tissue homogenates from healthy mice. Error bars, mean \pm standard deviation $(n=3)$.

\section{Preparation and characterization of RTP nanocrystals}

To make our RTP materials accessible in vivo, a top-down method was employed to formulate $\mathrm{M}-\mathrm{CH}_{3}$ and $\mathrm{M}-\mathrm{C}_{2} \mathrm{H}_{5}$ to form nanocrystals using the biocompatible amphiphilic co-polymer 
PEG-b-PPG-b-PEG (F127) as the encapsulation matrix (Fig. 2B). ${ }^{8,11-12}$ The hydrophilic PEG chains could extend to aqueous media, thus protecting the nanocrystals. Dynamic light scattering (DLS) and transmission electron microscopy (TEM) data revealed that both $\mathrm{M}-\mathrm{CH}_{3}$ and $\mathrm{M}-\mathrm{C}_{2} \mathrm{H}_{5}$ nanocrystals had an almost spherical morphology with a mean hydrodynamic diameter of $\sim 130$ nm (Fig. 2C and Fig. S5). Both kinds of nanocrystals exhibited good colloidal stability, indicative of little change in their size after incubation in PBS solution for one week (Fig. S6). On the other hand, strong resistance to photobleaching could be observed, and no obvious change in their afterglows could be observed after eight cycles of activation or eighty min of UV irradiation (Fig. S7). The persistent luminescence of our nanocrystals was then collected and monitored by an IVIS ${ }^{\circledR}$ bio-imaging instrument. The $\mathrm{M}-\mathrm{CH}_{3}$ and $\mathrm{M}-\mathrm{C}_{2} \mathrm{H}_{5}$ nanocrystals were suspended in various aqueous media, including Milli-Q water, $1 \times$ PBS solution ( $\mathrm{pH} 7.4$ ), and foetal bovine serum (FBS), followed by $1 \mathrm{~min}$ of irradiation with a $365 \mathrm{~nm}$ handheld UV lamp. After that, phosphorescent images were acquired at different time points after the end of light excitation using an IVIS $^{\circledR}$ instrument in bioluminescent mode. The qualitative and quantitative data, as depicted in Fig. 2D, indicate that $\mathrm{M}-\mathrm{CH}_{3}$ nanocrystals can emit persistent phosphorescence for 25 min, which is significantly longer than that of $\mathrm{M}-\mathrm{C}_{2} \mathrm{H}_{5}$ nanocrystals (20 min). To our knowledge, phosphorescence lasting for $25 \mathrm{~min}$ in aqueous media represents the longest among currently reported RTP materials. ${ }^{1-2,11-20}$

\section{In vivo imaging}

After we demonstrated the rather low cytotoxicities and in vivo side toxicities of $\mathrm{M}-\mathrm{CH}_{3}$ and M- $\mathrm{C}_{2} \mathrm{H}_{5}$ nanocrystals (Fig. 2E and Fig. S8-S9), their application in intravital phosphorescent 
imaging was carried out (Fig. 3). In this experiment, PBS solutions of $\mathrm{M}-\mathrm{CH}_{3}$ and $\mathrm{M}-\mathrm{C}_{2} \mathrm{H}_{5}$ nanocrystals were first irradiated by a $365 \mathrm{~nm}$ handheld UV lamp for $30 \mathrm{~s}$, and the nanocrystals were then subcutaneously injected into Balb/c nude mice, followed by imaging with an IVIS ${ }^{\circledR}$ instrument in bioluminescent mode. As displayed in Fig. 3B and Fig. S10, the in vivo phosphorescent imaging result reveals that both phosphorescent signals from $\mathrm{M}-\mathrm{CH}_{3}$ and $\mathrm{M}-\mathrm{C}_{2} \mathrm{H}_{5}$ nanocrystals can be seen underneath the mouse skin at $30 \mathrm{~s}$ after the end of light excitation. The signal-to-background ratios (SBRs) of subcutaneous phosphorescent imaging for $\mathrm{M}-\mathrm{CH}_{3}$ and M- $\mathrm{C}_{2} \mathrm{H}_{5}$ nanocrystals at $30 \mathrm{~s}$ are as high as 310 and 147 (Fig. S10), respectively, considerably higher than the SBR values of the reported fluorescence imaging, including NIR-II fluorescence imaging, ${ }^{22-24}$ showing the advantage of time-resolved phosphorescent imaging with negligible background interference. The subcutaneous phosphorescent signal from $\mathrm{M}-\mathrm{CH}_{3}$ nanocrystals can still be detected even at $24 \mathrm{~min}$ after the end of light excitation by virtue of its ultra-long phosphorescence duration. In contrast, under the same imaging conditions, a negligible phosphorescent signal from the $\mathrm{M}-\mathrm{C}_{2} \mathrm{H}_{5}$ nanocrystals is observed at $1 \mathrm{~min}$. Notably, this result demonstrates the first successful example of intravital phosphorescent imaging without real-time light excitation during the in vivo imaging process. 


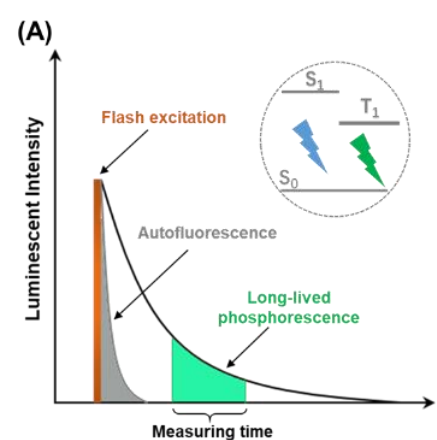

(D)
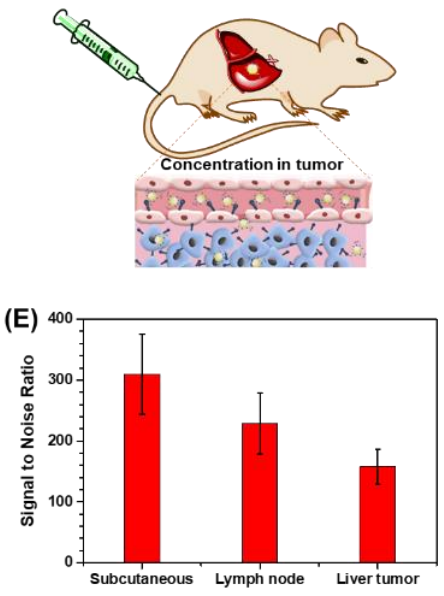

(B)

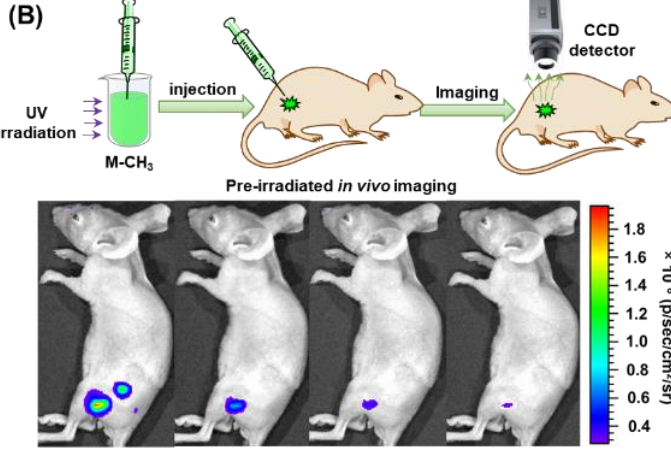

$30 \mathrm{~s} 1 \mathrm{~min}$

Subcutaneous imaging
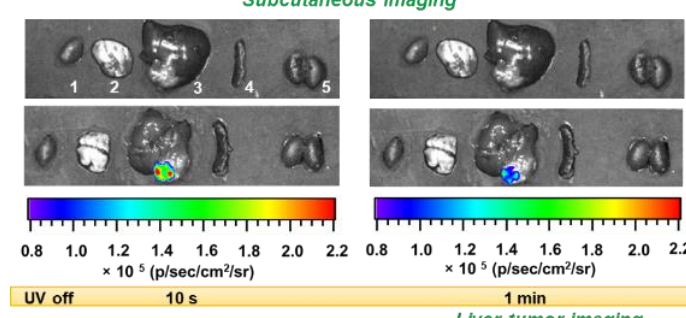

(F)

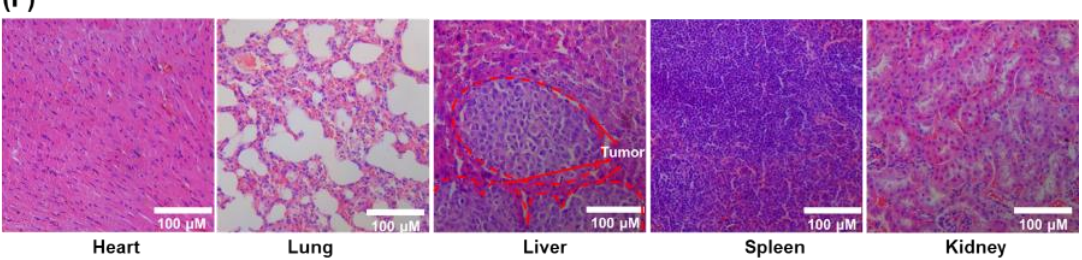

Fig. 3 Demonstration of bio-imaging applications based on $\mathrm{M}-\mathrm{CH}_{3}$ nanocrystals. (A) Schematic diagram of

time-resolved bio-imaging. (B) Time-resolved phosphorescence imaging of a mouse that received subcutaneous injection of $\mathrm{M}-\mathrm{CH}_{3}$ (down) and $\mathrm{M}-\mathrm{C}_{2} \mathrm{H}_{5}$ (upper) nanocrystals. The nanocrystals were pre-irradiated with 365 nm light, followed by subcutaneous injection in vivo. (C) Phosphorescence imaging of sentinel lymph nodes of mice 10 min after forepaw injection of $\mathrm{M}_{-} \mathrm{CH}_{3}$ nanocrystals. The phosphorescent signal was collected at $10 \mathrm{~s}$ after turning off the UV irradiation. (D) Time-resolved phosphorescence imaging of different organs (1-heart, 2-lung, 3-liver, 4-spleen and 5-kidney) from orthotopic LM3 liver tumour-bearing mice at $7 \mathrm{~h}$ post intravenous injection of saline (upper) or $\mathrm{M}^{-\mathrm{CH}_{3}}$ nanocrystals (lower). (E) In vivo SBR ratios for time-resolved phosphorescence imaging of subcutaneous, lymph node and liver tumour in (B-D). (F) H\&E-stained images of major organs of the orthotopic liver tumour-bearing mice after intravenous injection of $\mathrm{M}-\mathrm{CH}_{3}$ nanocrystals.

The utilization of sentinel lymph node imaging using $\mathrm{M}-\mathrm{CH}_{3}$ nanocrystals was further 
investigated. The $\mathrm{M}-\mathrm{CH}_{3}$ nanocrystals without pre-excitation were administered into the forepaw of live mice. At 10 min post-injection, the mice were exposed to $365 \mathrm{~nm}$ light irradiation for $30 \mathrm{~s}$, followed by phosphorescent imaging at $10 \mathrm{~s}$ after the end of light excitation. The subaxillary sentinel lymph node can be clearly delineated with a high SBR of 229 (Fig. 3C and 3E). The precision of the lymph node distribution of the nanocrystals was confirmed by haematoxylin and eosin (H\&E) staining (Fig. S11). Furthermore, similar to the subcutaneous imaging, the pre-excited $\mathrm{M}-\mathrm{CH}_{3}$ nanocrystals are also able to light up subaxillary sentinel lymph nodes with an SBR of 79 (Fig. S12).

Encouraged by the excellent phosphorescent properties of $\mathrm{M}-\mathrm{CH}_{3}$ nanocrystals and the above phosphorescent imaging results, the feasibility of applying the nanocrystals in cancer diagnosis in vivo was studied. It was surprising to observe that the phosphorescence of $\mathrm{M}-\mathrm{CH}_{3}$ nanocrystals was almost totally quenched in the blood due to the quenching effect of $\mathrm{Fe}^{2+}$ and $\mathrm{Fe}^{3+}$ ions (Fig. S13-S14), which would be beneficial for the labelling of tumours. For cancer diagnosis, the $\mathrm{M}-\mathrm{CH}_{3}$ nanocrystals were intravenously injected into orthotopic LM3 liver tumour-bearing mice. At $7 \mathrm{~h}$ post-injection, the mice were sacrificed, and the main tissues were excised for ex vivo imaging with $365 \mathrm{~nm}$ handheld UV lamp irradiation and phosphorescent signal collection by an IVIS ${ }^{\circledR}$ instrument. At $10 \mathrm{~s}$ after turning off the UV irradiation, the liver tumours that were verified by $H \& E$ staining could be fully delineated with clear margin differentiation between the tumours and normal liver (Fig. 3D-3F and Fig. S15). The SBR value (tumour-to-normal liver) was determined to be 158 (Fig. 3E), which represents one of the highest values, to our knowledge, among currently reported optical imaging studies of orthotopic liver tumours. ${ }^{25-26}$ Furthermore, the phosphorescent signal in liver tumours lasted at least 2 min after 
the end of $365 \mathrm{~nm}$ light excitation. Interestingly, as shown in Fig. 3D, only orthotopic liver tumours exhibited phosphorescent signals from the $\mathrm{M}-\mathrm{CH}_{3}$ nanocrystals, whereas other tissues, including heart, lung, spleen, kidneys and normal liver, did not emit phosphorescence. It has been well established that nanosized materials tend to be enriched in reticuloendothelial system (RES) organs, including the liver and spleen. Therefore, the $\mathrm{M}-\mathrm{CH}_{3}$ nanocrystals showed quenched phosphorescence in these RES organs, particularly the liver, where there is abundant blood supply. On the other hand, when the $\mathrm{M}-\mathrm{CH}_{3}$ nanocrystals passively target liver tumour tissues by the enhanced permeability and retention (EPR) effect, a number of nanocrystals could leak from the tumour vasculature to the tumour interstitial space, which may lead to the separation of nanocrystals with iron ion-rich components in the blood, significantly recovering their phosphorescence generation ability.

Furthermore, a pulmonary metastatic carcinoma-bearing mouse model was also employed to study the tumour diagnostic capability of $\mathrm{M}-\mathrm{CH}_{3}$ nanocrystals (Figs. S16-S17). The results in Fig. S16 indicate that the phosphorescence of $\mathrm{M}-\mathrm{CH}_{3}$ nanocrystals selectively occurred in orthotopic lung tumours, while nearly no phosphorescent signal was observed in other normal organs, including normal lung, liver and spleen. Thus, our nanocrystals can serve as a simple but "smart" probe for specific and high-contrast phosphorescence imaging of orthotopic tumours in vivo, which hence shows a unique signature over other persistent luminescence systems.

\section{Stimuli-responsive RTP effect and thermal printing application}

In addition to forming co-crystals, grinding or heating the host and guest mixtures could also produce bright RTP emission upon formation of an efficient intermolecular interaction (Fig. 
S18-S19). ${ }^{27-28}$ Accordingly, thermal printing was explored based on $\mathrm{M}-\mathrm{C}_{2} \mathrm{H}_{5}$ for its outstanding RTP efficiency. ${ }^{29}$ A thermal printer works mainly through heat derived from electricity, which produces a printed image by selectively heating coated thermochromic paper. However, commercial thermochromic paper contains the toxic substance bisphenol A, which has been found to be highly related to several human diseases. As shown in Figure S18, when the new thermal paper passes over the print head, the intermolecular interactions between $\mathrm{CS}-\mathrm{C}_{2} \mathrm{H}_{5}$ and $\mathrm{CzS}-\mathrm{C}_{2} \mathrm{H}_{5}$ could be strengthened under the combined actions of heating and pressure, leading to bright green emission. Various set patterns with green afterglow could be painted and clearly observed by the naked eye, making it possible to replace bisphenol A with $\mathrm{M}-\mathrm{C}_{2} \mathrm{H}_{5}$.

\section{Internal mechanism}

To clarify the origin of the boosted RTP performance in doping systems, their photophysical properties were studied. In comparison with the spectra of $\mathrm{CS}-\mathrm{CH}_{3}$ and $\mathrm{CzS}-\mathrm{CH}_{3}$, a new shoulder peak appears in the range of 350 to $420 \mathrm{~nm}$ for the UV-vis absorption spectrum of $\mathrm{M}-\mathrm{CH}_{3}$, indicating the occurrence an intermolecular charge transfer. Furthermore, the newly formed absorption peak is totally identical to the RTP excitation spectrum of $\mathrm{M}-\mathrm{CH}_{3}$ (Fig. 4A-4B), indicating the formation of a triplet exciplex (Fig. S20-S22). ${ }^{30-31}$ This is thought to be the main reason for the increased RTP performance in doping systems, as the triplet exciplex has previously been reported to be able to enhance the radiative transition of phosphorescence. ${ }^{30}$ 

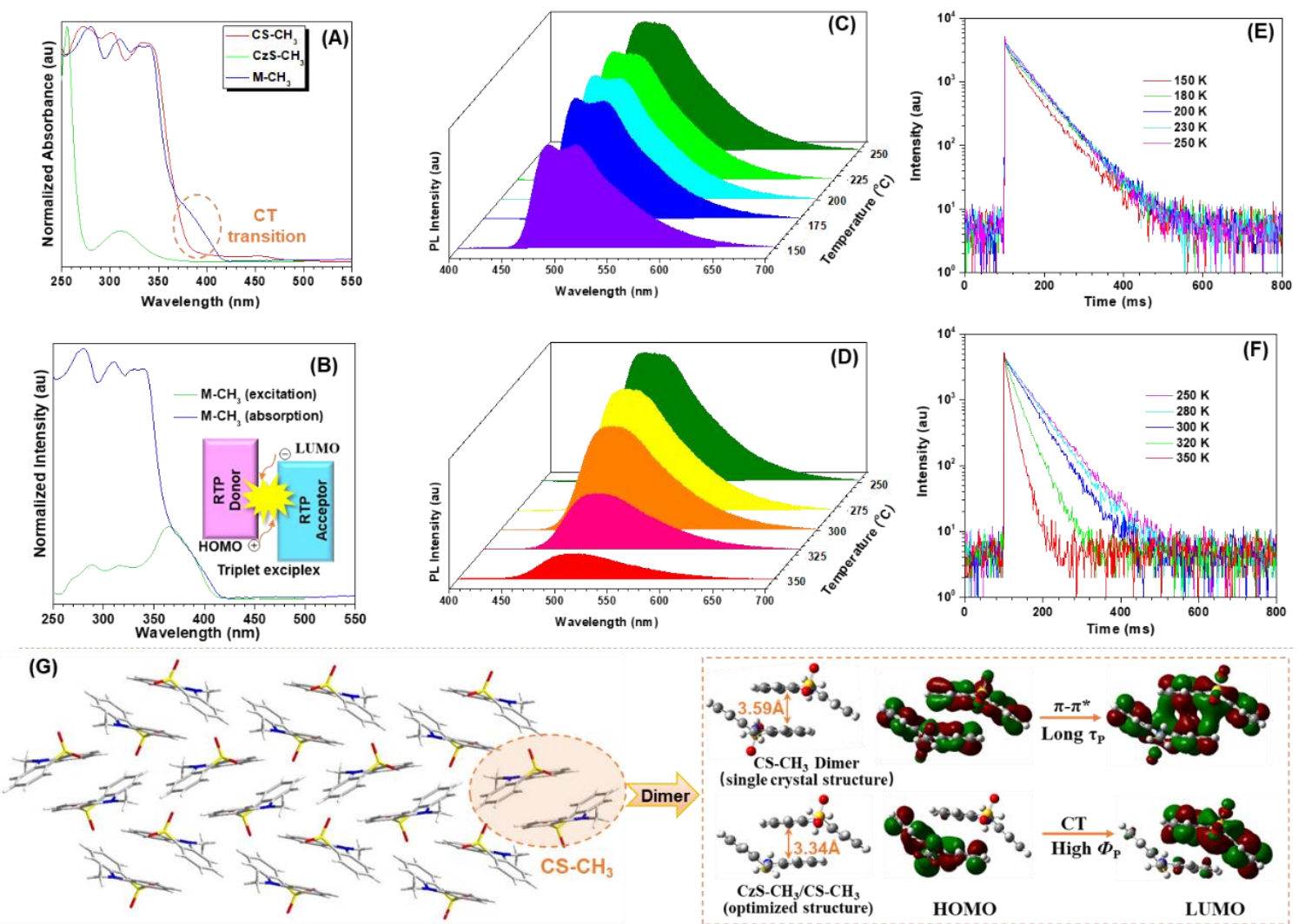

Fig.4 The photophysical properties of $\mathrm{M}-\mathrm{CH}_{3}$. (A) UV-vis absorption spectra of $\mathrm{CS}^{-\mathrm{CH}_{3}}$ (in crystal state),

CzS-CH $\mathrm{CH}_{3}$ (in THF solution) and M-CH 3 (in crystal state); (B) UV-vis absorption and RTP excitation spectra of $\mathrm{M}-\mathrm{CH}_{3}$ in crystal state. Inset: schematic diagram of the triplet exciplex; (C) PL spectra of $\mathrm{M}-\mathrm{CH}_{3}$ in the crystal state with the temperature ranging from 150 to $250 \mathrm{~K}$; (D) $\mathrm{PL}$ spectra of $\mathrm{M}_{-} \mathrm{CH}_{3}$ in the crystal state with the temperature ranging from 250 to $350 \mathrm{~K} ; \mathbf{( E )} \mathrm{PL}$ decay curves of $\mathrm{M}-\mathrm{CH}_{3}$ in the crystal state with the temperature ranging from 150 to $250 \mathrm{~K}$; (F) $\mathrm{PL}$ decay curves of $\mathrm{M}-\mathrm{CH}_{3}$ in the crystal state with the temperature ranging from 250 to $350 \mathrm{~K} ;(\mathbf{G})$ Crystal structure of $\mathrm{M}_{-}-\mathrm{CH}_{3}$ and the corresponding theoretical calculations.

On the other hand, a slight increase in the RTP intensity and lifetime from 150 to $250 \mathrm{~K}$ could be detected for the $\mathrm{M}-\mathrm{CH}_{3}$ crystal for the promoted formation of the triplet exciplex (Fig. 4C-4F). ${ }^{32}$ Correspondingly, obvious intermolecular charge transfer could be observed for $\mathrm{M}-\mathrm{CH}_{3}$, from the occupied orbital of $\mathrm{CzS}-\mathrm{CH}_{3}$ (donor) to the vacant orbital of the neighbouring $\mathrm{CS}-\mathrm{CH}_{3}$ 
(acceptor), leading to the much larger spin orbit coupling constant between $\mathrm{T}_{1}$ and $\mathrm{S}_{0}$ for $\mathrm{M}-\mathrm{CH}_{3}$ (32.03198) than for the $\mathrm{CS}_{-} \mathrm{CH}_{3}$ dimer (2.81142) (Table S1, Fig. S23-S26, Fig. 4G). Similar results could also be obtained for the system based on $\mathrm{CS}_{-} \mathrm{C}_{2} \mathrm{H}_{5}$ and $\mathrm{CzS}-\mathrm{C}_{2} \mathrm{H}_{5}$ (Table S2 and Fig. S27-S31). These experimental and calculated results further demonstrate the formation of the triplet exciplex and its significant role in increasing the RTP efficiency.

Why do these doping systems show more prolonged RTP lifetimes than the corresponding donors and acceptors? By analysing the PL spectra of the acceptor (host molecule) and corresponding triplet exciplex carefully, it can be found that they present similar RTP spectra with emission peaks at approximately $500 \mathrm{~nm}$, indicating their close energy levels in the $\mathrm{T}_{1}$ state. Thus, the triplet excitons could recycle between them, largely increasing the RTP lifetimes of both the acceptor and the corresponding triplet exciplex. Thus, two components exist in the PL decay curves for the doping systems: one is relatively short from the triplet exciplex, while the other can last for tens of min from the acceptor. 
(A)

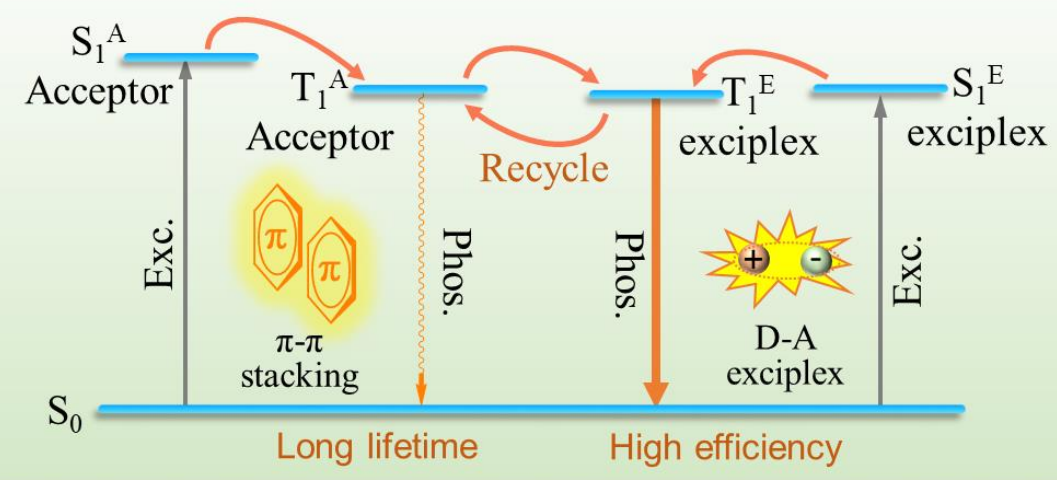

(B)

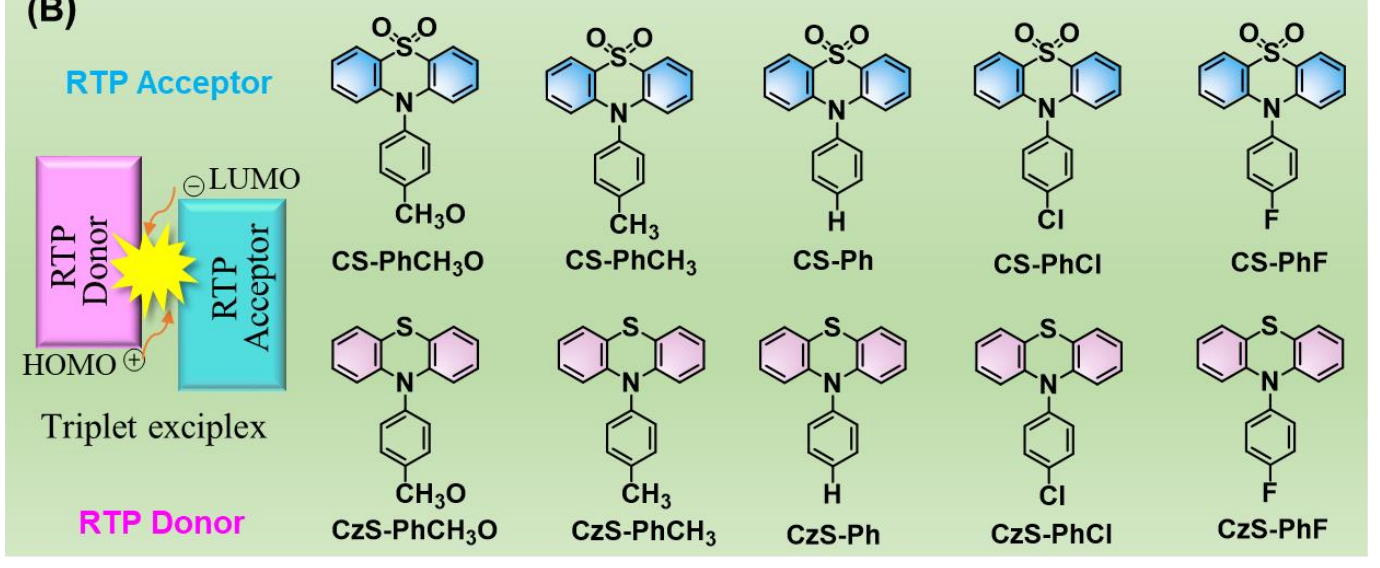

Fig. 5 The proposed RTP mechanism and expanded RTP systems. (A) The proposed excited-state process of the doping systems: when the molecules in the doping systems are irradiated with UV light, triplet excitons can be formed through two main approaches, one from acceptor/host molecules and the other from the triplet exciplex. As the acceptor and corresponding triplet exciplex share similar energy levels in the $T_{1}$ state, the triplet excitons could recycle between them, largely increasing the RTP lifetimes of both the acceptor and the corresponding triplet exciplex. (B) Molecular structures of some other RTP donors and acceptors used to form a triplet exciplex.

To verify the wide applicability of our design strategy to increase RTP performance with integrated RTP donors and acceptors, five other phenothiazine derivatives and their corresponding dioxide derivatives were investigated (Fig. S32-S43, Table S3-S6). After doping the RTP donor into an acceptor with a mass fraction of 100:1, the resultant co-crystals all showed 
excellent RTP performance with a maximum phosphorescence efficiency of $54.8 \%$ and afterglows lasting for several min in air, although only a moderate RTP effect could be observed for these RTP donors and acceptors separately. Careful analyses of their photophysical properties suggest that the formation of a triplet exciplex is also the main reason for their considerably increased RTP performance. Thus, the wide applicability of our design strategy was well verified.

\section{Conclusions}

In this work, by integrating the RTP host and RTP guest into one doping system, a series of efficient purely organic RTP materials were developed with both high phosphorescence efficiency $(>20 \%$ ) and a long afterglow of up to $25 \mathrm{~min}$ in an aqueous environment. Accordingly, the high-contrast labelling of tumours in living mice was successfully realized for the first time by utilizing time-resolved bioimaging technology. On the other hand, the double stimulus-responsive RTP effect upon grinding and heating could be easily realized based on the interaction between the host and guest, and encrypted patterns in thermal printing could be achieved. Thus, this work is expected to greatly promote the development of organic RTP research from both material design and practical applications.

\section{References}

1. Kenry. Chen, C \& Liu, B. Enhancing the performance of pure organic room temperature phosphorescent luminophores. Nat. Commun. 10, 2111 (2019).

2. Zhao, W. He, Z. \& Tang, B. Room-temperature phosphorescence from organic aggregates. Nat. Rev. Mater. DOI: 10.1038/s41578-020-0223-z (2020). 
3. Zhang, K. et al. Long-Lived Emissive Probes for Time-Resolved Photoluminescence Bioimaging and Biosensing. Chem. Rev. 118, 1770-1839 (2018).

4. Zhang, G. Palmer, G. Dewhirst, M. \& Fraser, C. A dual-emissive-materials design concept enables tumour hypoxia imaging. Nat. Mater. 8, 747-751 (2009).

5. Kabe, R. \& Adachi, C. Organic long persistent luminescence. Nature 550, 384-387 (2017).

6. An. Z. et al. Stabilizing triplet excited states for ultralong organic phosphorescence. Nat. Mater. 14, 685-690 (2015).

7. Bolton, O. Lee, K. Kim, H. Lin, K. \& Kim, J. Activating efficient phosphorescence from purely organic materials by crystal design. Nat. Chem. 3, 205-210 (2011).

8. Yang, J. et al. The influence of the molecular packing on the room temperature phosphorescence of purely organic luminogens. Nat. Commun. 9, 840 (2018).

9. Yang, Z. et al. Intermolecular Electronic Coupling of Organic Units for Efficient Persistent Room-Temperature Phosphorescence. Angew. Chem. Int. Ed. 55, 2181-2185 (2016).

10. Zhang, Z. Chen, Y. \& Liu, Y. Efficient Room-Temperature Phosphorescence of a Solid-State Supramolecule Enhanced by Cucurbit[6]uril. Angew. Chem. Int. Ed. 58, 6028-6032 (2019).

11. Zhen, X. et al. Ultralong Phosphorescence of Water-Soluble Organic Nanoparticles for In Vivo Afterglow Imaging. Adv. Mater. 29, 1606665 (2017).

12. He, Z. et al. Achieving Persistent, Efficient, and Robust Room-Temperature Phosphorescence from Pure Organics for Versatile Applications. Adv. Mater. 31, 1807222 (2019).

13. Zhang, T. et al. Hydrogen bonding boosted the persistent room temperature phosphorescence of pure organic compounds for multiple applications. J. Mater. Chem. C 7, 9095-9101 (2019).

14. Wang, J. et al. A facile strategy for realizing room temperature phosphorescence and single 
molecule white light emission. Nat. Commun. 9, 2963 (2018)

15. Yang, J. et al. The odd-even effect of alkyl chain in organic room temperature phosphorescence luminogens and the corresponding in vivo imaging. Mater. Chem. Front. 3, 1391-1397 (2019).

16. Liao, Qiu. et al. 9,9-Dimethylxanthene Derivatives with Room-Temperature Phosphorescence: Substituent Effects and Emissive Properties. Angew. Chem. Int. Ed. 59, 9946-9951 (2020).

17. Xu, L. et al. Ultralong Organic Phosphorescent Nanocrystals with Long-Lived Triplet Excited States for Afterglow Imaging and Photodynamic Therapy. ACS Appl. Mater. Interfaces 12, 18385-18394 (2020).

18. Fateminia, S. et al. Organic Nanocrystals with Bright Red Persistent Room-Temperature Phosphorescence for Biological Applications. Angew. Chem. Int. Ed. 56, 12160-12164 (2017).

19. Shi, H. et al. A Highly Efficient Red Metal-free Organic Phosphor for Time-Resolved Luminescence Imaging and Photodynamic Therapy. ACS Appl. Mater. Interfaces 11, 20, 18103-18110 (2019).

20. Jin, J. et al. Thermally activated triplet exciton release for highly efficient tri-mode organic afterglow. Nat. Commun. 11, 842 (2020).

21. Yang. J. et al. Elucidating the Excited State of Mechanoluminescence in Organic Luminogens with Room-Temperature Phosphorescence. Angew. Chem. Int. Ed. 56, 15299-15303 (2017).

22. Li, Y. et al. Design of AIEgens for near-infrared IIb imaging through structural modulation at molecular and morphological levels. Nat. Commun. 11, 1255 (2020).

23. Li, C. Chen, G. Zhang, Y. Wu, F. \& Wang, Q. Advanced Fluorescence Imaging Technology in 
the Near-Infrared-II Window for Biomedical Applications. J. Am. Chem. Soc. 142, 14789-14804 (2020).

24. Lu, L. et al. NIR-II bioluminescence for in vivo high contrast imaging and in situ ATP-mediated metastases tracing. Nat. Commun. 11, 4192 (2020).

25. Wu, L. et al. $\mathrm{H}_{2} \mathrm{~S}$-activatable near-infrared afterglow luminescent probes for sensitive molecular imaging in vivo. Nat. Commun. 11, 446 (2020).

26. Zheng, X. et al. Successively activatable ultrasensitive probe for imaging tumour acidity and hypoxia. Nat. Biomed. Eng. 1, 0057 (2017).

27. Deng, R. Wang, J. Chen, R. Huang, W \& Liu, X. Enabling Förster Resonance Energy Transfer from Large Nanocrystals through Energy Migration. J. Am. Chem. Soc. 138, 15972-15979 (2016).

28. Wang, J. et al. Enhancing multiphoton upconversion through energy clustering at sublattice level, Nat. Mater. 13, 157-162 (2014).

29. Wang, Y. et al. Förster Resonance Energy Transfer: An Efficient way to Develop Stimulus-Responsive Room-Temperature Phosphorescence Materials and Their Applications. Matter 3, 449-463 (2020).

30. Lim, E. Molecular Triplet Excimers. Acc. Chem. Res. 20, 8-17 (1987).

31. Goushi, K. Yoshida, K. Sato, K. \& Adachi, C. Organic light-emitting diodes employing efficient reverse intersystem crossing for triplet-to-singlet state conversion. Nat. Photonics $\mathbf{6}$, 253-258 (2012).

32. Chen, Y. et al. Insight into the mechanism and outcoupling enhancement of excimer-associated white light generation. Chem. Sci. 7, 3556-3563 (2016). 


\section{Methods}

\section{Syntheses and Photophysical Characterization}

${ }^{1} \mathrm{H}$ NMR spectra and ${ }^{13} \mathrm{C}$ NMR spectra were recorded on a 300 or $400 \mathrm{MHz}$ Bruker Ascend spectrometer. Elemental analyses of carbon, hydrogen, nitrogen and sulfur were measured on a Perkin-Elmer microanalyzer. Mass spectra were measured on a ZAB 3F-HF mass or UHPLC/Q-TOF MS spectrophotometer. UV-vis spectra were measured on a Shimadzu UV-2600. Photoluminescence spectra and long RTP lifetimes were performed on a Hitachi F-4600 fluorescence spectrophotometer. Powder X-ray diffraction (PXRD) patterns were recorded by Rigaku Smartlab9KW. The single-crystal X-ray diffraction data of these samples were collected in XtaLAB SuperNova X-ray diffractometer. Photoluminescence quantum yields and lifetimes were determined with FLS1000 spectrometer.

The Gaussian 09 program was utilized to perform the calculations. The ground state $\left(\mathrm{S}_{0}\right)$ geometries of $\mathrm{CS}-\mathrm{CH}_{3}$ and $\mathrm{CS}-\mathrm{C}_{2} \mathrm{H}_{5}$ dimers were obtained from the single crystal structures and no further geometry optimization was conducted in order to maintain the specific molecular configurations and corresponding intermolecular locations. The ground state $\left(\mathrm{S}_{0}\right)$ geometries of $\mathrm{CS}-\mathrm{CH}_{3} / \mathrm{CzS}-\mathrm{CH}_{3}$ and $\mathrm{CS}-\mathrm{C}_{2} \mathrm{H}_{5} / \mathrm{CzS}-\mathrm{C}_{2} \mathrm{H}_{5}$ were optimized based on m062x/6-31 $\mathrm{g}^{*}$. The spin-orbit coupling (SOC) constants were studied with Pysoc package under the same functional/basis set based on their ground state geometry.

\section{Bio-imaging measurement}

\section{Materials}

Tetrahydrofuran (THF) was purchased from J\&K Chemical Scientific Ltd. and distilled before 
use. The amphiphilic co-polymer PEG-b-PPG-b-PEG (F127) was purchased from Aladdin Ltd. Fetal bovine serum (FBS) was provided by Thermo Fisher Scientific Inc. (Waltham, MA, USA). Transmission electron microscopy (TEM) images were acquired from a JEM-2010F transmission electron microscope with an accelerating voltage of $200 \mathrm{kV}$. Dynamic light scattering (DLS) was measured on a 90 plus particle size analyzer. In vitro and in vivo afterglow imaging was performed by IVIS ${ }^{\circledR}$ Lumina II imaging system.

\section{Preparation of NPs.}

To $1 \mathrm{~mL}$ of the aqueous solution of $\mathrm{F} 127(10 \mathrm{mg})$, the $\mathrm{M}-\mathrm{CH}_{3}, \mathrm{M}-\mathrm{C}_{2} \mathrm{H}_{5}, \mathrm{M}-\mathrm{PhCH}_{3} \mathrm{O}$, $\mathrm{M}-\mathrm{PhCH}_{3}, \mathrm{M}-\mathrm{Ph}, \mathrm{M}-\mathrm{PhCl}, \mathrm{M}-\mathrm{PhF}$ crystals $(1 \mathrm{mg})$ were added. The mixture was then sonicated by a microtip-equipped probe sonicator (Branson, S-250D) for $10 \mathrm{~min}$. The resultant suspension was filtered through a $0.45 \mu \mathrm{m}$ syringe driven filter to afford solution of nanocrystals.

\section{In vitro phosphorescent imaging of nanocrystal solutions.}

The phosphorescent intensities of $\mathrm{M}-\mathrm{CH}_{3}, \mathrm{M}-\mathrm{C}_{2} \mathrm{H}_{5}, \mathrm{M}-\mathrm{PhCH}_{3} \mathrm{O}, \mathrm{M}-\mathrm{PhCH}_{3}, \mathrm{M}-\mathrm{Ph}, \mathrm{M}-\mathrm{PhCl}$ and M-PhF nanocrystals were recorded using IVIS ${ }^{\circledR}$ Lumina II imaging system after each kind of nanocrystal solutions were irradiated by $365 \mathrm{~nm}$ handheld UV lamp (12 W) for $1 \mathrm{~min}$. The IVIS system was set in bioluminescence mode with open filter setting (exposure time: $17 \mathrm{~s}$ ).

\section{Photostability study.}

Nanocrystal solutions were irradiated by glare flashlight (960 lumen) with varying exposure times of $0,20,40,60$, and $80 \mathrm{~min}$. The phosphorescent intensities were recorded using IVIS ${ }^{\circledR}$ system in bioluminescence mode with open filter setting (exposure time: $17 \mathrm{~s}$ ).

\section{Cell Culture.}

HeLa cervical cancer cells, 4T1 breast cancer cell, and LM3 hepatoma cells were obtained 
from American Type Culture Collection (ATCC). The cells were cultured in DMEM (Dulbecco's Modified Eagle Medium) (GIBCO) supplemented with 10\% FBS and 1\% penicillin-streptomycin at $37{ }^{0} \mathrm{C}$ in a humidified environment containing $5 \% \mathrm{CO}_{2}$, which were regularly checked for mycoplasma contamination.

\section{Cytotoxicity Study.}

In vitro cytotoxicities of the nanocrystals against cancer cells were assessed by 3-(4,5-dimethylthiazol-2-yl)-2,5-diphenyl tetrazolium bromide (MTT) assay. Briefly, HeLa cancer cells seeded in 96-well plates (Costar, IL, USA) were exposed to each kind of nanocrystals at the RTP dye concentrations of $12.5,25,50,100,200 \mu \mathrm{g} \mathrm{mL} \mathrm{m}^{-1}$, respectively, at $37{ }^{\circ} \mathrm{C}$. After $24 \mathrm{~h}$ incubation, the wells were washed twice with $1 \times \mathrm{PBS}$, and $100 \mu \mathrm{L}$ of freshly prepared MTT $\left(0.5 \mathrm{mg} \mathrm{mL}^{-1}\right)$ solution in culture medium was added into each well. The MTT medium solution was carefully removed after $3 \mathrm{~h}$ incubation in the incubator. DMSO $(100 \mu \mathrm{L})$ was then added into each well and the plate was gently shaken for $10 \mathrm{~min}$ at room temperature to dissolve all the precipitates formed. The absorbance of MTT at $490 \mathrm{~nm}$ was monitored by the microplate reader (Genios Tecan). Cell viability was expressed by the ratio of absorbance of the cells incubated with nanocrystal suspension to that of the cells incubated with culture medium only.

\section{Animals and tumor models.}

All animal studies were conducted under the guidelines set by Tianjin Committee of Use and Care of Laboratory Animals, and the overall project protocols were approved by the Animal Ethics Committee of Nankai University. Six-weeks-old BALB/c nude mice were purchased from the Laboratory Animal Center of the Academy of Military Medical Sciences (Beijing, China). 
To set up the orthotopic liver tumor-bearing mouse model, the BALB/c nude mice were injected subcutaneously in the right flank region with $100 \mu \mathrm{L}$ of cell suspension containing $4 \times$ $10^{6} \mathrm{LM} 3$ hepatoma cells. When the tumor volume reached around $500 \mathrm{~mm}^{3}$, the nude mice were sacrificed and the LM3 tumor tissues were harvested. The tumor tissue was cut into small pieces of around $1 \mathrm{~mm}^{3}$. The orthotopic hepatoma model was constructed by surgical implantation of the small tumor tissue about $1 \mathrm{~mm}^{3}$ into the liver of healthy BALB/c nude mouse.

To establish the pulmonary metastatic carcinoma-bearing mouse model, $5 \times 10^{5} 4 \mathrm{~T} 1$ cancer cells in $100 \mu \mathrm{L}$ of cell culture medium were injected into the healthy mice via tail vein. After about 7 days, the pulmonary metastatic tumors were formed with many nodules including the ones with size $<1 \mathrm{~mm}$ scattering in the lung.

\section{In vivo Afterglow Imaging.}

\section{Subcutaneous phosphorescent imaging with pre-irradiated nanocrystals}

The healthy nude mice were anesthetized using $2 \%$ isoflurane in oxygen and placed into the box of IVIS ${ }^{\circledR}$ instrument. Then, the $\mathrm{M}-\mathrm{CH}_{3}$ and $\mathrm{M}-\mathrm{C}_{2} \mathrm{H}_{5}$ nanocrystals were pre-irradiated by 365 nm hand-held UV lamp (12 W) for $30 \mathrm{~s}$. After that, $100 \mu \mathrm{L}$ of the activated $\mathrm{M}-\mathrm{CH}_{3}$ and $\mathrm{M}-\mathrm{C}_{2} \mathrm{H}_{5}$ nanocrystals (1 mg mL $\mathrm{m}^{-1}$ based on nanocrystals) were subcutaneously injected into the mice, respectively, followed by imaging with IVIS $^{\circledR}$ instrument at different time points. The phosphorescent images were acquired in bioluminescence mode with open filter setting (exposure time: $17 \mathrm{~s}$ ). During the imaging process, the mice were warmed with a heating pad under continued isoflurane anesthesia.

\section{Phosphorescent imaging of sentinel lymph node}


$100 \mu \mathrm{L}$ of $\mathrm{M}-\mathrm{CH}_{3}$ nanocrystals ( $1 \mathrm{mg} \mathrm{mL} \mathrm{m}^{-1}$ based on nanocrystals) were injected into the forepaws of live nude mice. At 10 min post-injection, the mice were irradiated by $365 \mathrm{~nm}$ hand-held UV lamp (12 W) for $30 \mathrm{~s}$ and then imaged with IVIS ${ }^{\circledR}$ instrument in bioluminescence mode with open filter setting (exposure time: $17 \mathrm{~s}$ ) at $10 \mathrm{~s}$ after stoppage of light excitation.

\section{Phosphorescent imaging of orthotopic tumors in vivo}

$200 \mu \mathrm{L}$ of $\mathrm{M}-\mathrm{CH}_{3}$ nanocrystals ( $4 \mathrm{mg} \mathrm{mL}^{-1}$ based on nanocrystals) were injected into the orthotopic LM3 liver tumor-bearing mice via the tail vein. At $7 \mathrm{~h}$ post-injection, the tumor-bearing mice were sacrificed and main tissues including heart, lung, spleen, kidneys and liver with tumors were excised. These organs were irradiated by $365 \mathrm{~nm}$ hand-held UV lamp (12 W) for $30 \mathrm{~s}$ and then imaged with $\operatorname{IVIS}^{\circledR}$ instrument in bioluminescence mode with open filter setting (exposure time: $17 \mathrm{~s}$ ) at $10 \mathrm{~s}, 1 \mathrm{~min}$ and $2 \mathrm{~min}$ after stoppage of light excitation, respectively. The phosphorescent imaging of $\mathrm{M}-\mathrm{CH}_{3}$ nanocrystals in pulmonary metastatic carcinoma-bearing mouse model was performed following the same experimental procedure as that for orthotopic liver tumor-bearing mouse model

\section{In vivo side toxicity study}

Healthy BALB/c mice were used to evaluate the in vivo toxicity of the $\mathrm{M}-\mathrm{CH}_{3}$ nanocrystals, which were randomly assigned into 2 groups $\left(n=3\right.$ per group; two groups were named as $\mathrm{M}-\mathrm{CH}_{3}$ nanocrystals and untreated groups). Then, $200 \mu \mathrm{L}$ of $\mathrm{M}^{-\mathrm{CH}_{3}}$ nanocrystals $\left(4 \mathrm{mg} \mathrm{mL} \mathrm{m}^{-1}\right.$ based on $\mathrm{M}-\mathrm{CH}_{3}$ ) were injected into each healthy mouse in "M- $\mathrm{CH}_{3}$ nanocrystals" groups via the tail vein. The weights of mice in two groups were monitored within 7 days. On day 7 post-injection, all the mice in two groups were sacrificed and the blood was collected through cardiac puncture at time of sacrifice for blood chemistry analyses by Tianjin First Central Hospital. Furthermore, on day 7, 
the normal tissues including liver, spleen and kidneys of each mouse were excised, which were subsequently fixed in $10 \%$ neutral buffered formalin, processed routinely into paraffin, sliced at thickness of $4 \mu \mathrm{m}$, and stained with hematoxylin and eosin (H\&E). The H\&E-stained slices were imaged by optical microscopy and assessed by 3 independent pathologists.

\section{Statistical analysis}

Quantitative data were expressed as mean \pm standard deviation (SD). Statistical comparisons were made by ANOVA analysis and two-sample Student's $t$-test. $P$ value $<0.05$ was considered statistically significant.

\section{Acknowledgements}

We are grateful to the starting grants of Tianjin University and Tianjin Government, National Natural Science Foundation of China (no. 51903188), and Natural Science Foundation of Tianjin City (no. 19JCQNJC04500) for financial support.

\section{Author contributions}

J.Y., D.D., and Z.L. conceived the project and designed the experiments. B.Z.T. gave valuable suggestions. Y.W., M.M.F., and J.Y. were primarily responsible for the tests and analyses of the photophysical data. All the single crystal analyses and corresponding theoretical calculations were conducted by Y.S.W. and J.Y. All bioassays were completed by H.Q.G. under the supervision of D.D. The manuscript was written jointly by J.Y., D.D. and Z.L. 


\section{Competing interests}

The authors declare no competing interests

\section{Additional Information}

Supplementary Information is available for this paper. 


\section{Supplementary Information}

\section{High performance of simple organic phosphorescence host-guest materials}

Yunsheng Wang ${ }^{1, \#}$, Heqi Gao ${ }^{2, \#}$, Jie Yang ${ }^{1 *}$, Manman Fang ${ }^{1}$, Dan Ding ${ }^{2 *}$, Ben Zhong Tang ${ }^{1,4^{*}}$ and Zhen $\mathrm{Li}^{1,3,5 *}$
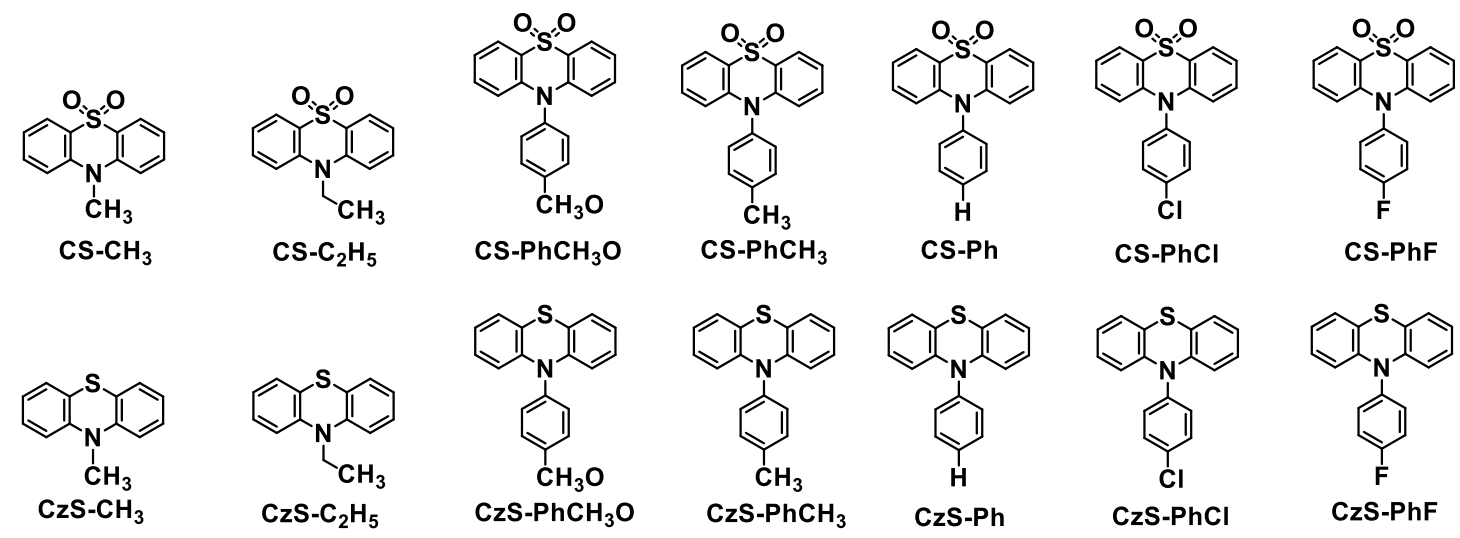

Scheme S1 The molecular structures of the target compounds.

The target compounds are synthesized according to the previous reports, and their structural characterizations are listed as below:

CzS-CH3: ${ }^{1} \mathrm{H}-\mathrm{NMR}\left(400 \mathrm{MHz}, \mathrm{CDCl}_{3}\right) \delta$ (ppm): 7.13-7.18 (m, 4H), 6.90-6.94 (t, 2H), 6.79-6.81 $(\mathrm{d}, 2 \mathrm{H}), 3.36(\mathrm{~s}, 3 \mathrm{H}) .{ }^{13} \mathrm{C}-\mathrm{NMR}\left(100 \mathrm{MHz}, \mathrm{CDCl}_{3}\right) \delta$ (ppm): 145.8, 127.5, 127.2, 123.4, 122.5, 114.1, 35.3. MS (EI), m/z: $\left[\mathrm{M}^{+}\right]$, calcd. for $\mathrm{C}_{13} \mathrm{H}_{11} \mathrm{NS}, 213.06$. Found, 212.09. Anal. Calcd for $\mathrm{C}_{13} \mathrm{H}_{11} \mathrm{NS}$ : C, 73.20; H, 5.20; N, 6.57; S 15.03. Found: C, 72.97; H, 5.45; N, 6.54; S, 15.27.

CS-CH3: ${ }^{1} \mathrm{H}$ NMR $\left(400 \mathrm{MHz}, \mathrm{CDCl}_{3}\right) \delta(\mathrm{ppm}):$ 8.10-8.13 (d, 2H), 7.61-7.65 (t, 2H), 7.27-7.32 $(\mathrm{m}, 4 \mathrm{H}), 3.71(\mathrm{~s}, 3 \mathrm{H}) .{ }^{13} \mathrm{C}-\mathrm{NMR}\left(100 \mathrm{MHz}, \mathrm{CDCl}_{3}\right) \delta(\mathrm{ppm}): 142.1,133.2,124.4,123.4,121.9$, 115.6, 35.8. MS (HRMS), m/z: $[\mathrm{M}+\mathrm{H}]^{+}$, calcd for $\mathrm{C}_{13} \mathrm{H}_{12} \mathrm{NO}_{2} \mathrm{~S}, 246.0589$. Found, 246.0585 . Anal. Calcd for $\mathrm{C}_{13} \mathrm{H}_{11} \mathrm{NO}_{2} \mathrm{~S}$ : C, 63.65; H, 4.52; N, 5.71; S 13.07. Found: C, 63.85; H, 4.24; N, 
$5.87 ; \mathrm{S}, 12.95$.

CzS-C2 $\mathrm{H}_{5}:{ }^{1} \mathrm{H}-\mathrm{NMR}\left(400 \mathrm{MHz}, \mathrm{CDCl}_{3}\right) \delta(\mathrm{ppm})$ : 7.11-7.15 (m, 4H), 6.84-6.86 (m, 4H), 3.91 (s, 2H), 1.38-1.42 (t, 3H). ${ }^{13} \mathrm{C}-\mathrm{NMR}\left(100 \mathrm{MHz}, \mathrm{CDCl}_{3}\right) \delta(\mathrm{ppm}): 144.9,127.4,127.3,124.5,122.5$, 115.3, 41.8, 13.1. MS (EI), m/z: [M+], calcd for $\mathrm{C}_{14} \mathrm{H}_{13} \mathrm{NS}, 227.08$. Found, 227.01. Anal. Calcd for $\mathrm{C}_{14} \mathrm{H}_{13} \mathrm{NS}$ : C, 73.97; H, 5.76; N, 6.16; S, 14.10. Found: C, 73.81; H, 5.60; N, 6.03; S, 14.18.

CS-C $2 \mathrm{H}_{5}:{ }^{1} \mathrm{H}-\mathrm{NMR}\left(400 \mathrm{MHz}, \mathrm{CDCl}_{3}\right) \delta(\mathrm{ppm}):$ 8.13-8.15 (d, 2H), 7.61-7.66 (t, 2H), 7.38-7.40 $(\mathrm{d}, 2 \mathrm{H}), 7.26-7.30(\mathrm{~d}, 2 \mathrm{H}), 4.26-4.32(\mathrm{~m}, 2 \mathrm{H}), 1.56-1.59$ (t, 3H). ${ }^{13} \mathrm{C}$ NMR $\left(100 \mathrm{MHz}, \mathrm{CDCl}_{3}\right) \delta$ (ppm): 140.4, 133.3, 123.8, 123.7, 121.7, 115.6, 43.2, 12.5. HRMS (EI), m/z: [M+H] $]^{+}$, calcd for $\mathrm{C}_{14} \mathrm{H}_{14} \mathrm{NO}_{2} \mathrm{~S}, 260.0745$. Found, 260.0738. Anal. Calcd for $\mathrm{C}_{14} \mathrm{H}_{13} \mathrm{NO}_{2} \mathrm{~S}$ : C, 64.84; $\mathrm{H}, 5.05 ; \mathrm{N}$, 5.40; S, 12.36. Found: C, 64.99; H, 5.25; N, 5.51; S, 12.26 .

CzS-PhCH $30:{ }^{1} \mathrm{H}-\mathrm{NMR}\left(300 \mathrm{MHz}, \mathrm{CDCl}_{3}\right) \quad \delta$ (ppm): 7.29-7.31 (d, 2H), 7.09-7.11 (d, 2H), 6.97-6.99 (d, 2H), 6.77-6.83 (m, 4H), 6.17-6.20 (d, 2H), 3.89 (s, 3H). ${ }^{13} \mathrm{C}-\mathrm{NMR}(75 \mathrm{MHz}$, $\left.\mathrm{CDCl}_{3}\right) \delta(\mathrm{ppm}): 159.3,144.7,133.4,132.3,126.9,126.7,122.3,119.7,115.9,115.7,55.6$. HRMS (EI), m/z: [M+'], calcd. for $\mathrm{C}_{19} \mathrm{H}_{15} \mathrm{NOS}, 305.0874$. Found, 305.0860.

CS-PhCH3 O: ${ }^{1} \mathrm{H}-\mathrm{NMR}\left(300 \mathrm{MHz}, \mathrm{CDCl}_{3}\right) \delta(\mathrm{ppm}): 8.15-8.17(\mathrm{~d}, 2 \mathrm{H}), 7.36-7.39(\mathrm{t}, 2 \mathrm{H})$, 7.16-7.30 (m, 6H), 6.66-6.69 (d, 2H), $3.94(\mathrm{~s}, 3 \mathrm{H}) .{ }^{13} \mathrm{C}-\mathrm{NMR}\left(75 \mathrm{MHz}, \mathrm{CDCl}_{3}\right) \delta(\mathrm{ppm}): 160.4$, 141.3, 133.0, 131.6, 131.4, 123.5, 122.7, 122.2, 117.6, 116.6, 55.9. MS (EI), m/z: [M+ $]$, calcd. for $\mathrm{C}_{19} \mathrm{H}_{15} \mathrm{NO}_{3} \mathrm{~S}$, 337.08. Found, 336.98. Anal. Calcd for $\mathrm{C}_{19} \mathrm{H}_{15} \mathrm{NO}_{3} \mathrm{~S}$ : C, 67.64; H, 4.48; N, 4.15; $\mathrm{S}$, 9.50. Found: C, 67.53; H, 4.22; N, 4.29; S, 9.75.

CzS-PhCH3: ${ }^{1} \mathrm{H}-\mathrm{NMR}\left(300 \mathrm{MHz}, \mathrm{CDCl}_{3}\right) \delta(\mathrm{ppm}):$ 7.38-7.40 (d, 2H), 7.24-7.27 (d, 2H), 6.97-6.99 (d, 2H), 6.80-6.82 (d, 4H), 6.18-6.20 (d, 2H), 2.45 (s, 3H). ${ }^{13} \mathrm{C}-\mathrm{NMR}(75 \mathrm{MHz}$, $\left.\mathrm{CDCl}_{3}\right) \delta(\mathrm{ppm}): 144.5,139.2,131.5,130.9,126.9,126.7,122.3,119.9,115.9,21.3$. HRMS (EI), $\mathrm{m} / \mathrm{z}:\left[\mathrm{M}^{+}\right]$, calcd. for $\mathrm{C}_{19} \mathrm{H}_{15} \mathrm{NS}, 289.0925$. Found, 289.0917.

CS-PhCH3: ${ }^{1} \mathrm{H}-\mathrm{NMR}\left(300 \mathrm{MHz}, \mathrm{CDCl}_{3}\right) \delta(\mathrm{ppm}):$ 8.15-8.18 (dd, 2H), 7.47-7.50 (d, 2H), 
7.35-7.41 (m, 2H), 7.21-7.26 (m, 4H), 6.64-6.67 (d, 2H), $2.52(\mathrm{~s}, 3 \mathrm{H}) .{ }^{13} \mathrm{C}-\mathrm{NMR}(75 \mathrm{MHz}$, $\left.\mathrm{CDCl}_{3}\right) \delta(\mathrm{ppm}): 141.1,140.1,136.4,132.9,132.2,130.3,123.5,122.7,122.1,117.5,21.6 . \mathrm{MS}$ (EI), m/z: $\left[\mathrm{M}^{+}\right]$, calcd. for $\mathrm{C}_{19} \mathrm{H}_{15} \mathrm{NO}_{2} \mathrm{~S}, 321.08$. Found, 320.98. Anal. Calcd for $\mathrm{C}_{19} \mathrm{H}_{15} \mathrm{NO}_{2} \mathrm{~S}: \mathrm{C}$, 71.01; H, 4.70; N, 4.36; S, 9.98. Found: C, 71.28; H, 4.52; N, 4.67; S, 10.09.

CzS-Ph: ${ }^{1} \mathrm{H}-\mathrm{NMR}\left(300 \mathrm{MHz}, \mathrm{CDCl}_{3}\right) \quad \delta(\mathrm{ppm})$ : 7.57-7.60 (t, 2H), 7.44-7.48 (t, 1H), 7.37-7.39 (d, 2H), 6.99-7.02 (d, 2H), 6.81-6.83 (d, 4H), 6.18-6.20 (d, 2H). ${ }^{13} \mathrm{C}-\mathrm{NMR} \quad(75 \mathrm{MHz}$, $\left.\mathrm{CDCl}_{3}\right) \delta(\mathrm{ppm}): 144.3,141.1,130.9,130.8,128.2,126.9,126.8,122.5,120.3,116.1 . \mathrm{HRMS}$ (EI), m/z: $\left[\mathrm{M}^{+}\right]$, calcd. for $\mathrm{C}_{18} \mathrm{H}_{13} \mathrm{NS}, 275.0769$. Found, 275.0773 .

CS-Ph: ${ }^{1} \mathrm{H}-\mathrm{NMR}\left(300 \mathrm{MHz}, \mathrm{CDCl}_{3}\right) \quad \delta$ (ppm): 8.16-8.19 (d, 2H), 7.63-7.73 (m, 3H), 7.36-7.40 (m, 4H), 7.22-7.26 (m, 2H), 6.61-6.63 (d, 2H). ${ }^{13} \mathrm{C}-\mathrm{NMR}\left(75 \mathrm{MHz}, \mathrm{CDCl}_{3}\right) \delta(\mathrm{ppm}): 140.7$, $138.8,132.7,131.2,130.3,129.7,123.3,122.5,121.9,117.1 . \mathrm{MS}(\mathrm{EI}), \mathrm{m} / \mathrm{z}:\left[\mathrm{M}^{+}\right]$, calcd. for $\mathrm{C}_{18} \mathrm{H}_{13} \mathrm{NO}_{2} \mathrm{~S}, 307.07$. Found, 306.97. Anal. Calcd for $\mathrm{C}_{18} \mathrm{H}_{13} \mathrm{NO}_{2} \mathrm{~S}: \mathrm{C}, 70.34 ; \mathrm{H}, 4.26 ; \mathrm{N}, 4.56$; $\mathrm{S}$, 10.43. Found: C, 70.36; H, 4.11; N, 4.69; S, 10.65 .

CzS-PhCl: ${ }^{1} \mathrm{H}-\mathrm{NMR}\left(400 \mathrm{MHz}, \mathrm{CDCl}_{3}\right) \delta(\mathrm{ppm}): 7.53-7.55(\mathrm{~d}, 2 \mathrm{H})$, 7.30-7.33 (d, 2H), 7.02-7.04 (d, 2H), 6.80-6.89 (m, 4H), 6.21-6.23 (d, 2H). ${ }^{13} \mathrm{C}-\mathrm{NMR}\left(100 \mathrm{MHz}, \mathrm{CDCl}_{3}\right) \delta(\mathrm{ppm})$ : 143.9, 139.8, 133.8, 131.9, 131.0, 127.0, 122.9, 121.0, 116.4. HRMS (EI), m/z: [M] $]^{+}$calcd. for $\mathrm{C}_{18} \mathrm{H}_{12} \mathrm{ClNS}, 309.0379$. Found, 309.0386.

CS-PhCl: ${ }^{1} \mathrm{H}-\mathrm{NMR}\left(400 \mathrm{MHz}, \mathrm{CDCl}_{3}\right) \delta(\mathrm{ppm}): 8.17-8.19(\mathrm{~m}, 2 \mathrm{H}), 7.67-7.70(\mathrm{~m}, 2 \mathrm{H})$, 7.39-7.43 (m, 2H), 7.34-7.36 (m, 2H), 7.25-7.29 (m, 2H), 6.61-6.63 (m, 2H). ${ }^{13} \mathrm{C}-\mathrm{NMR}(100$ $\left.\mathrm{MHz}, \mathrm{CDCl}_{3}\right) \delta(\mathrm{ppm}): 140.6,137.3,135.9,132.9,132.0,131.7,123.5,122.8,122.3,117.0 . \mathrm{MS}$ (EI), m/z: $\left[\mathrm{M}^{+}\right]$, calcd. for $\mathrm{C}_{18} \mathrm{H}_{12} \mathrm{ClNO}_{2} \mathrm{~S}, 341.03$. Found, 340.92. Anal. Calcd for $\mathrm{C}_{18} \mathrm{H}_{12} \mathrm{ClNO}_{2} \mathrm{~S}$ : C, 63.25; H, 3.54; N, 4.10; S, 9.38. Found: C, 63.30; H, 3.82; N, 4.20; S, 9.28.

CzS-PhF: ${ }^{1} \mathrm{H}-\mathrm{NMR} \quad\left(400 \mathrm{MHz}, \mathrm{CDCl}_{3}\right) \delta$ (ppm): 7.36-7.39 (m, 2H), 7.25-7.31 (m, 2H), 7.00-7.02 (d, 2H), 6.80-6.86 (m, 4H), 6.15-6.17 (d, 2H). ${ }^{13} \mathrm{C}-\mathrm{NMR}\left(100 \mathrm{MHz}, \mathrm{CDCl}_{3}\right)$ $\delta$ (ppm): 163.3, 160.9, 144.3, 136.8, 133.0, 132.9, 126.9, 126.8, 122.6, 120.2, 117.9, 117.7, 115.8 . 
MS (EI), m/z: [M+], calcd. for $\mathrm{C}_{18} \mathrm{H}_{12} \mathrm{FNS}, 293.0674$. Found, 293.0673.

CS-PhF: ${ }^{1} \mathrm{H}-\mathrm{NMR}\left(400 \mathrm{MHz}, \mathrm{CDCl}_{3}\right) \quad \delta(\mathrm{ppm}):$ 8.16-8.18 (m, 2H), 7.38-7.43 (m, 6H), 7.24-7.28 $(\mathrm{m}, 2 \mathrm{H}), 6.61-6.63(\mathrm{~m}, 2 \mathrm{H}) .{ }^{13} \mathrm{C}-\mathrm{NMR}\left(100 \mathrm{MHz}, \mathrm{CDCl}_{3}\right) \delta(\mathrm{ppm}): 164.0,161.5,140.7,134.6$, 132.8, 132.4, 132.3, 123.4, 122.7, 122.2, 118.5, 118.3, 117.0. MS (EI), m/z: $\left[\mathrm{M}^{+}\right]$, calcd. for $\mathrm{C}_{18} \mathrm{H}_{12} \mathrm{FNO}_{2} \mathrm{~S}, 325.06$. Found, 324.95. Anal. Calcd for $\mathrm{C}_{18} \mathrm{H}_{12} \mathrm{FNO}_{2} \mathrm{~S}: \mathrm{C}, 66.45 ; \mathrm{H}, 3.72 ; \mathrm{N}, 4.31$; S, 9.85. Found: C, 66.22; H, 3.50; N, 4.50; S, 10.07.

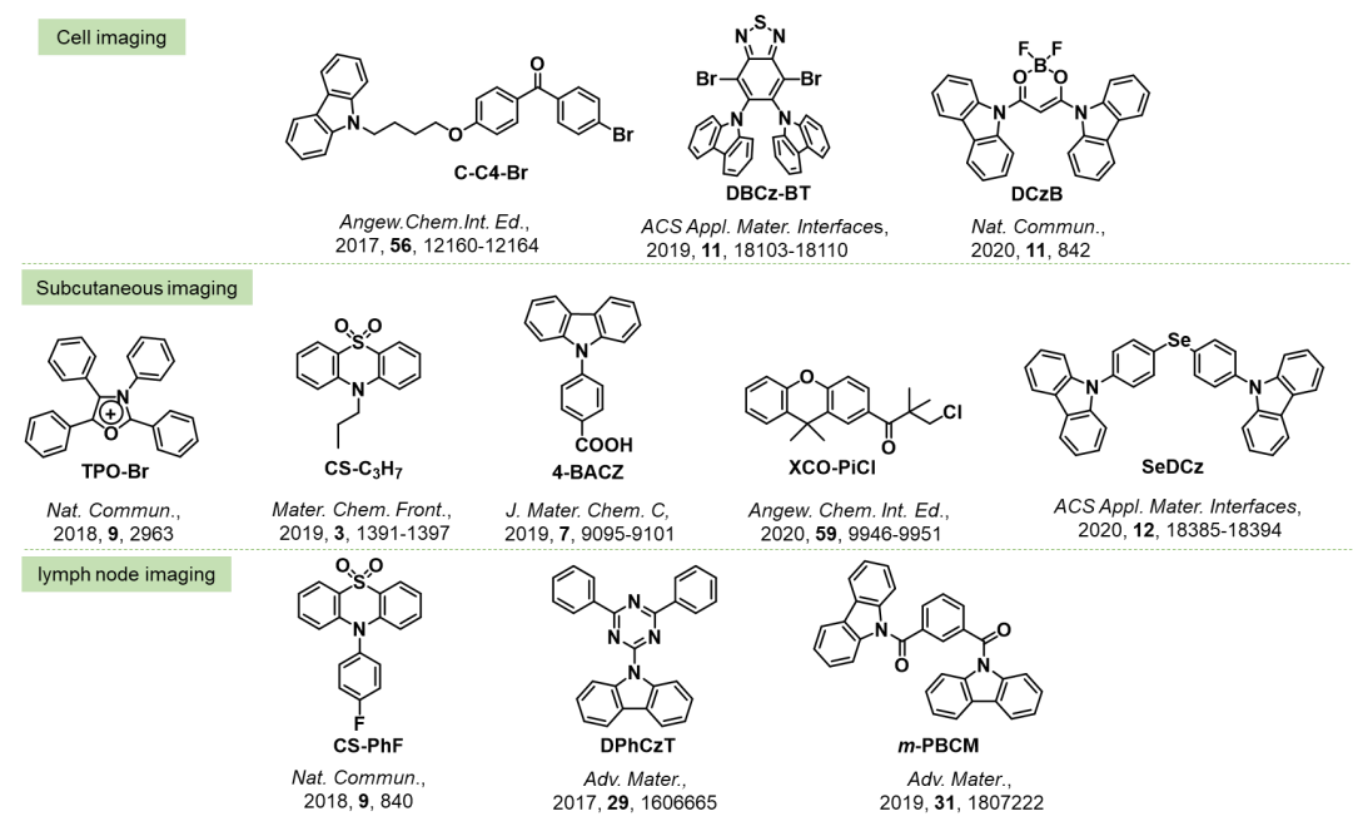

Chart S1 The molecular structures of some organic RTP materials applied in time-gated bio-imaging.
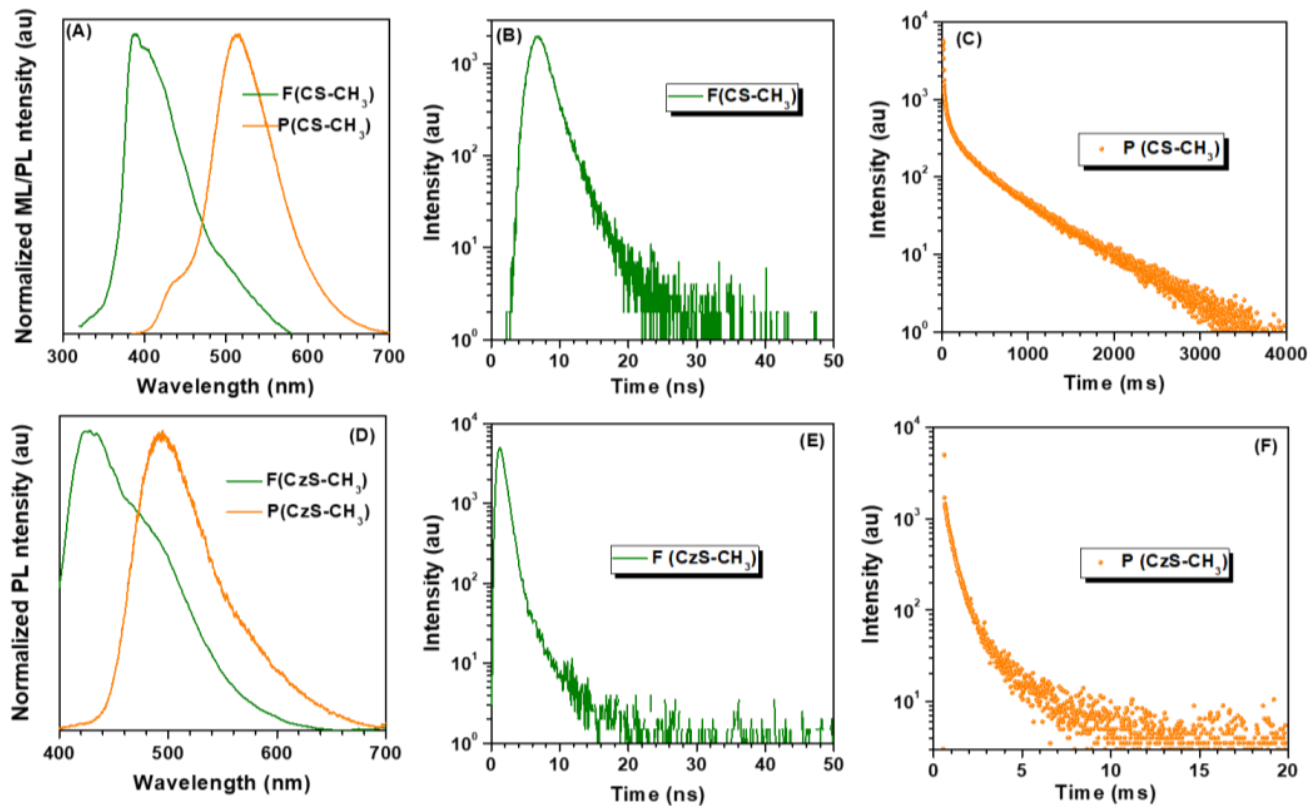
Figure S1 (A) Normalized fluorescence and phosphorescence spectra of $\mathrm{CS}-\mathrm{CH}_{3}$ crystal at room temperature; (B) Fluorescence decay curve of $\mathrm{CS}^{-\mathrm{CH}_{3}}$ crystal at room temperature; (C) Phosphorescence decay curve of $\mathrm{CS}_{-} \mathrm{CH}_{3}$ crystal at room temperature; (D) Normalized fluorescence and phosphorescence spectra of $\mathrm{CzS}-\mathrm{CH}_{3}$ crystal at room temperature; (E) Fluorescence decay curve of $\mathrm{CzS}-\mathrm{CH}_{3}$ crystal at room temperature; (F) Phosphorescence decay curve of $\mathrm{CzS}-\mathrm{CH}_{3}$ crystal at room temperature.
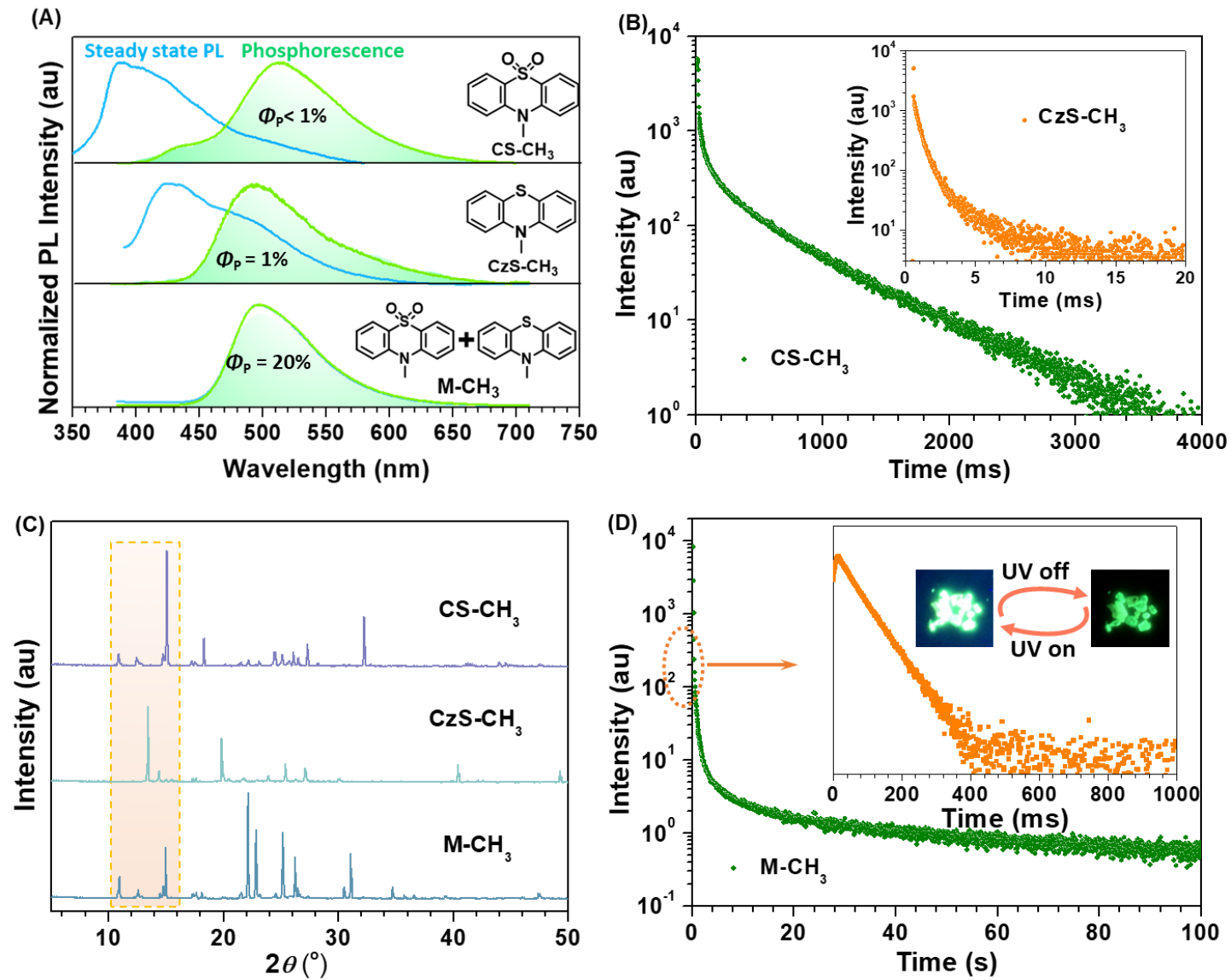

Figure S2 (A) The steady state PL and RTP spectra of $\mathrm{CS}-\mathrm{CH}_{3}, \mathrm{CzS}-\mathrm{CH}_{3}$ and their co-crystal $\left(\mathrm{M}-\mathrm{CH}_{3}\right)$ with mass ratio of $100: 1$; (B) The RTP decay curves of $\mathrm{CS}-\mathrm{CH}_{3}$ and $\mathrm{CzS}-\mathrm{CH}_{3}$ crystals; (C) The powder XRD patterns of $\mathrm{CS}-\mathrm{CH}_{3}, \mathrm{CzS}-\mathrm{CH}_{3}$ and their co-crystal $\left(\mathrm{M}-\mathrm{CH}_{3}\right)$, in which $\mathrm{CS}-\mathrm{CH}_{3}$ and $\mathrm{M}-\mathrm{CH}_{3}$ are similar, indicating the traces $\mathrm{CzS}-\mathrm{CH}_{3}$ doesn't change the packing of CS-CH $\mathrm{CH}_{3}$; (D) The RTP decay curves of $\mathrm{M}-\mathrm{CH}_{3}$, in which two components exist, the former one is relatively shorter and later one is ultra-long. 

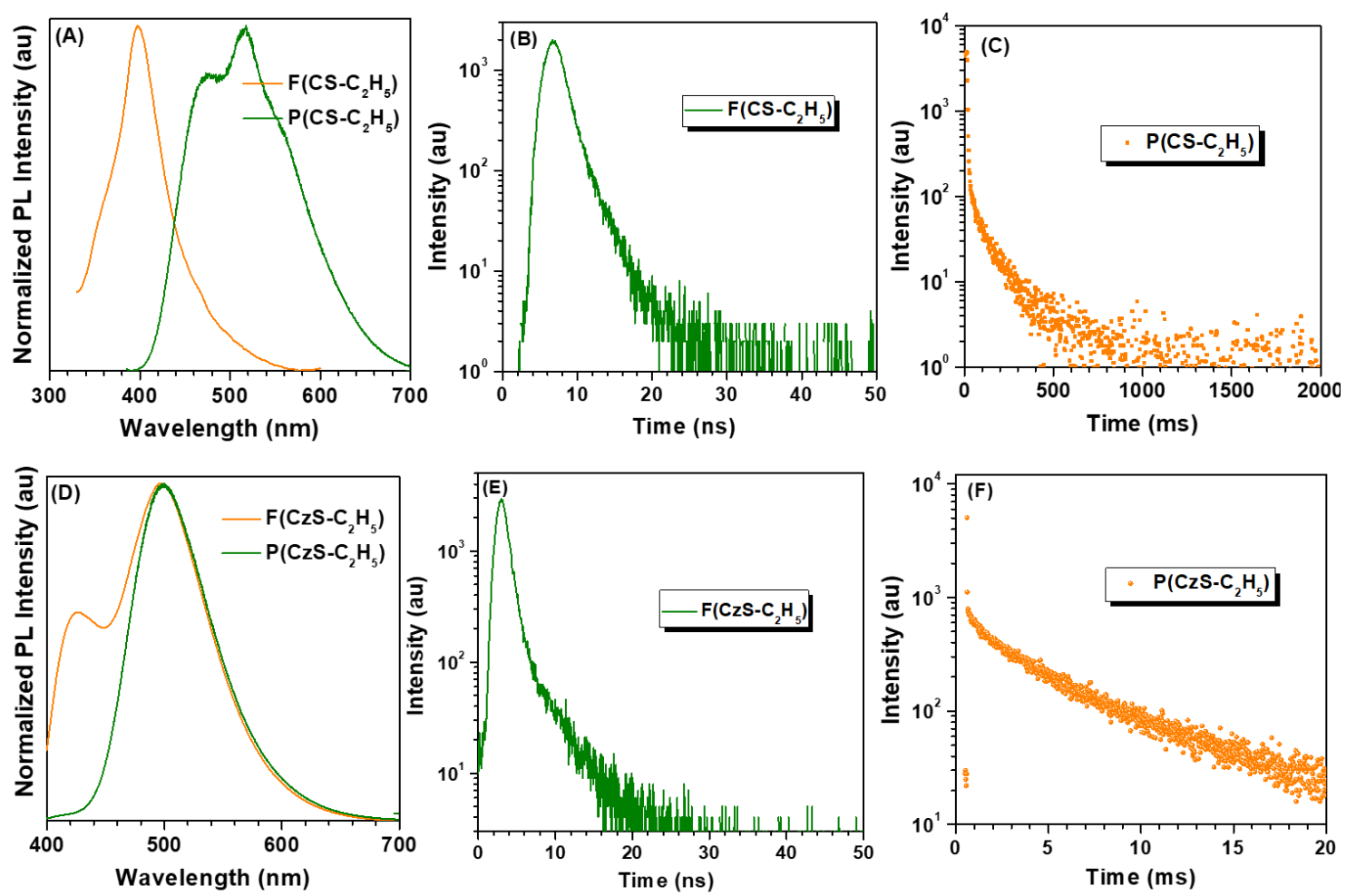

Figure S3 (A) Normalized fluorescence and phosphorescence spectra of $\mathrm{CS}_{-}-\mathrm{C}_{2} \mathrm{H}_{5}$ crystal at room temperature; (B) Fluorescence decay curve of $\mathrm{CS}_{-} \mathrm{C}_{2} \mathrm{H}_{5}$ crystal at room temperature; (C) Phosphorescence decay curve of $\mathrm{CS}-\mathrm{C}_{2} \mathrm{H}_{5}$ crystal at room temperature; (D) Normalized fluorescence and phosphorescence spectra of $\mathrm{CzS}-\mathrm{C}_{2} \mathrm{H}_{5}$ crystal at room temperature; (E) Fluorescence decay curve of $\mathrm{CzS}-\mathrm{C}_{2} \mathrm{H}_{5}$ crystal at room temperature; (F) Phosphorescence decay curve of $\mathrm{CzS}-\mathrm{C}_{2} \mathrm{H}_{5}$ crystal at room temperature. 
(A)
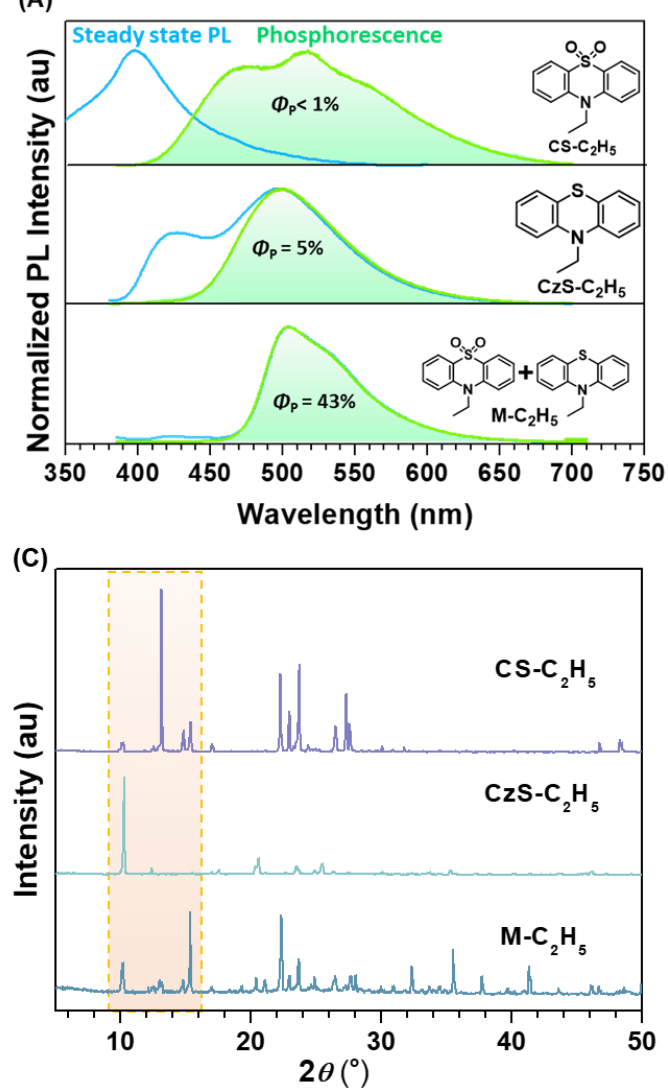

(B)

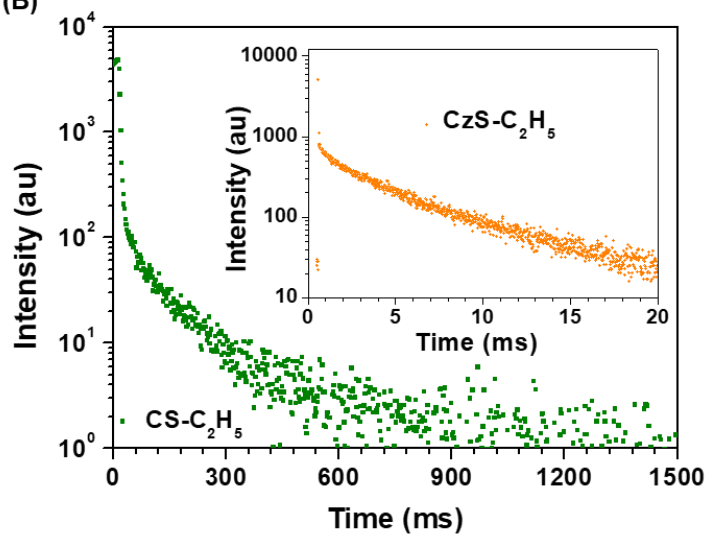

(D) 10

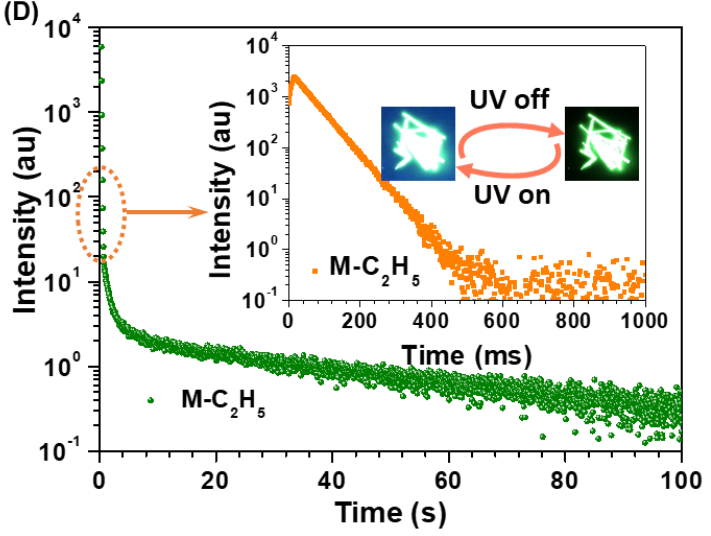

Figure S4 (A) The steady state PL and RTP spectra of CS- $\mathrm{C}_{2} \mathrm{H}_{5}, \mathrm{CzS}-\mathrm{C}_{2} \mathrm{H}_{5}$ and their co-crystal (M- $\mathrm{C}_{2} \mathrm{H}_{5}$ ) with mass ratio of 100:1; (B) The RTP decay curves of CS- $\mathrm{C}_{2} \mathrm{H}_{3}$ and $\mathrm{CzS}-\mathrm{C}_{2} \mathrm{H}_{5}$ crystals; (C) The powder XRD patterns of $\mathrm{CS}-\mathrm{C}_{2} \mathrm{H}_{5}, \mathrm{CzS}-\mathrm{C}_{2} \mathrm{H}_{5}$ and their co-crystal $\left(\mathrm{M}-\mathrm{C}_{2} \mathrm{H}_{5}\right)$; (D) The RTP decay curves of $\mathrm{M}-\mathrm{C}_{2} \mathrm{H}_{5}$, in which two components exist, one is relatively shot and another is ultra-long.

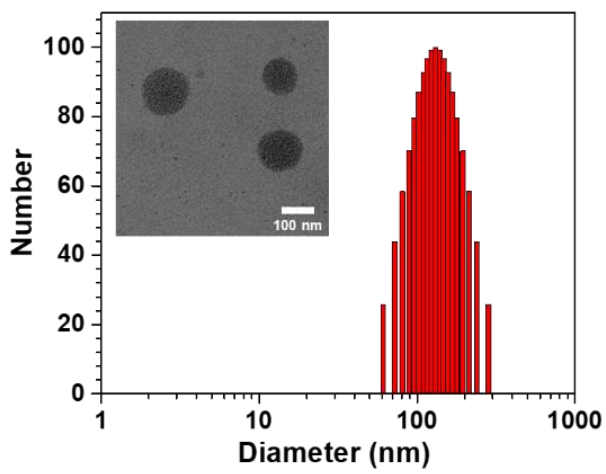

Figure S5 The TEM image and size distribution of $\mathrm{M}-\mathrm{C}_{2} \mathrm{H}_{5}$ nanocrystals. 


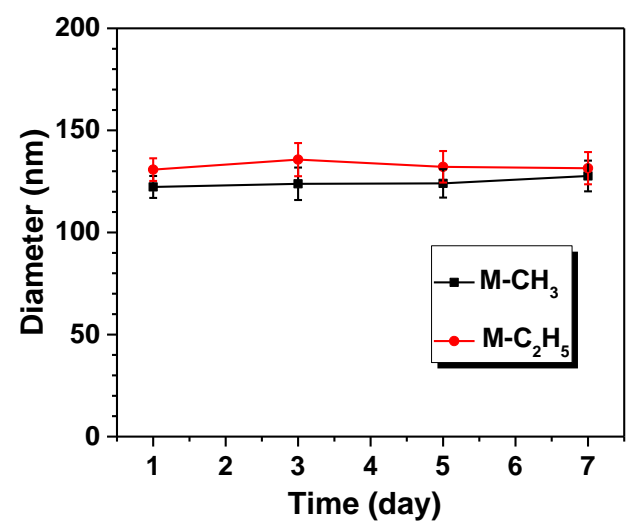

Figure 6 Colloidal stabilities of $\mathrm{M}-\mathrm{CH}_{3}$ and $\mathrm{M}-\mathrm{C}_{2} \mathrm{H}_{5}$ nanocrystals in PBS solution measured by DLS.
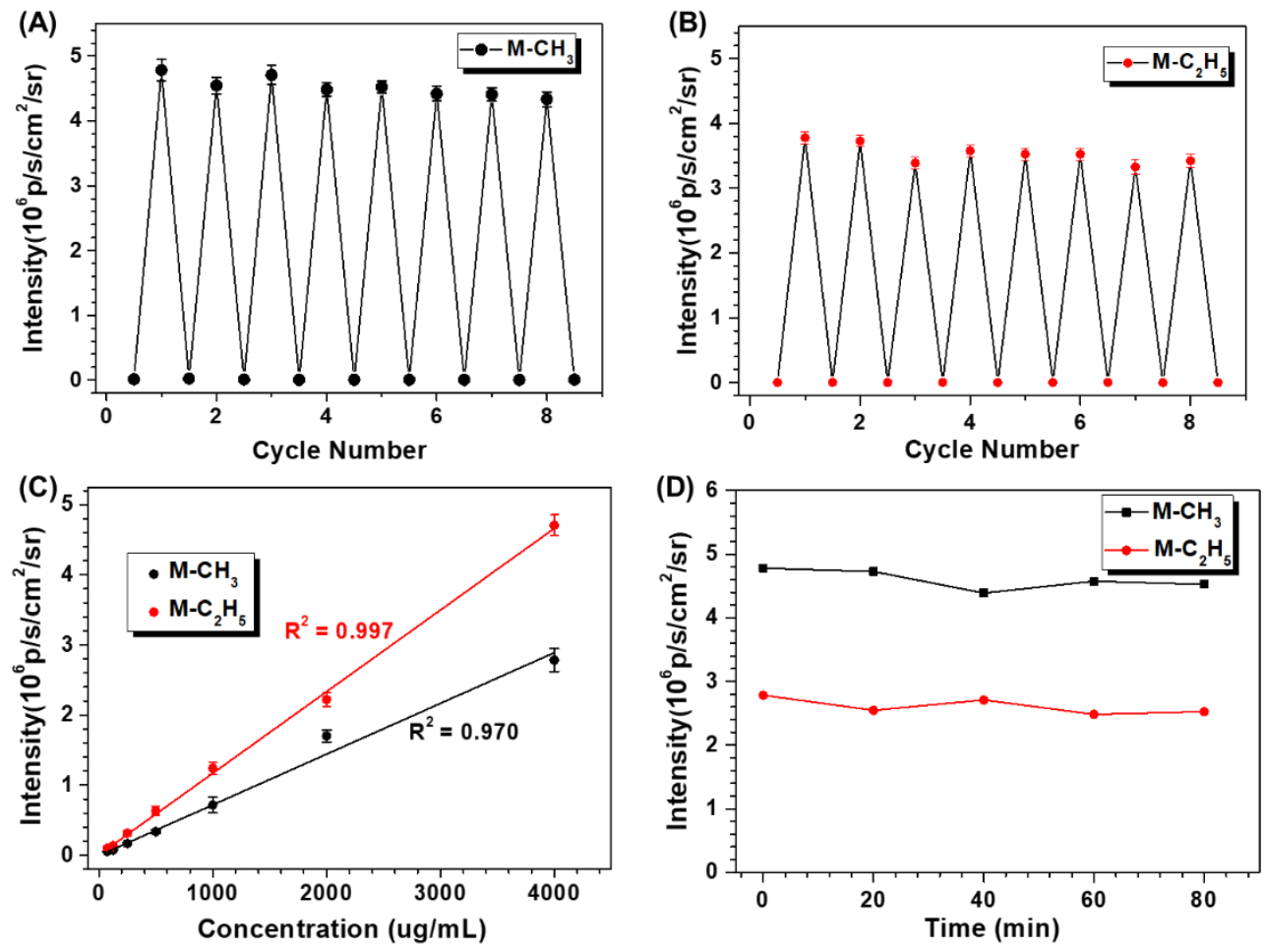

Figure S7 (A) The afterglow intensities of $\mathrm{M}-\mathrm{CH}_{3}$ nanocrystals as a function of the cycle number of light activation; (B) The afterglow intensities of $\mathrm{M}-\mathrm{C}_{2} \mathrm{H}_{5}$ nanocrystals as a function of the cycle number of light activation; (C) The afterglow intensities as a function of the concentration of $\mathrm{M}-\mathrm{CH}_{3}$ and $\mathrm{M}-\mathrm{C}_{2} \mathrm{H}_{5}$; (D) The afterglow intensities for four nanoparticles with varying UV exposure time. Error bars, mean \pm standard deviation $(\mathrm{n}=3)$. 


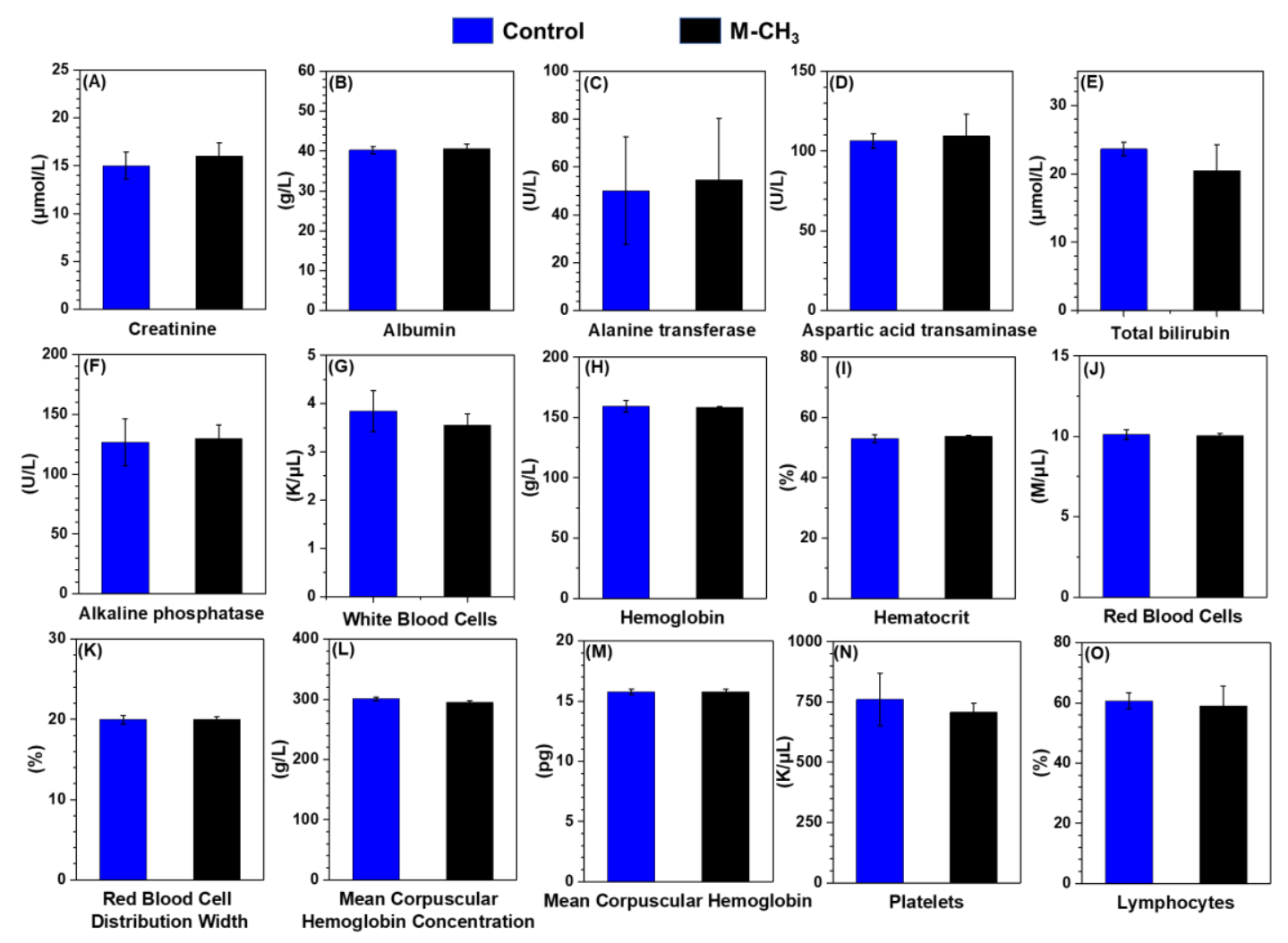

Figure S8 In vivo side toxicity study of M-CH3 nanocrystals. Routine blood and blood biochemical tests on mice after intravenous injection of M-CH3 nanoparticles $(200 \mu \mathrm{L}, 4 \mathrm{mg}$ mL-1 M-CH3 concentration) or saline as the control: (A) creatinine; (B) albumin; (C) alanine transferase; (D) aspartic acid transaminase; (E) total bilirubin; (F) alkaline phosphatase; (G) white blood cells; (H) haemoglobin; (I) haematocrit; (J) red blood cells; (K) red blood cell distribution width; (L) mean corpuscular haemoglobin concentration; (M) mean corpuscular haemoglobin; (N) platelets; (O) lymphocytes.
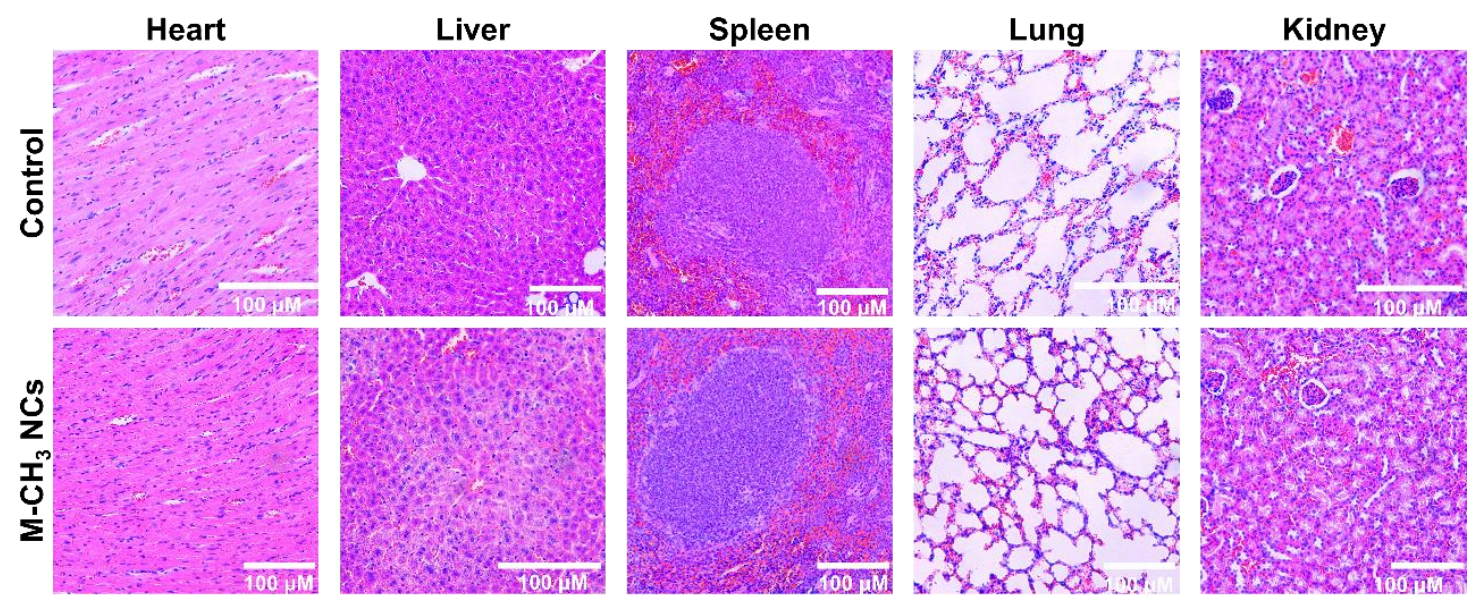

Figure S9 H\&E-stained images of major organs of mice after intravenous injection of saline and $\mathrm{M}-\mathrm{CH}_{3}$ nanocrystals. respectively. 

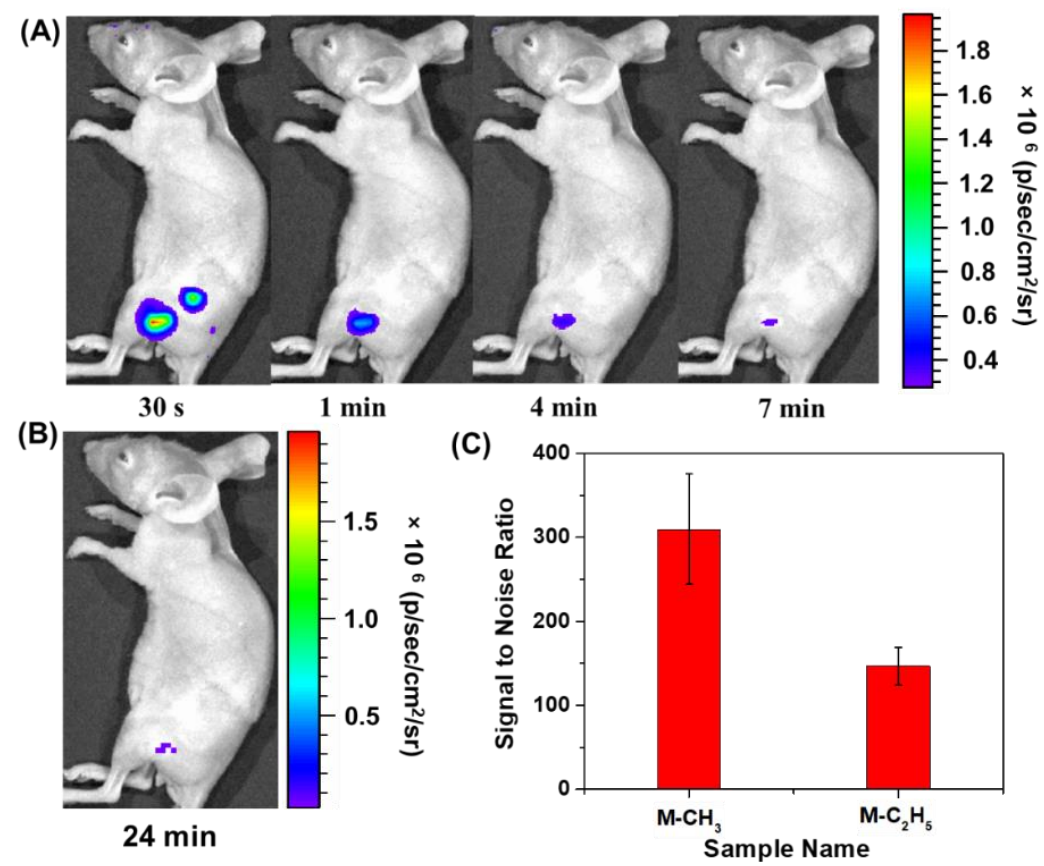

Figure S10 Time-resolved phosphorescence imaging of healthy mice received subcutanous injection of $\mathrm{M}-\mathrm{CH}_{3}$ (down) and $\mathrm{M}-\mathrm{C}_{2} \mathrm{H}_{5}$ (upper) nanocrystals. The nanocrystals were pre-irradiated with $365 \mathrm{~nm}$ light, followed by subcutanous injection into the mice. The phosphorescence imaging was performed at (A) $30 \mathrm{~s}$ to $7 \mathrm{~min}$ and (B) $24 \mathrm{~min}$ after stoppage of excitation. (C) In vivo SBR values for phosphorescence imaging of subcutaneously injected $\mathrm{M}-\mathrm{CH}_{3}$ and $\mathrm{M}-\mathrm{C}_{2} \mathrm{H}_{5}$ nanocrystals at $30 \mathrm{~s}$ after stoppage of excitation. Error bars, mean \pm standard deviation $(n=3)$.

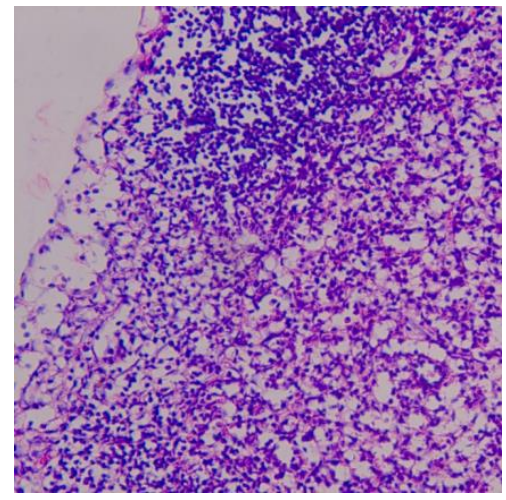

Figure 11 H\&E-stained image indicated that the light-up tissue was lymph node. 
(A)

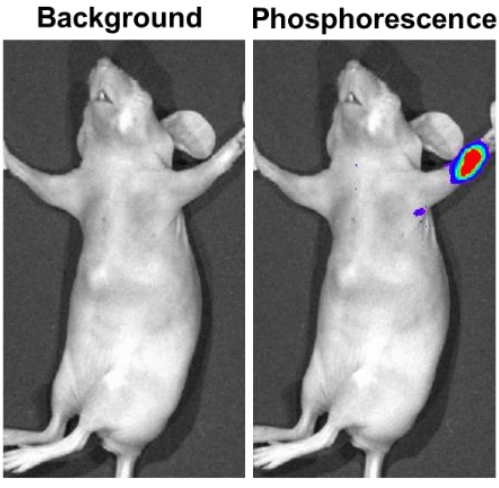

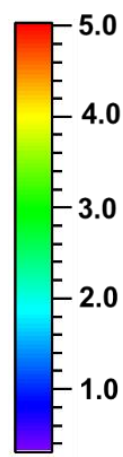

(B)

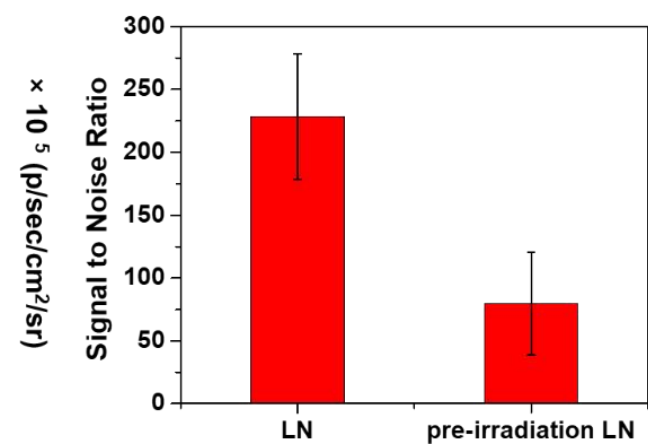

Figure S12 (A) Phosphorescence imaging of sentinel lymph node of mice after forepaw injection of pre-irradiated $\mathrm{M}-\mathrm{CH}_{3}$ nanocrystals. The $\mathrm{M}-\mathrm{CH}_{3}$ nanocrystals were pre-irradiated by $365 \mathrm{~nm}$ hand-held UV lamp (12 W) for $30 \mathrm{~s}$, followed by forepaw injection. The phosphorescent image was acquired at 5 min after stoppage of light excitation; (B) SBR values of lymph node imaging based on the phosphorescent images in (A) and Fig. 3C. Error bars, mean \pm standard deviation (n $=3)$.

(A)

PBS Herat Liver Spleen Lung Kidney Tumo Blood

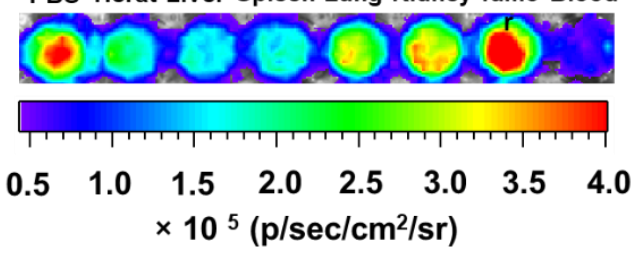

(B)

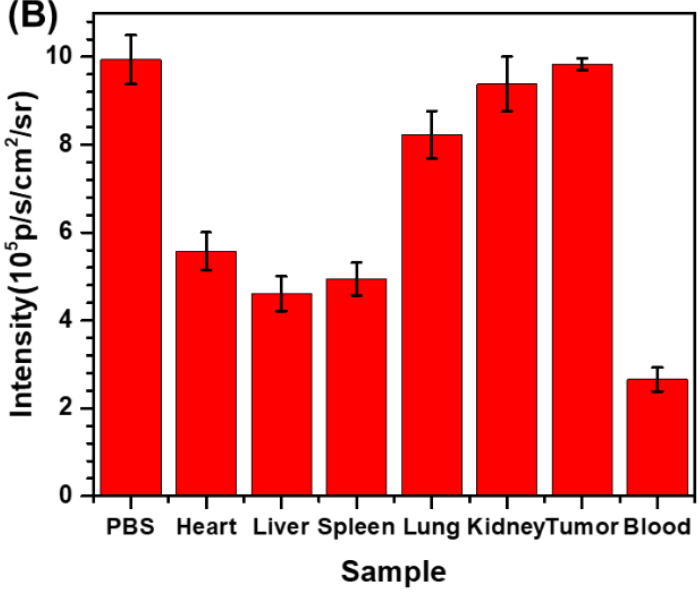

Figure S13 (A) The phosphorescent imaging of $\mathrm{M}-\mathrm{CH}_{3}$ nanocrystals in different tissue homogenates. The $\mathrm{M}-\mathrm{CH}_{3}$ nanocrystals were incubated with each tissue homogenate for $30 \mathrm{~min}$. Upon irradiation by $365 \mathrm{~nm}$ hand-held UV lamp (12 W) for $30 \mathrm{~s}$, the mixture was imaged by IVIS $^{\circledR}$ instrument at $10 \mathrm{~s}$ after stoppage of light excitation.; (B) Plot of phosphorescent intensities of $\mathrm{M}-\mathrm{CH}_{3}$ nanocrystals after incubation with different tissue homogenates, respectively. Error bars, mean \pm standard deviation $(\mathrm{n}=3)$. 
(A)
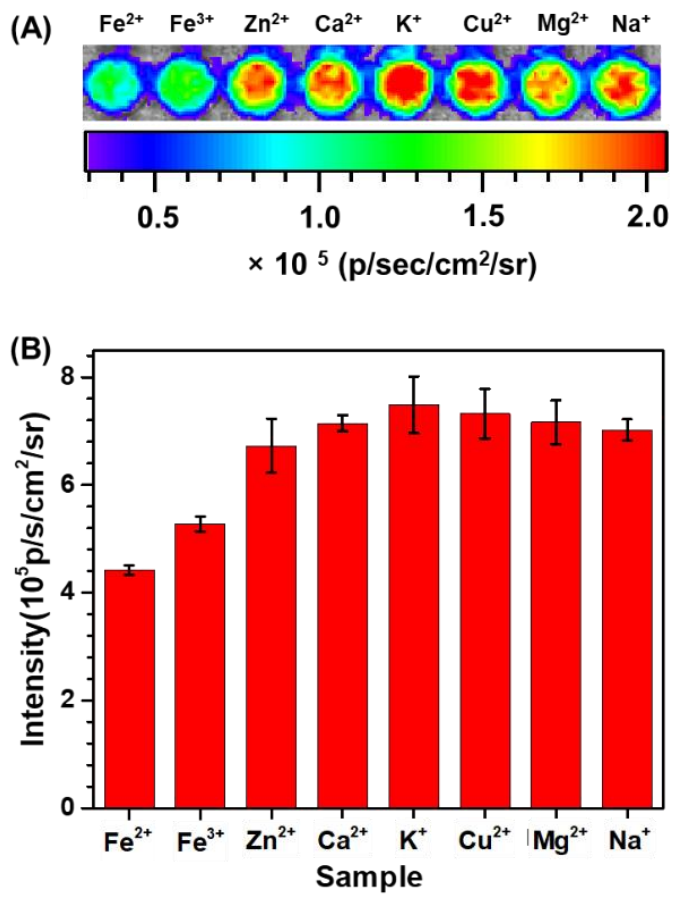

(C)

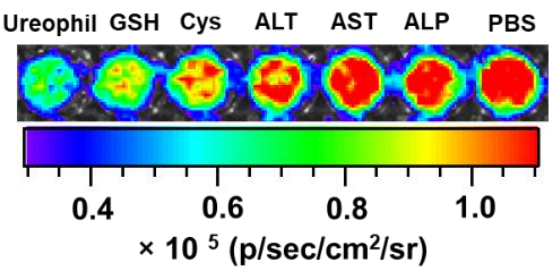

(D)

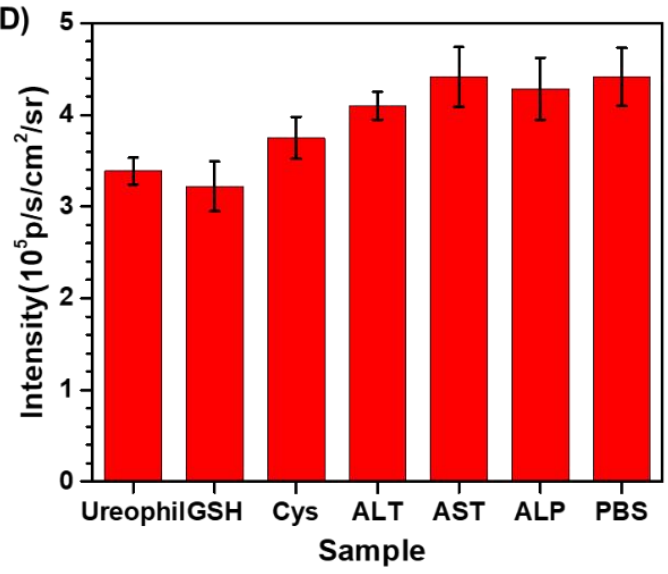

Figure S14 (A, C) The phosphorescent imaging of $\mathrm{M}-\mathrm{CH}_{3}$ nanocrystals interacted with various biomolecules including different metal ions, glutathione (GSH), cysteine (Cys), alanine transaminase (ALT), aspartate aminotransferase (AST), and alkaline phosphatase (ALP). The $\mathrm{M}-\mathrm{CH}_{3}$ nanocrystals were incubated with each biomolecule for $30 \mathrm{~min}$. Upon irradiation by 365 $\mathrm{nm}$ hand-held UV lamp $(12 \mathrm{~W})$ for $30 \mathrm{~s}$, the mixture was imaged by IVIS $^{\circledR}$ instrument at $10 \mathrm{~s}$ after stoppage of light excitation; (B, D) Plot of phosphorescent intensities of $\mathrm{M}^{-\mathrm{CH}_{3}}$ nanocrystals after incubation with different biomolecules, respectively. Error bars, mean \pm standard deviation $(\mathrm{n}=3)$.

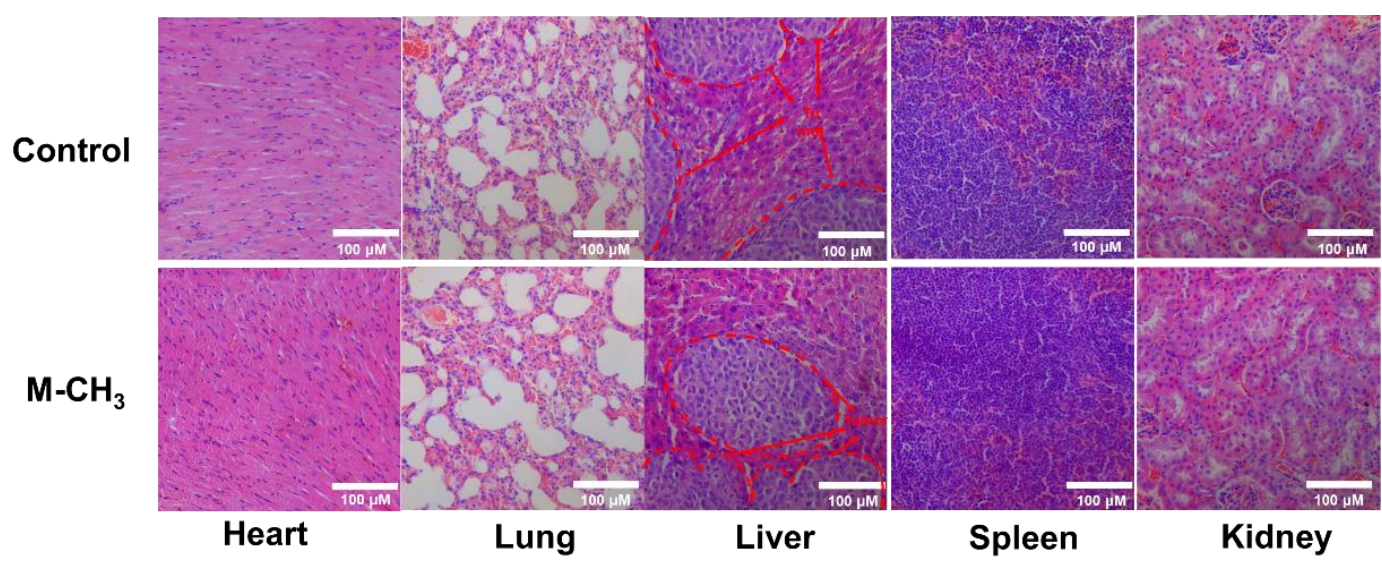

Figure S15 H\&E-stained images of major organs of the orthotopic liver tumor-bearing mice after intravenous injection of saline and $\mathrm{M}-\mathrm{CH}_{3}$ nanocrystals, respectively. 

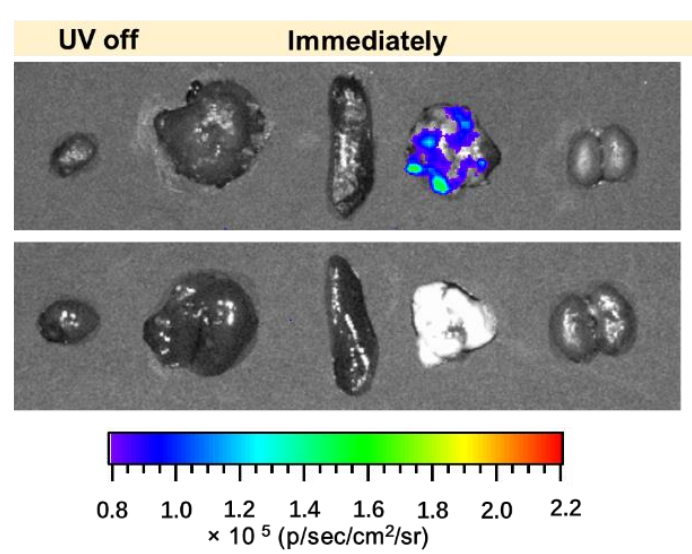
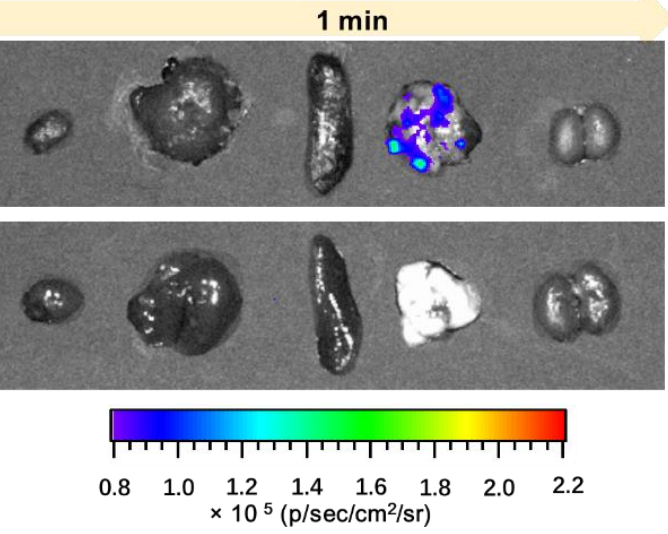

Figure S16 Time-resolved phosphorescence imaging of different organs from pulmonary metastatic carcinoma-bearing mice at $2 \mathrm{~h}$ post intravenous injection of $\mathrm{M}-\mathrm{CH}_{3}$ nanocrystals (upper) or saline (down). The tissues were irradiated by $365 \mathrm{~nm}$ hand-held UV lamp (12 W) for $30 \mathrm{~s}$ and then imaged with IVIS ${ }^{\circledR}$ instrument at $10 \mathrm{~s}$ and $1 \mathrm{~min}$ after stoppage of light excitation, respectively.

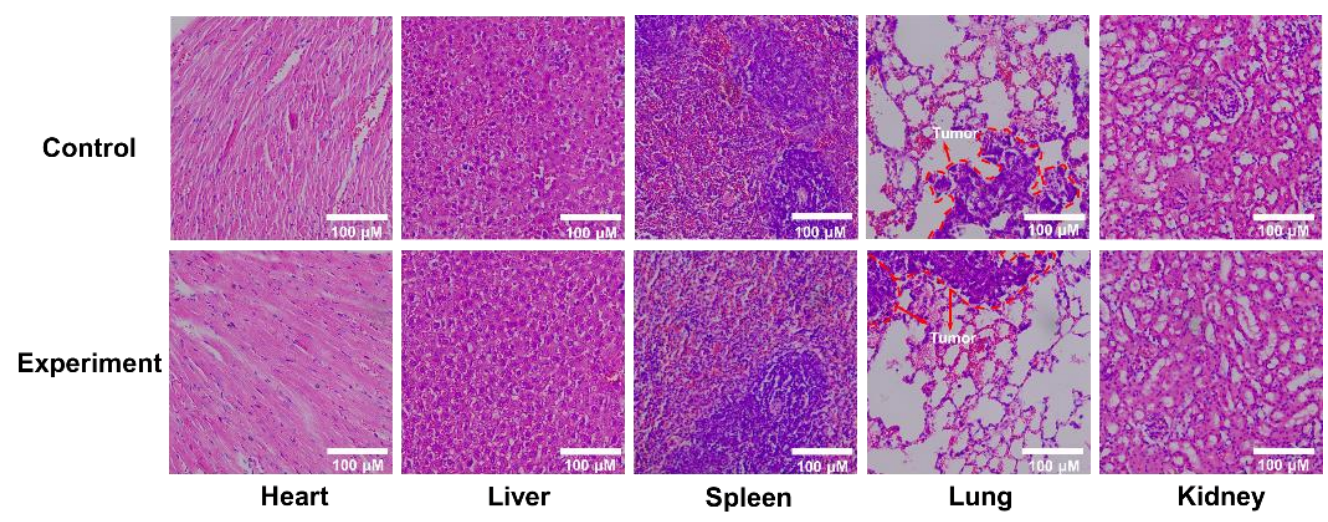

Figure S17 H\&E-stained images of major organs of pulmonary metastatic carcinoma-bearing mice after intravenous injection of saline and $\mathrm{M}-\mathrm{CH}_{3}$ nanocrystals, respectively. 


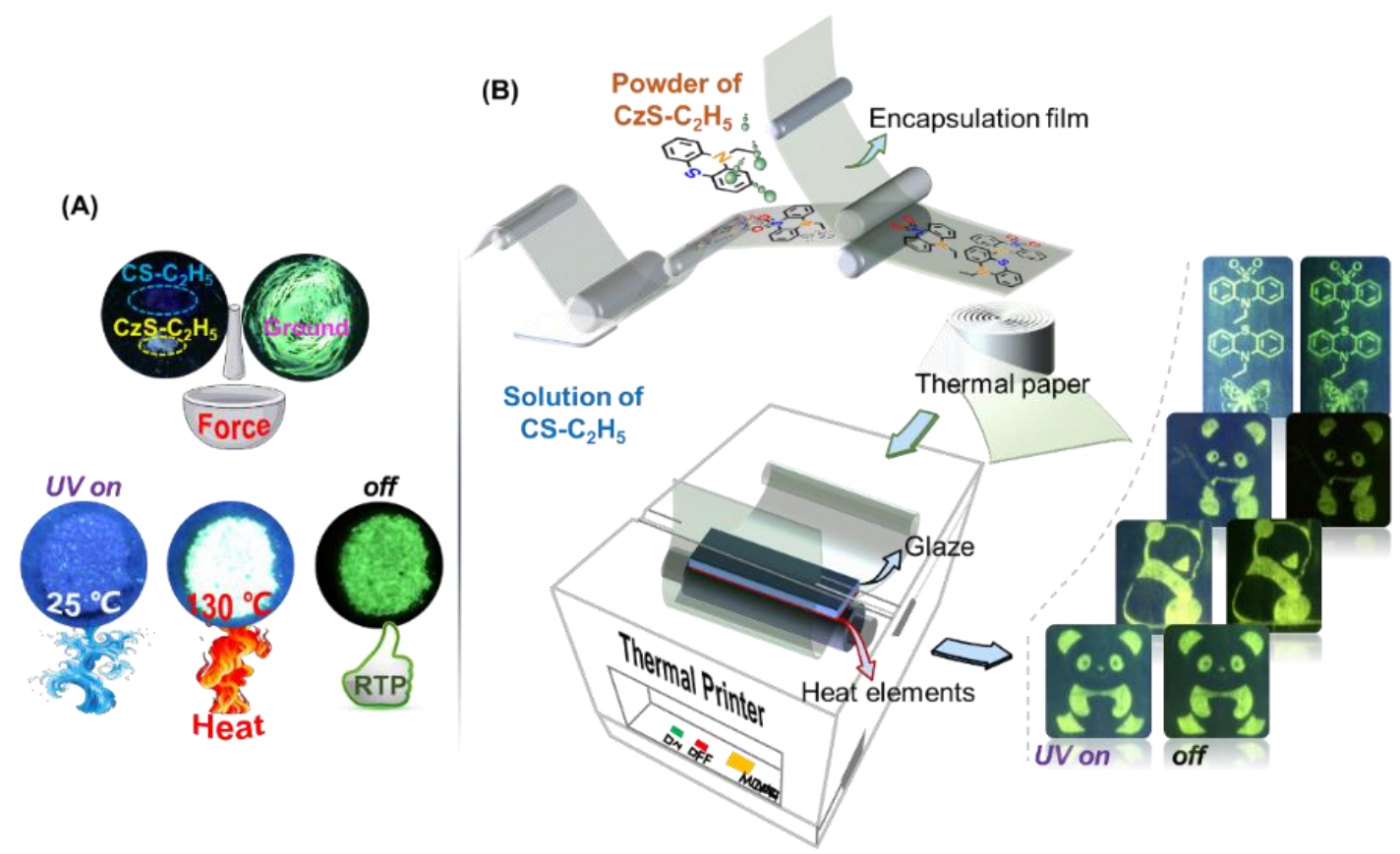

Figure S18 (A) The force and heating-responsive RTP effects based on the system of CS- $\mathrm{C}_{2} \mathrm{H}_{5}$ and $\mathrm{CzS}-\mathrm{C}_{2} \mathrm{H}_{5}$; (B) Schematic diagram of the thermal printer based on the system of $\mathrm{CS}-\mathrm{C}_{2} \mathrm{H}_{5}$ and $\mathrm{CzS}-\mathrm{C}_{2} \mathrm{H}_{5}$ : the thermal paper passed over the print head, then the preset pattern was painted for the interaction of donor and acceptor; and finally, the structural formulas and pandas with green afterglow could be clearly observed by the naked eye.
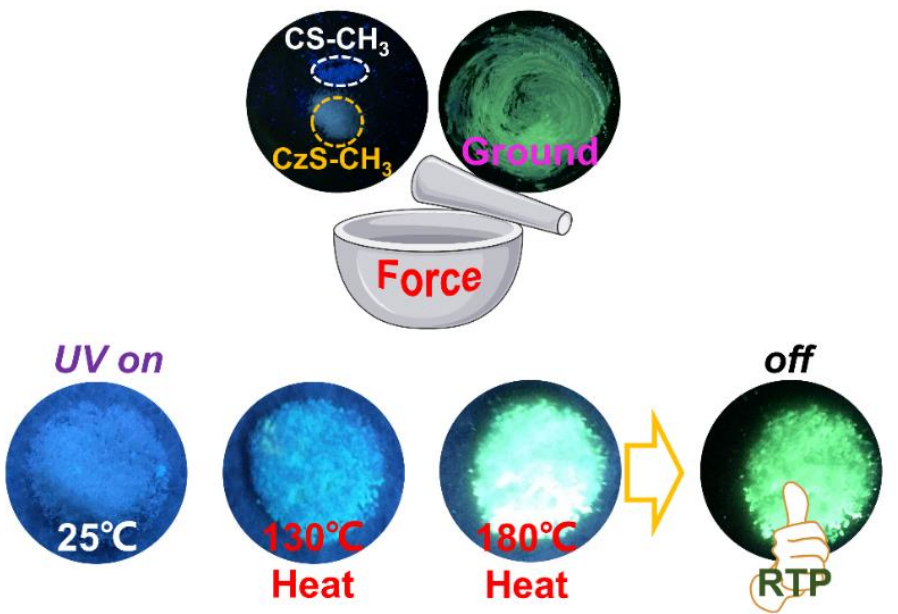

Figure S19 The force/thermal-responsive RTP effect based on the system of $\mathrm{CS}-\mathrm{CH}_{3}$ and $\mathrm{CzS}-\mathrm{CH}_{3}$. 


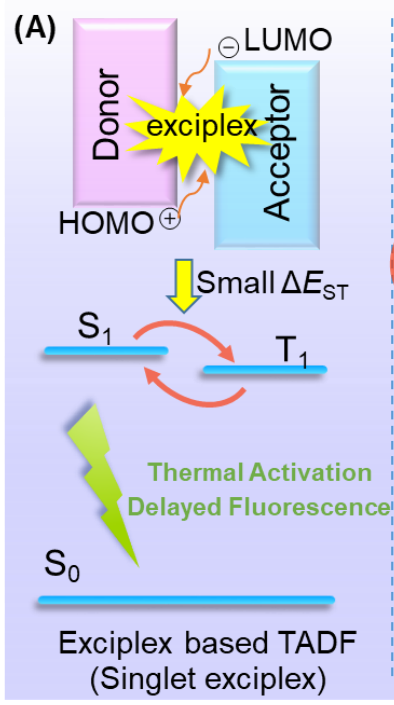

(B)
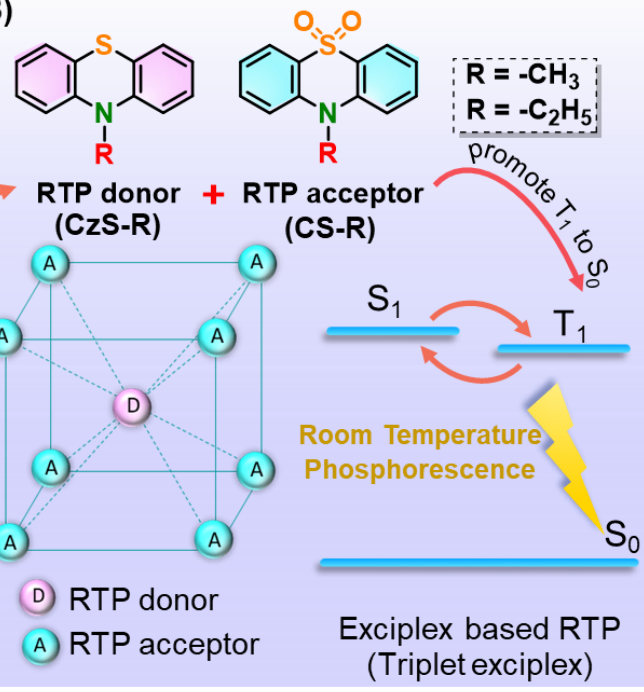

Figure S20 (A) The schematic diagram of TADF based on singlet exciplex; (B) The proposed diagram to develop triplet exciplex based on RTP donor and acceptor.
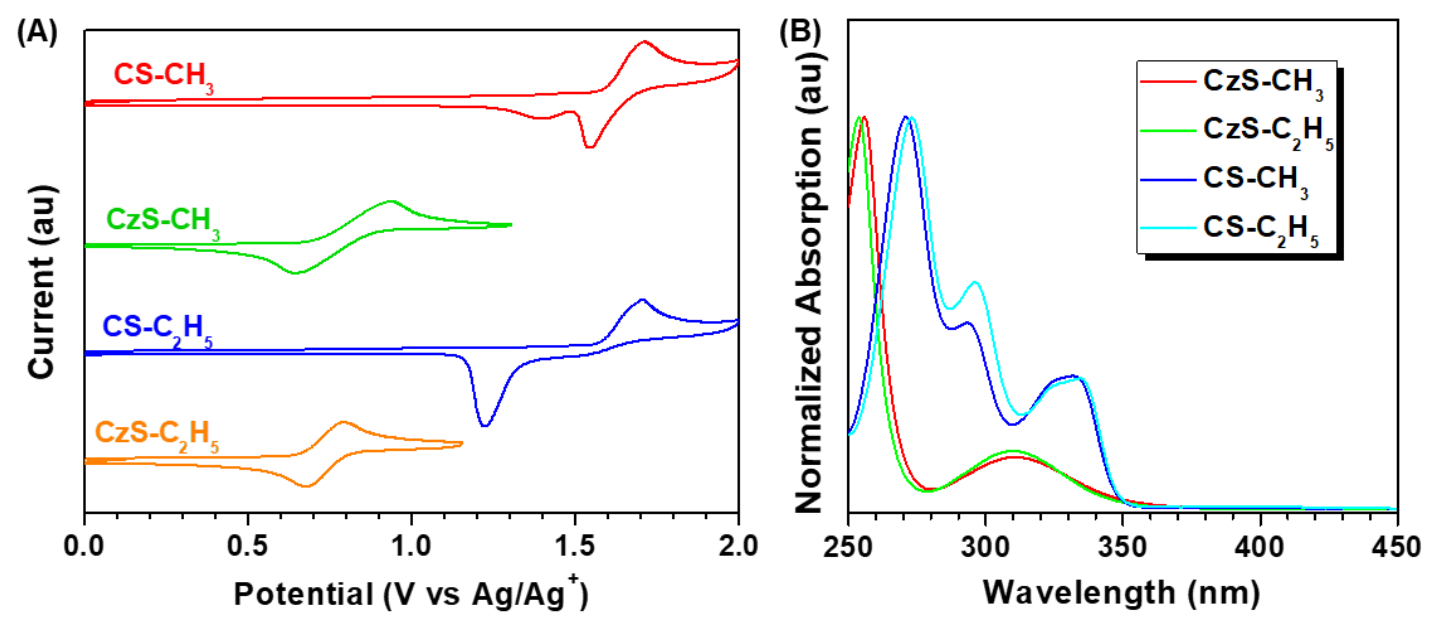

Figure S21 (A) The CV curves of $\mathrm{CS}-\mathrm{CH}_{3}, \mathrm{CS}-\mathrm{C}_{2} \mathrm{H}_{5}, \mathrm{CzS}-\mathrm{CH}_{3}$ and $\mathrm{CzS}_{2} \mathrm{C}_{2} \mathrm{H}_{5}$; (B) The UV-vis absorption spectra of CS-CH $3, C S-\mathrm{C}_{2} \mathrm{H}_{5}, \mathrm{CzS}_{3}-\mathrm{CH}_{3}$ and $\mathrm{CzS}-\mathrm{C}_{2} \mathrm{H}_{5}$ in THF solution (concentration: $\left.10^{-5} \mathrm{M}\right)$.

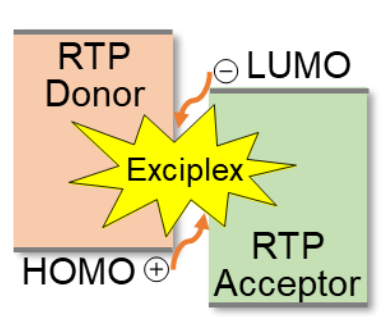

\begin{tabular}{|c|c|c|c|}
\hline Compound & $E_{\mathrm{g}}(\mathrm{eV})$ & $E_{\mathrm{HOMO}}(\mathrm{eV})$ & $E_{\mathrm{LUMO}}(\mathrm{eV})$ \\
\hline $\mathrm{CS}-\mathrm{CH}_{3}$ & 3.56 & -5.97 & -2.41 \\
\hline $\mathrm{CzS}-\mathrm{CH}_{3}$ & 3.50 & -5.09 & -1.59 \\
\hline $\mathrm{CS}-\mathrm{C}_{2} \mathrm{H}_{5}$ & 3.58 & -5.97 & -2.39 \\
\hline $\mathrm{CzS}-\mathrm{C}_{2} \mathrm{H}_{5}$ & 3.57 & -5.05 & -1.48 \\
\hline
\end{tabular}

Figure S22 The calculated energy levels of CS-CH$, C S-\mathrm{C}_{2} \mathrm{H}_{5}, \mathrm{CzS}-\mathrm{CH}_{3}$ and $\mathrm{CzS}-\mathrm{C}_{2} \mathrm{H}_{5}$. 
Table S1. The crystal data of $\mathrm{CS}-\mathrm{CH}_{3}, \mathrm{CzS}-\mathrm{CH}_{3}$ and their co-crystal $\mathrm{M}-\mathrm{CH}_{3}$ with the mass ratio of $100: 1 .^{15,21}$

\begin{tabular}{llll}
\hline Name & CS-CH3 & CzS-CH3 & M-CH3 \\
\hline Formula & $\mathrm{C}_{13} \mathrm{H}_{11} \mathrm{NO}_{2} \mathrm{~S}$ & $\mathrm{C}_{13} \mathrm{H}_{11} \mathrm{NS}$ & $\mathrm{C}_{13} \mathrm{H}_{11} \mathrm{NO}_{2} \mathrm{~S}$ \\
Wavelength $(\AA)$ & 0.71000 & 1.54184 & 1.54184 \\
Space Group & $\mathrm{P} 21 / \mathrm{n}$ & $\mathrm{C} 1 \mathrm{n} 1$ & $\mathrm{P} 21 / \mathrm{n}$ \\
Cell Lengths $(\AA)$ & $\mathrm{a}=8.78316(19)$ & $\mathrm{a}=11.363(5)$ & $\mathrm{a}=8.7883(4)$ \\
& $\mathrm{b}=11.4642(2)$ & $\mathrm{b}=14.386(5)$ & $\mathrm{b}=11.4615(5)$ \\
& $\mathrm{c}=11.1048(2)$ & $\mathrm{c}=6.545(5)$ & $\mathrm{c}=11.1107(5)$ \\
Cell Angles $\left({ }^{\circ}\right)$ & $\alpha=90$ & $\alpha=90$ & $\alpha=90$ \\
& $\beta=91.3006(19)$ & $\beta=90.000(5)$ & $\beta=91.308(4)$ \\
Cell Volume $\left(\AA^{3}\right)$ & $1117.88(4)$ & $\gamma=90$ & $\gamma=90$ \\
$\mathrm{Z}$ & 4 & $1069.9(10)$ & $1118.86(9)$ \\
Density $\left(\mathrm{g} / \mathrm{cm}^{3}\right)$ & 1.457 & 4 & 4 \\
$\mathrm{~F}(000)$ & 512.0 & 1.324 & 1.456 \\
$\mathrm{~h}_{\text {max }}, \mathrm{k}_{\max }, 1_{\max }$ & $10,14,13$ & 448.0 & 512.0 \\
CCDC Number & 1879164 & $13,17,7$ & $10,13,13$ \\
\hline
\end{tabular}


Table S2. The crystal data of $\mathrm{CS}-\mathrm{C}_{2} \mathrm{H}_{5}, \mathrm{CzS}-\mathrm{C}_{2} \mathrm{H}_{5}$ and their co-crystal $\mathrm{M}-\mathrm{C}_{2} \mathrm{H}_{5}$ with the mass ratio of $100: 1 .^{15,21}$

\begin{tabular}{|c|c|c|c|}
\hline Name & $\mathrm{CS}-\mathrm{C}_{2} \mathrm{H}_{5}$ & $\mathrm{CzS}-\mathrm{C}_{2} \mathrm{H}_{5}$ & $\mathrm{M}-\mathrm{C}_{2} \mathrm{H}_{5}$ \\
\hline Formula & $\mathrm{C}_{14} \mathrm{H}_{13} \mathrm{NO}_{2} \mathrm{~S}$ & $\mathrm{C}_{14} \mathrm{H}_{13} \mathrm{NS}$ & $\mathrm{C}_{14} \mathrm{H}_{13} \mathrm{NO}_{2} \mathrm{~S}$ \\
\hline Wavelength $(\AA)$ & 1.54184 & 1.54184 & 1.54184 \\
\hline Space Group & $\mathrm{P} 21 / \mathrm{n}$ & P n a 21 & $\mathrm{P} 21 / \mathrm{n}$ \\
\hline \multirow[t]{3}{*}{ Cell Lengths $(\AA \AA)$} & $\mathrm{a}=7.9027(3)$ & $\mathrm{a}=14.2619(8)$ & $\mathrm{a}=7.9148(2)$ \\
\hline & $b=11.1576(4)$ & $b=10.7913(7)$ & $b=11.1799(3)$ \\
\hline & $\mathrm{c}=13.5298(6)$ & $\mathrm{c}=7.6508(4)$ & $\mathrm{c}=13.5622(3)$ \\
\hline \multirow[t]{3}{*}{ Cell Angles $\left({ }^{\circ}\right)$} & $\alpha=90$ & $\alpha=90$ & $\alpha=90$ \\
\hline & $\beta=93.338(4)$ & $\beta=90$ & $\beta=93.335(2)$ \\
\hline & $\gamma=90$ & $\gamma=90$ & $\gamma=90$ \\
\hline Cell Volume $\left(\AA^{3}\right)$ & $1190.97(8)$ & $1177.49(12)$ & $1198.04(5)$ \\
\hline Z & 4 & 4 & 4 \\
\hline Density $\left(\mathrm{g} / \mathrm{cm}^{3}\right)$ & 1.446 & 1.282 & 1.438 \\
\hline $\mathrm{F}(000)$ & 544.0 & 480.0 & 544 \\
\hline $\mathrm{h}_{\max }, \mathrm{k}_{\max }, 1_{\max }$ & $9,13,16$ & $17,12,9$ & $9,13,16$ \\
\hline CCDC Number & 1879165 & 1562903 & 2013397 \\
\hline
\end{tabular}
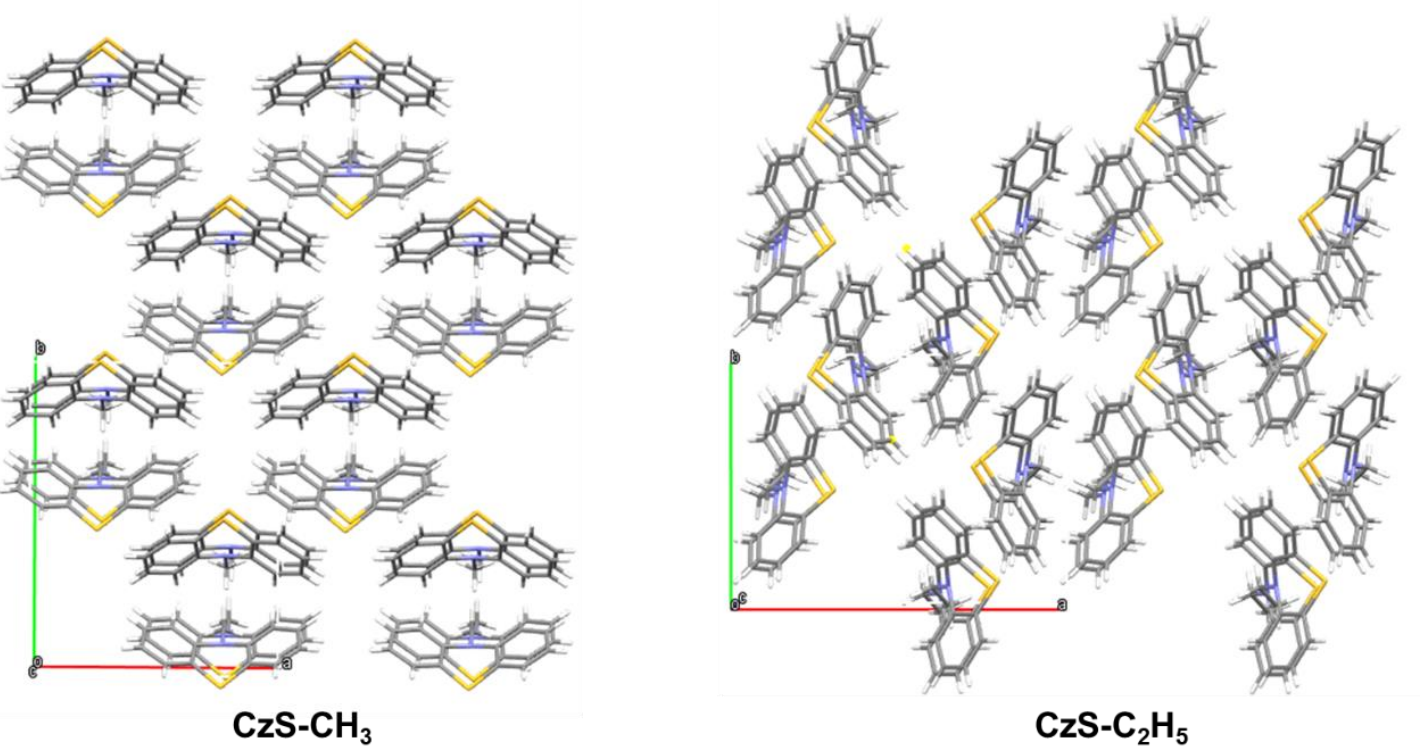

Figure S23 The molecular packing modes of $\mathrm{CzS}-\mathrm{CH}_{3}$ and $\mathrm{CzS}-\mathrm{C}_{2} \mathrm{H}_{5}$ crystals. 

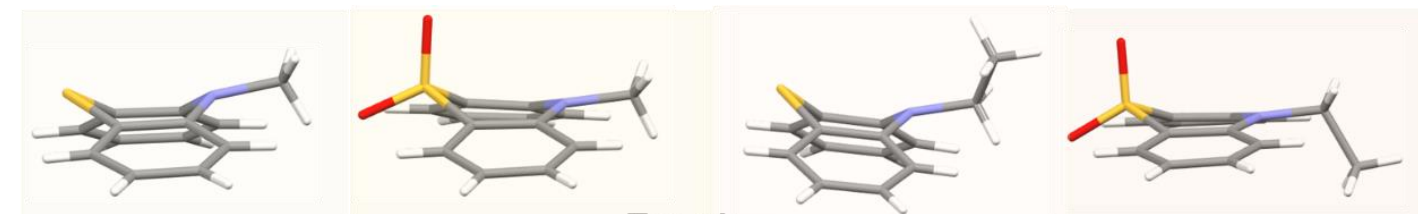

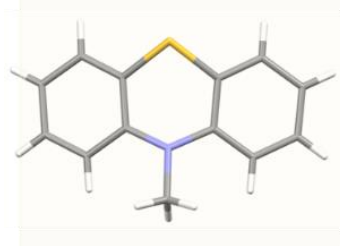

$\mathrm{CzS}-\mathrm{CH}_{3}$

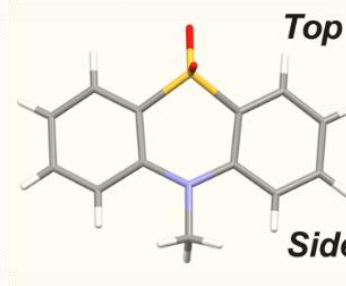

$\mathrm{CS}-\mathrm{CH}_{3}$

Top view

Side view

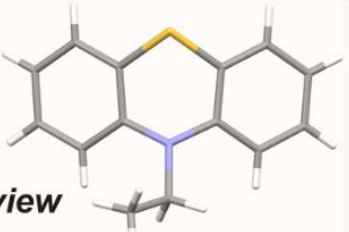

CzS- $\mathrm{C}_{2} \mathrm{H}_{5}$

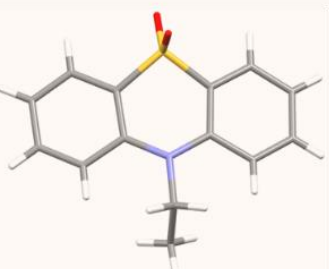

CS- $\mathrm{C}_{2} \mathrm{H}_{5}$

Figure S24 The molecular conformations of $\mathrm{CzS}-\mathrm{CH}_{3}, \mathrm{CS}-\mathrm{CH}_{3}, \mathrm{CzS}-\mathrm{C}_{2} \mathrm{H}_{5}$ and $\mathrm{CS}_{-} \mathrm{C}_{2} \mathrm{H}_{5}$ : they present similar molecular conformation in crystal state, regardless of their minor difference in molecular structure, which would help them integrate with each other in co-crystal.

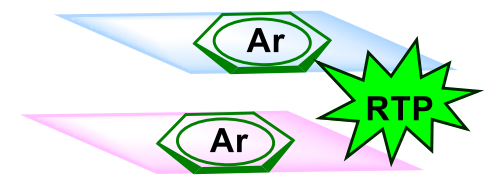

Efficient $\pi-\pi$ interaction

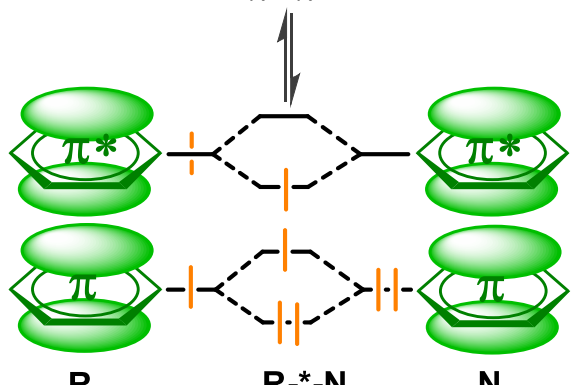

$\mathbf{R}$

$\mathbf{R} \mathbf{-}^{*}-\mathbf{N}$

$\mathbf{N}$

two electrons stabilized @ $₫-\pi$ stacking

Figure S25 The persistent RTP mechanism based on the classical perturbation theory: On one hand, the intermolecular $\pi-\pi$ interaction can lower the energy level of excited state, then reducing the RTP radiative rate $\left(k_{\mathrm{P}}\right)$; on the other hand, the non-radiative transition $\left(k_{\mathrm{P}, \mathrm{nr}}\right)$ would also be restricted for the rigid environment leading by it. Thus, the RTP lifetime $\left(\tau_{\mathrm{P}}\right)$ is prolonged based on the equation of $\tau_{\mathrm{P}}=1 /\left(k_{\mathrm{P}}+k_{\mathrm{P}, \mathrm{nr}}\right)$. 
(A)

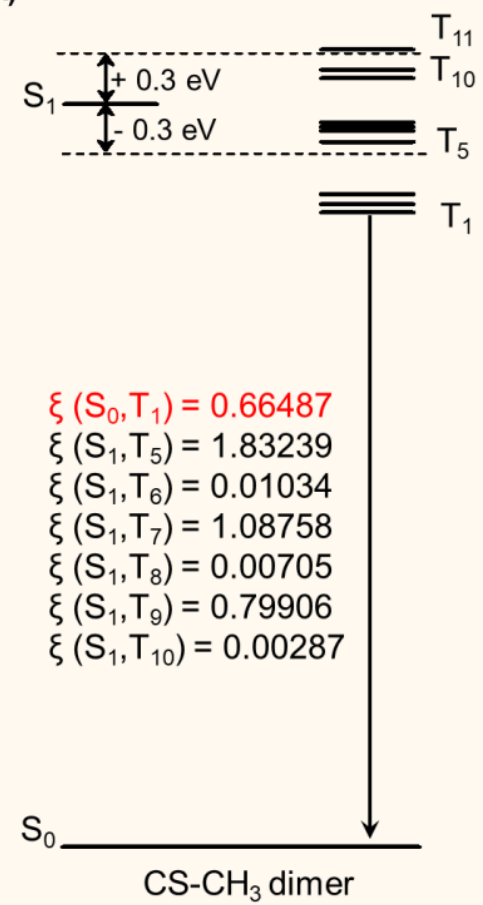

(B)

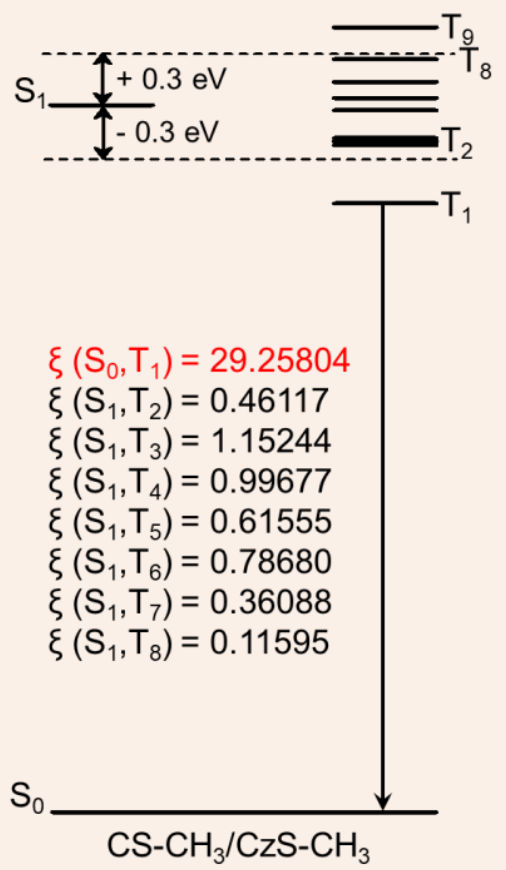

Figure S26 (A) Calculated spin-orbit coupling constants between the $\mathrm{S}_{0} / \mathrm{S}_{1}$ and $\mathrm{T}_{\mathrm{n}}$ for $\mathrm{CS}-\mathrm{CH}_{3}$ dimer; (B) Calculated spin-orbit coupling constants between the $\mathrm{S}_{0} / \mathrm{S}_{1}$ and $\mathrm{T}_{\mathrm{n}}$ for $\mathrm{CS}-\mathrm{CH}_{3} / \mathrm{CzS}-\mathrm{CH}_{3}$.
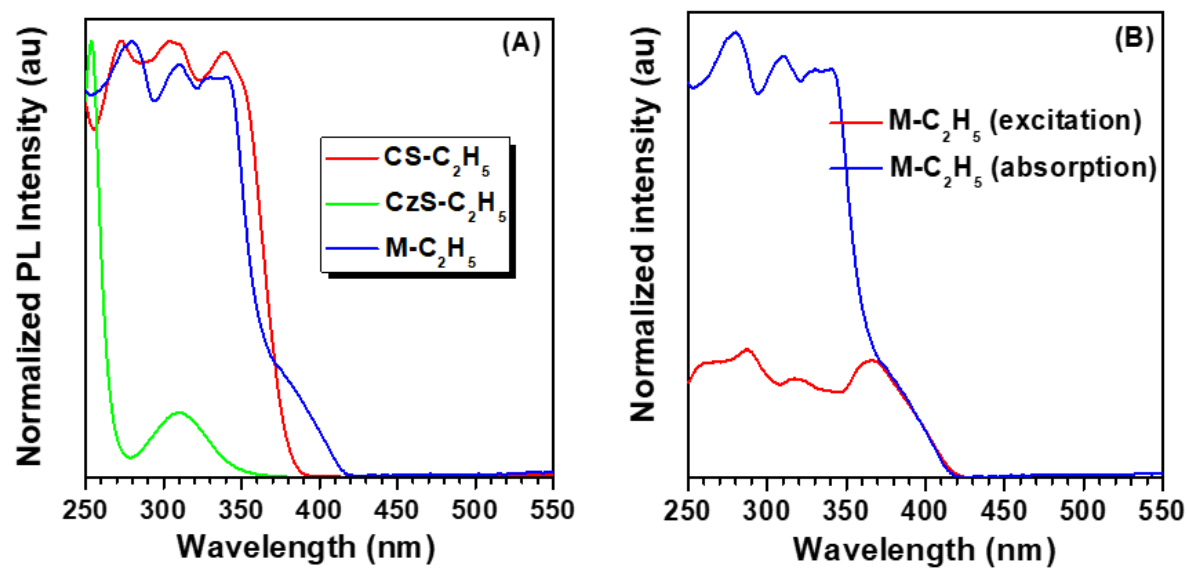

Figure S27 (A) UV-vis absorption spectra of $\mathrm{CS}_{-} \mathrm{C}_{2} \mathrm{H}_{5}$ (in crystal state), $\mathrm{CzS}-\mathrm{C}_{2} \mathrm{H}_{5}$ (in $\mathrm{THF}$ solution) and $\mathrm{M}-\mathrm{C}_{2} \mathrm{H}_{5}$ (in crystal state); (B) UV-vis absorption and RTP excitation spectra of $\mathrm{M}-\mathrm{C}_{2} \mathrm{H}_{5}$ in crystal state. 

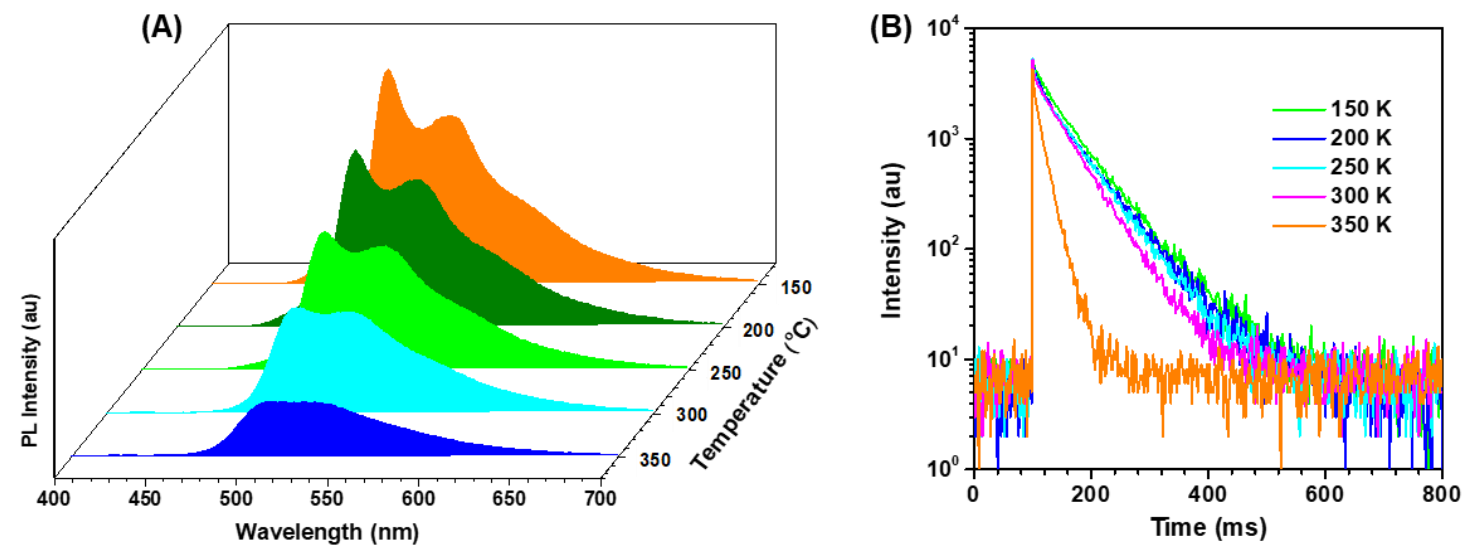

Figure S28 (A) PL spectra of $\mathrm{M}-\mathrm{C}_{2} \mathrm{H}_{5}$ in crystal state with temperature ranging from 150 to 350 $\mathrm{K}$; (B) PL decay curves of $\mathrm{M}-\mathrm{C}_{2} \mathrm{H}_{5}$ in crystal state with temperature ranging from 150 to $350 \mathrm{~K}$.

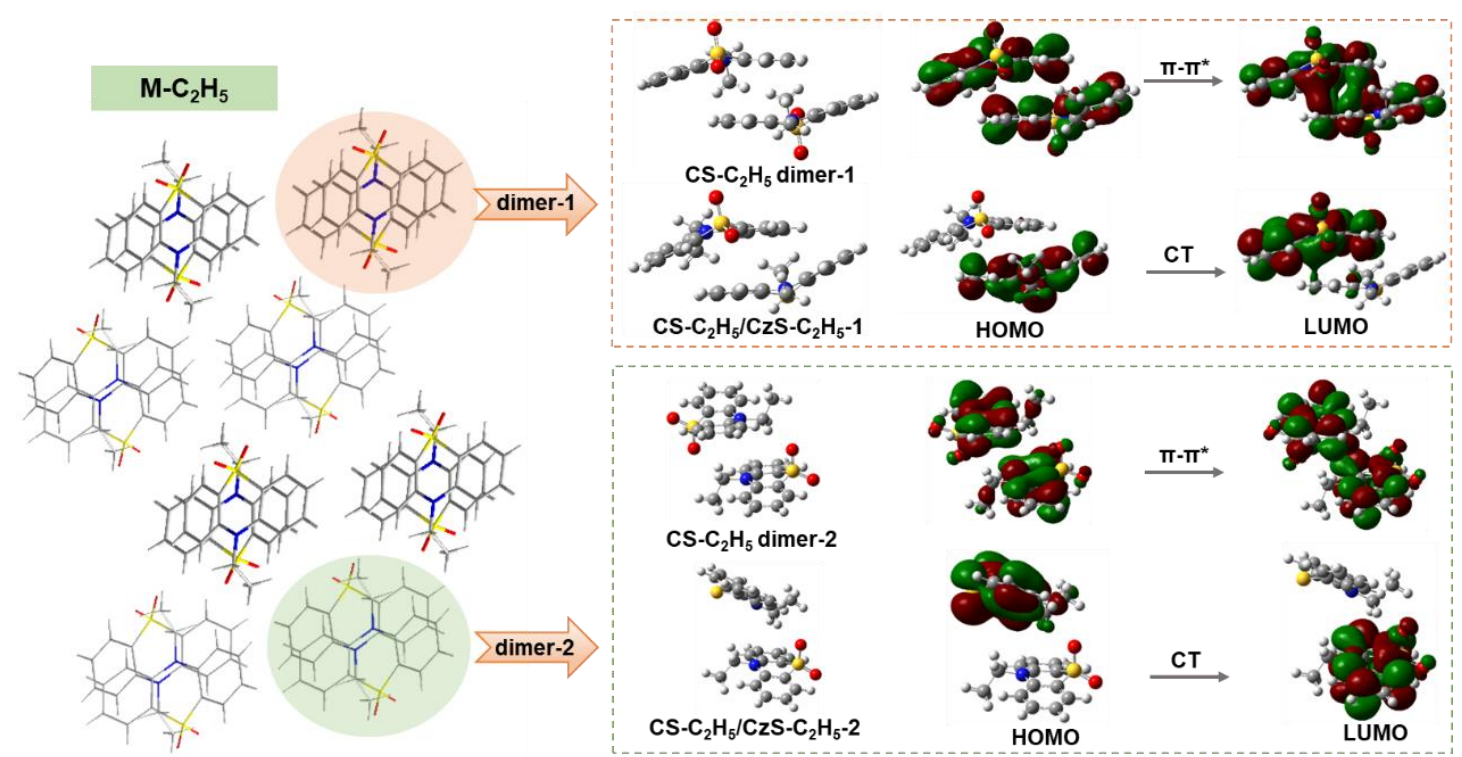

Figure S29 Crystal structure of $\mathrm{M}-\mathrm{C}_{2} \mathrm{H}_{5}$ and the corresponding theoretical calculations: $\mathrm{CS}-\mathrm{C}_{2} \mathrm{H}_{5}$ dimers show typical $\pi-\pi^{*}$ transition from HOMO to LUMO. When one $\mathrm{CS}_{-} \mathrm{C}_{2} \mathrm{H}_{5}$ molecule is replaced by $\mathrm{CzS}-\mathrm{C}_{2} \mathrm{H}_{5}$, the optimized structure of the new dimer presents an obvious intermolecular CT transition, from the occupied orbital of $\mathrm{CzS}-\mathrm{C}_{2} \mathrm{H}_{5}$ to the vacant orbital of the neighboring $\mathrm{CS}-\mathrm{C}_{2} \mathrm{H}_{5}$ molecule. 


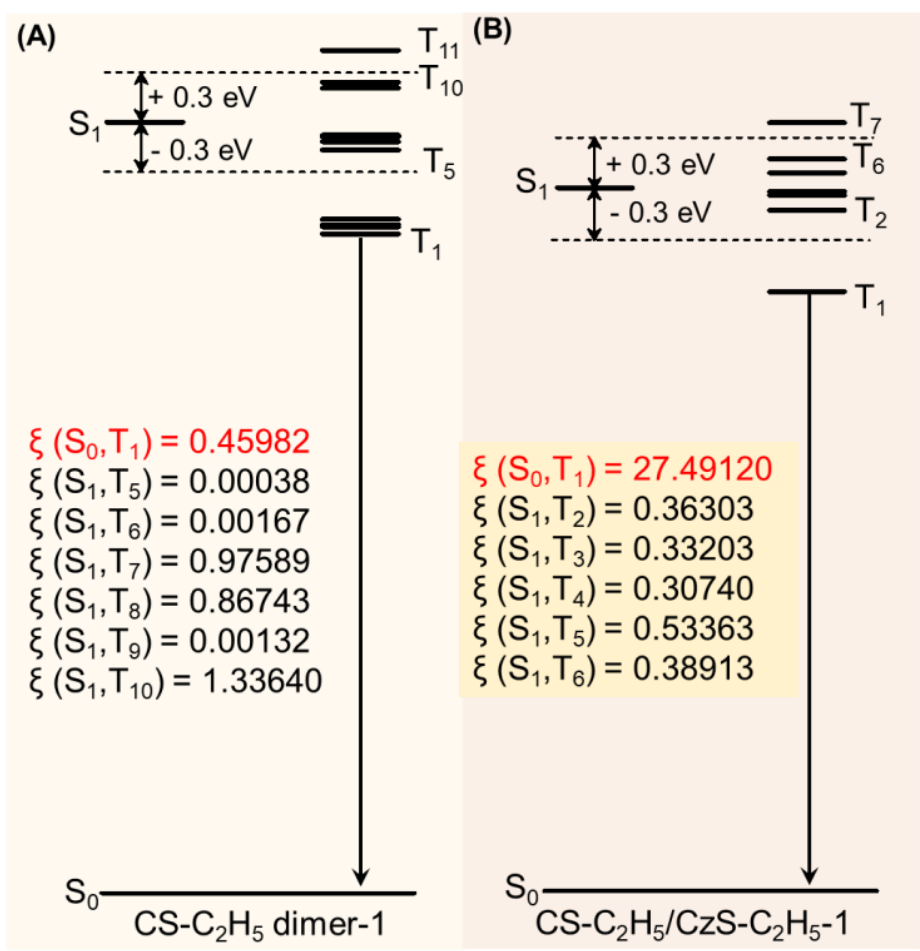

Figure S30 (A) Calculated spin-orbit coupling constants between the $\mathrm{S}_{0} / \mathrm{S}_{1}$ and $\mathrm{T}_{\mathrm{n}}$ for $\mathrm{CS}-\mathrm{C}_{2} \mathrm{H}_{5}$ dimer-1; (B) Calculated spin-orbit coupling constants between the $\mathrm{S}_{0} / \mathrm{S}_{1}$ and $\mathrm{T}_{\mathrm{n}}$ and for $\mathrm{CS}-\mathrm{C}_{2} \mathrm{H}_{5} / \mathrm{CzS}-\mathrm{C}_{2} \mathrm{H}_{5}-1$.
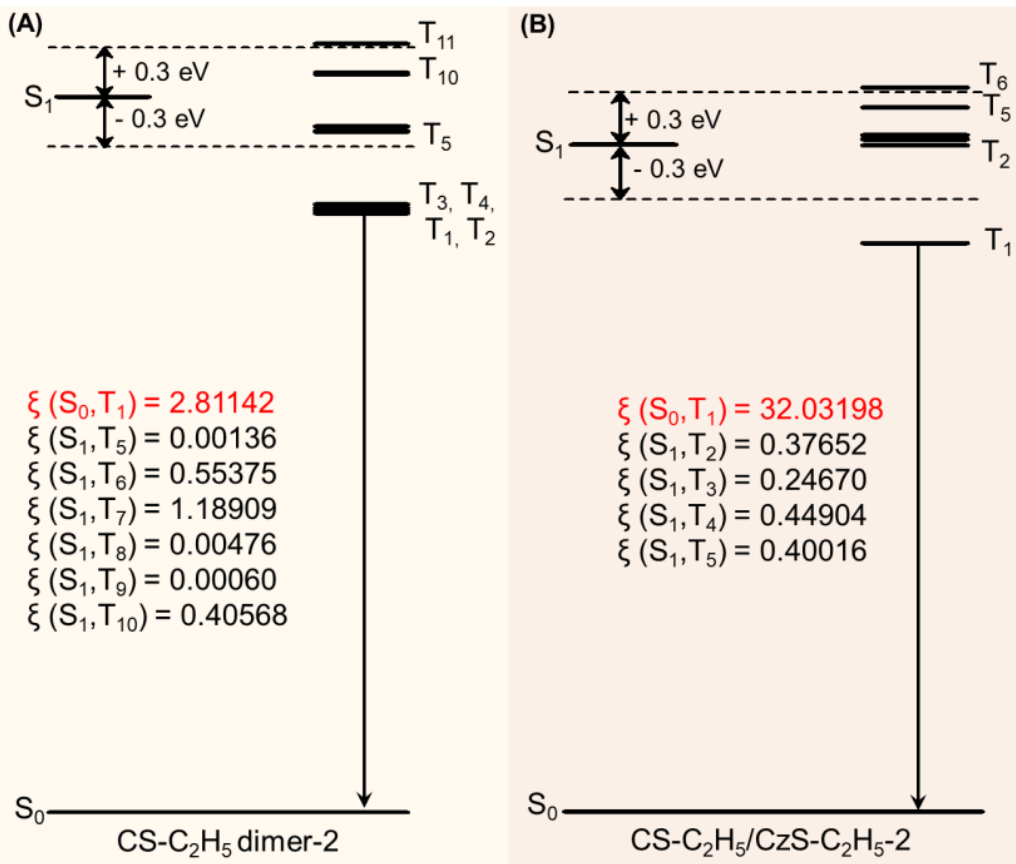

Figure S31 (A) Calculated spin-orbit coupling constants between the $\mathrm{S}_{0} / \mathrm{S}_{1}$ and $\mathrm{T}_{\mathrm{n}}$ for $\mathrm{CS}-\mathrm{C}_{2} \mathrm{H}_{5}$ dimer-2; (B) Calculated spin-orbit coupling constants between the $\mathrm{S}_{0} / \mathrm{S}_{1}$ and $\mathrm{T}_{\mathrm{n}}$ for $\mathrm{CS}-\mathrm{C}_{2} \mathrm{H}_{5} / \mathrm{CzS}-\mathrm{C}_{2} \mathrm{H}_{5}-2$. 


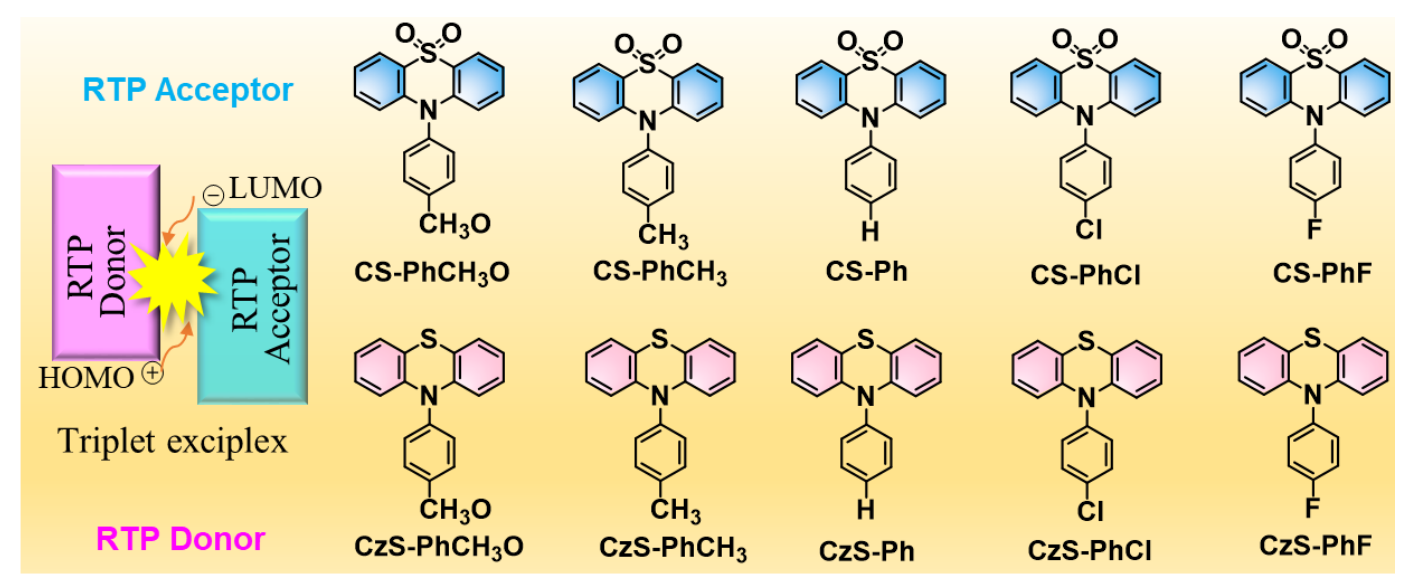

Figure S32 Molecular structures of some other RTP donors and acceptors.
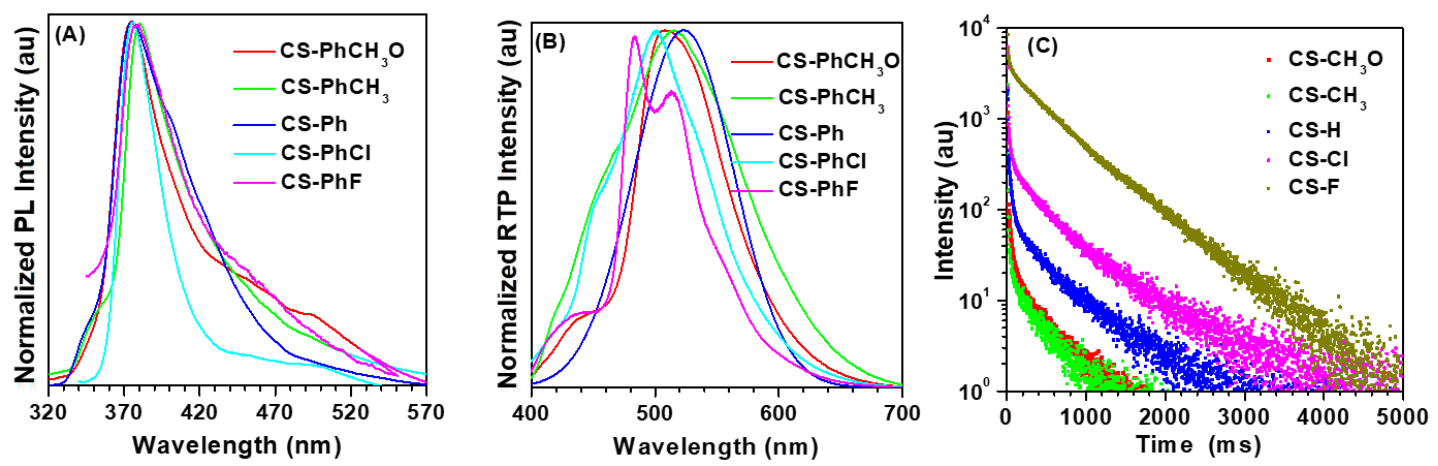

Figure S33 (A) The steady state $\mathrm{PL}$ spectra of $\mathrm{CS}-\mathrm{PhCH}_{3} \mathrm{O}, \mathrm{CS}-\mathrm{PhCH}_{3}, \mathrm{CS}-\mathrm{Ph}, \mathrm{CS}-\mathrm{PhCl}$ and CS-PhF; (B) The RTP spectra, acquired after $10 \mathrm{~ms}$ delay, of $\mathrm{CS}-\mathrm{PhCH}_{3} \mathrm{O}, \mathrm{CS}-\mathrm{PhCH}_{3}, \mathrm{CS}-\mathrm{Ph}$, CS-PhCl and CS-PhF; (C) The RTP decay curves of $\mathrm{CS}-\mathrm{PhCH}_{3} \mathrm{O}, \mathrm{CS}-\mathrm{PhCH}_{3}, \mathrm{CS}-\mathrm{Ph}, \mathrm{CS}-\mathrm{PhCl}$ and CS-PhF. 

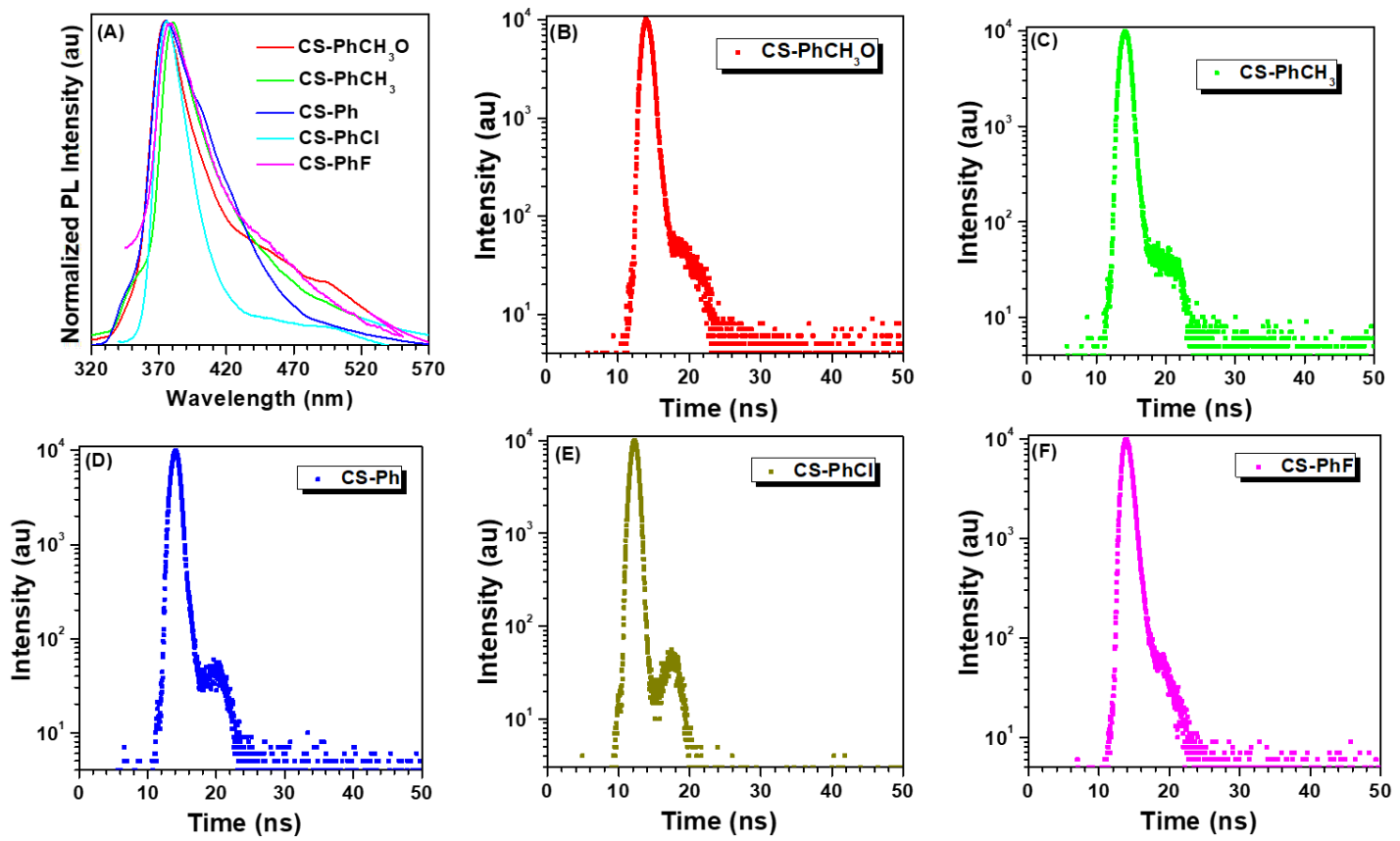

Figure S34 The steady state $\mathrm{PL}$ spectra of $\mathrm{CS}-\mathrm{PhCH}_{3} \mathrm{O}, \mathrm{CS}-\mathrm{PhCH}_{3}, \mathrm{CS}-\mathrm{Ph}, \mathrm{CS}-\mathrm{PhCl}$ and $\mathrm{CS}-\mathrm{PhF}$ (A) and their corresponding fluorescence decay curves (B-F).
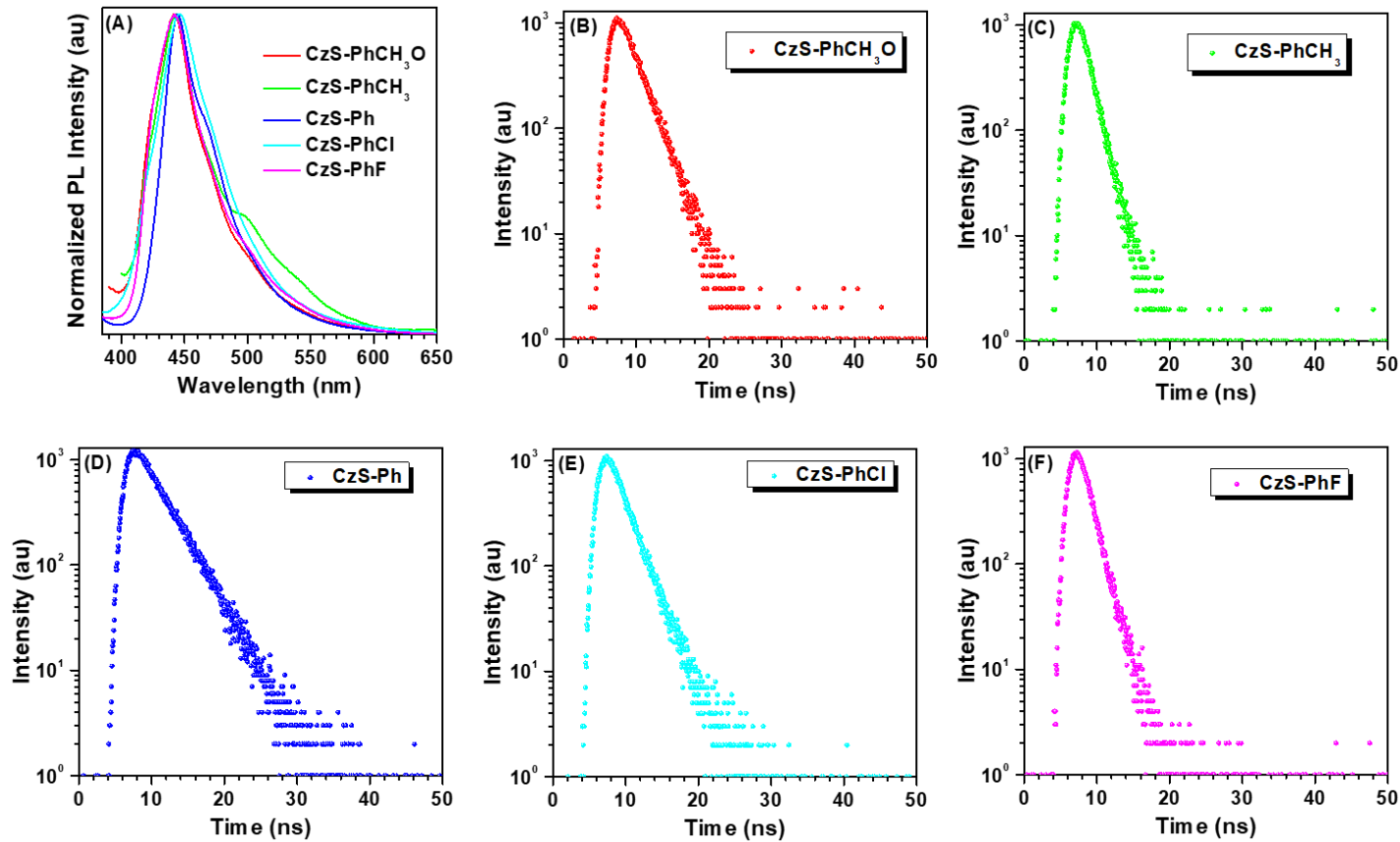

Figure S35 The steady state $\mathrm{PL}$ spectra of $\mathrm{CzS}-\mathrm{PhCH}_{3} \mathrm{O}, \mathrm{CzS}-\mathrm{PhCH}_{3}, \mathrm{CzS}-\mathrm{Ph}, \mathrm{CzS}-\mathrm{PhCl}$ and $\mathrm{CzS}-\mathrm{PhF}(\mathbf{A})$ and their corresponding fluorescence decay curves (B-F). 

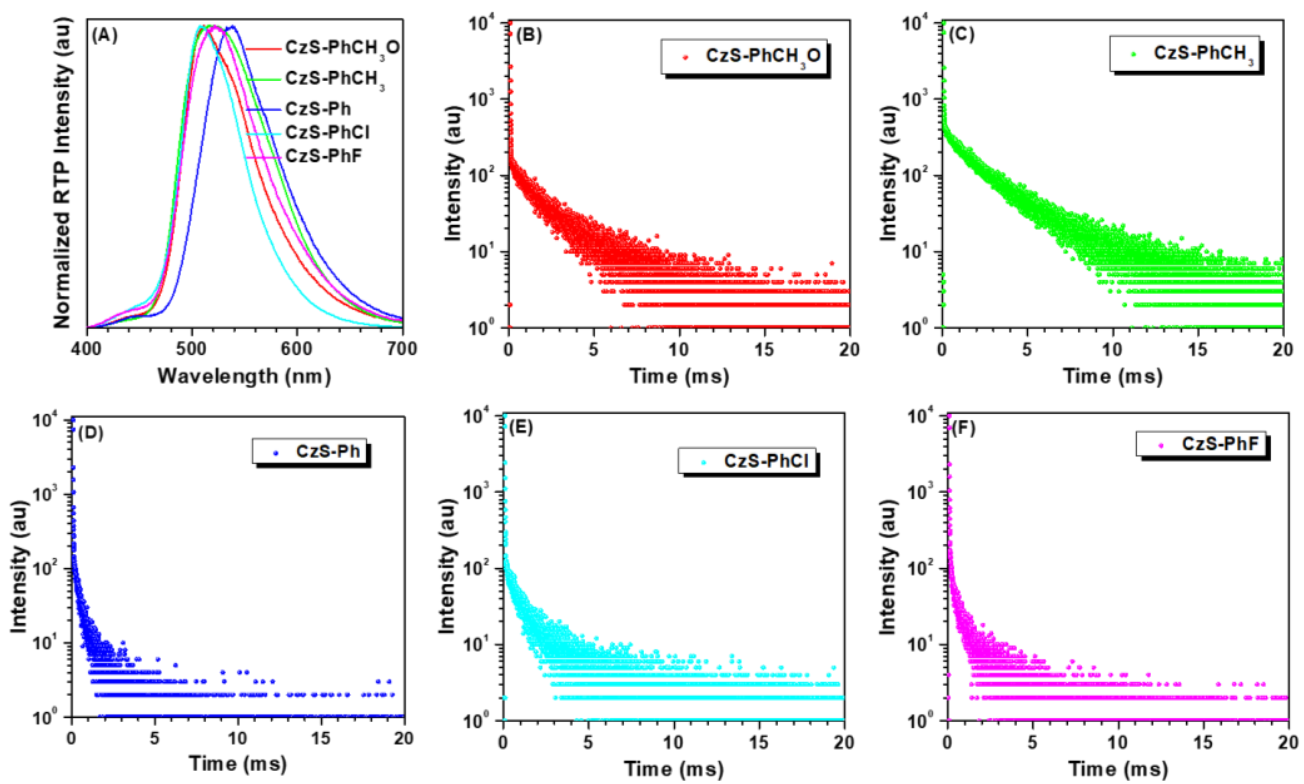

Figure S36 The RTP spectra of CzS-PhCH $\mathrm{P}_{3} \mathrm{O}, \mathrm{CzS}-\mathrm{PhCH}_{3}, \mathrm{CzS}-\mathrm{Ph}, \mathrm{CzS}-\mathrm{PhCl}$ and $\mathrm{CzS}-\mathrm{PhF}$ (A) and their corresponding phosphorescence decay curves (B-F).
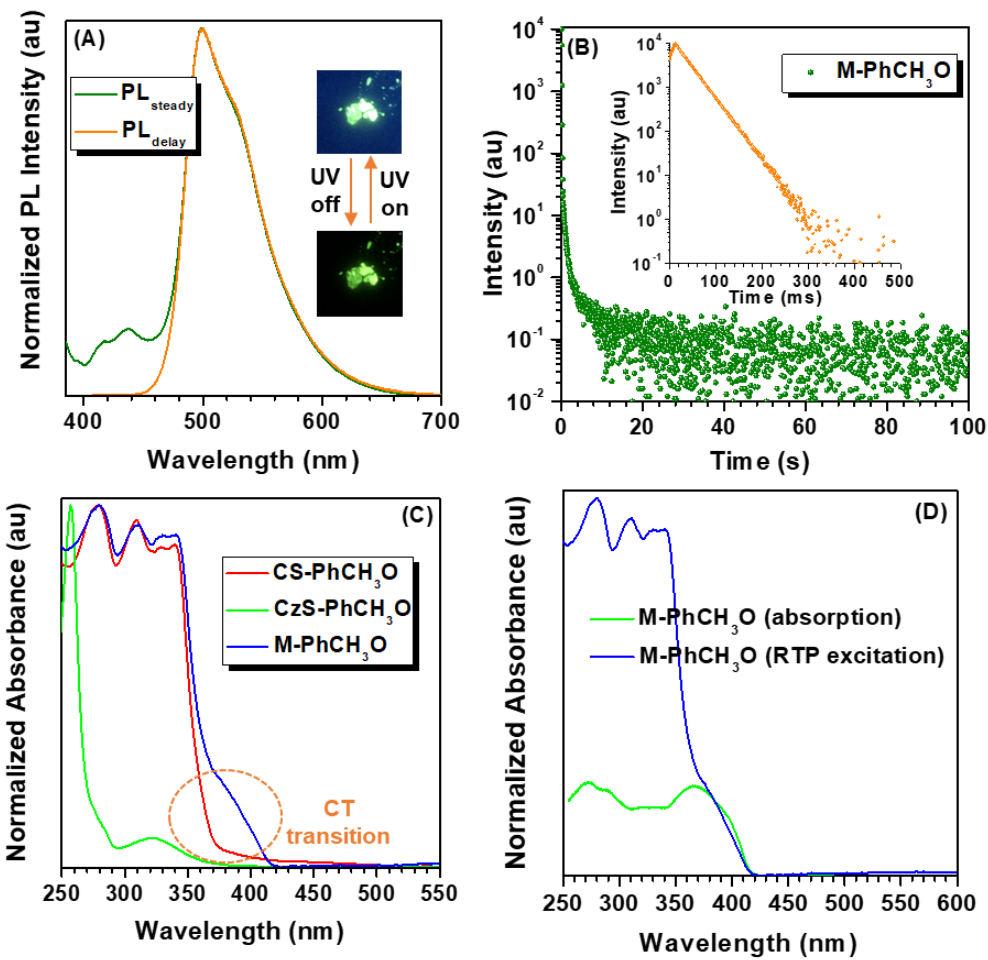

Figure S37 (A) The steady state PL and RTP spectra of co-crystal $\left(\mathrm{M}-\mathrm{PhCH}_{3} \mathrm{O}\right)$ based on $\mathrm{CS}-\mathrm{PhCH}_{3} \mathrm{O}$ and $\mathrm{CzS}-\mathrm{PhCH}_{3} \mathrm{O}$ with mass ratio of 100:1; (B) The RTP decay curves of $\mathrm{M}-\mathrm{PhCH}_{3} \mathrm{O}$, in which two components exist, the former one is relatively shorter and later one is ultra-long; (C) UV-vis absorption spectra of CS-PhCH $3 \mathrm{O}$ (in crystal state), $\mathrm{CzS}-\mathrm{PhCH}_{3} \mathrm{O}$ (in THF solution) and $\mathrm{M}-\mathrm{PhCH}_{3} \mathrm{O}$ (in crystal state); (B) UV-vis absorption and RTP excitation spectra of $\mathrm{M}-\mathrm{PhCH}_{3} \mathrm{O}$ in crystal state. 

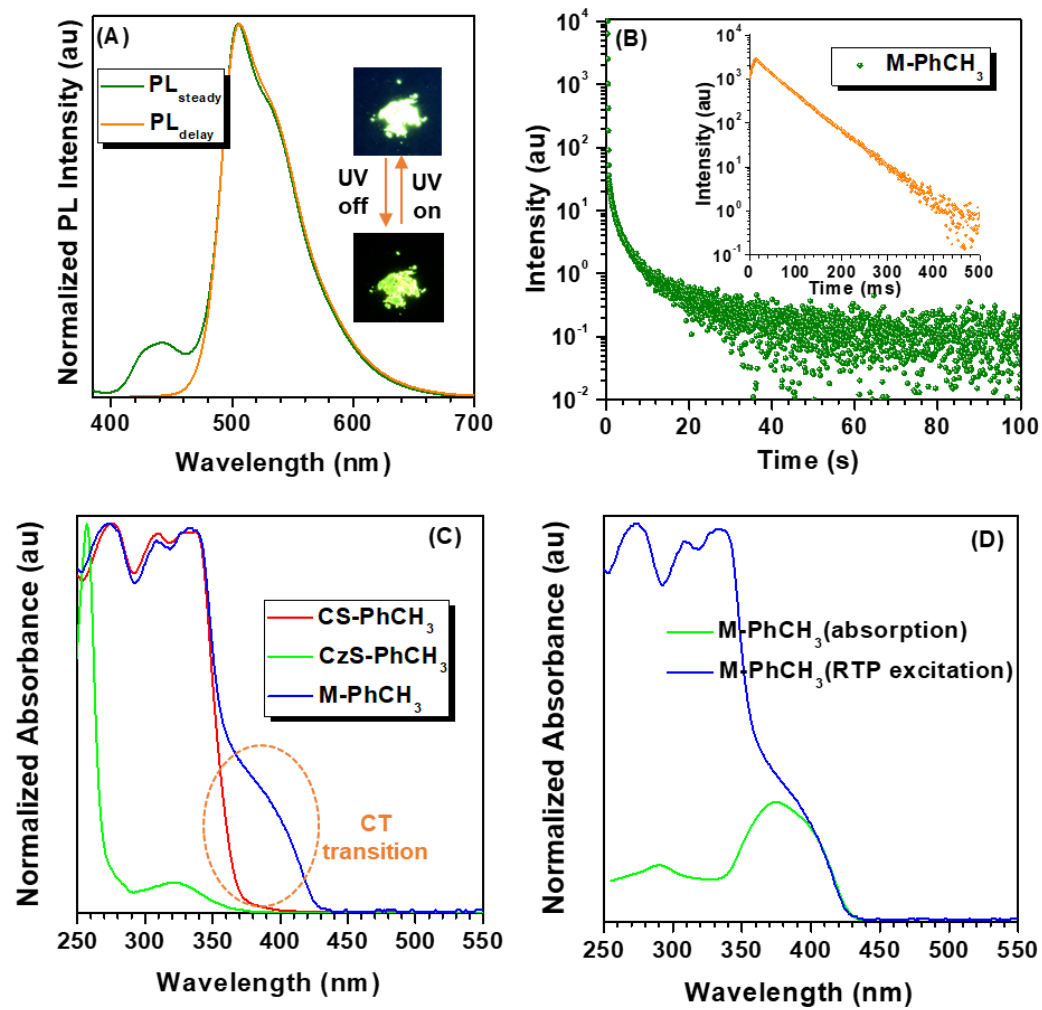

Figure S38 (A) The steady state PL and RTP spectra of co-crystal $\left(\mathrm{M}-\mathrm{PhCH}_{3}\right)$ based on CS-PhCH 3 and $\mathrm{CzS}-\mathrm{PhCH}_{3}$ with mass ratio of 100:1; (B) The RTP decay curves of $\mathrm{M}-\mathrm{PhCH}_{3}$, in which two components exist, the former one is relatively shorter and later one is ultra-long; (C) UV-vis absorption spectra of $\mathrm{CS}-\mathrm{PhCH}_{3}$ (in crystal state), $\mathrm{CzS}-\mathrm{PhCH}_{3}$ (in THF solution) and

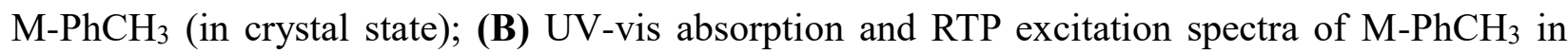
crystal state. 

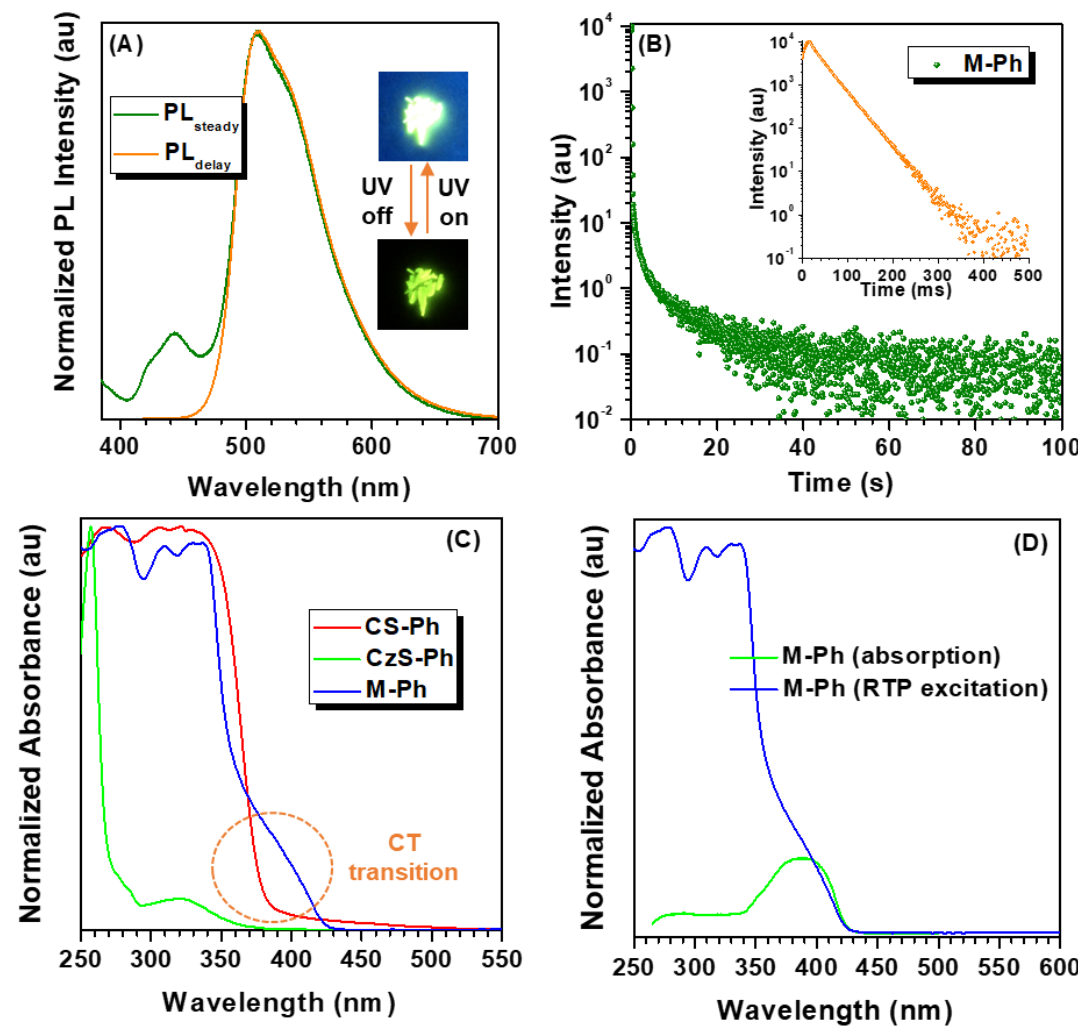

Figure S39 (A) The steady state PL and RTP spectra of co-crystal (M-Ph) based on CS-Ph and CzS-Ph with mass ratio of 100:1; (B) The RTP decay curves of M-Ph, in which two components exist, the former one is relatively shorter and later one is ultra-long; (C) UV-vis absorption spectra of CS-Ph (in crystal state), CzS-Ph (in THF solution) and M-Ph (in crystal state); (B) UV-vis absorption and RTP excitation spectra of M-Ph in crystal state. 

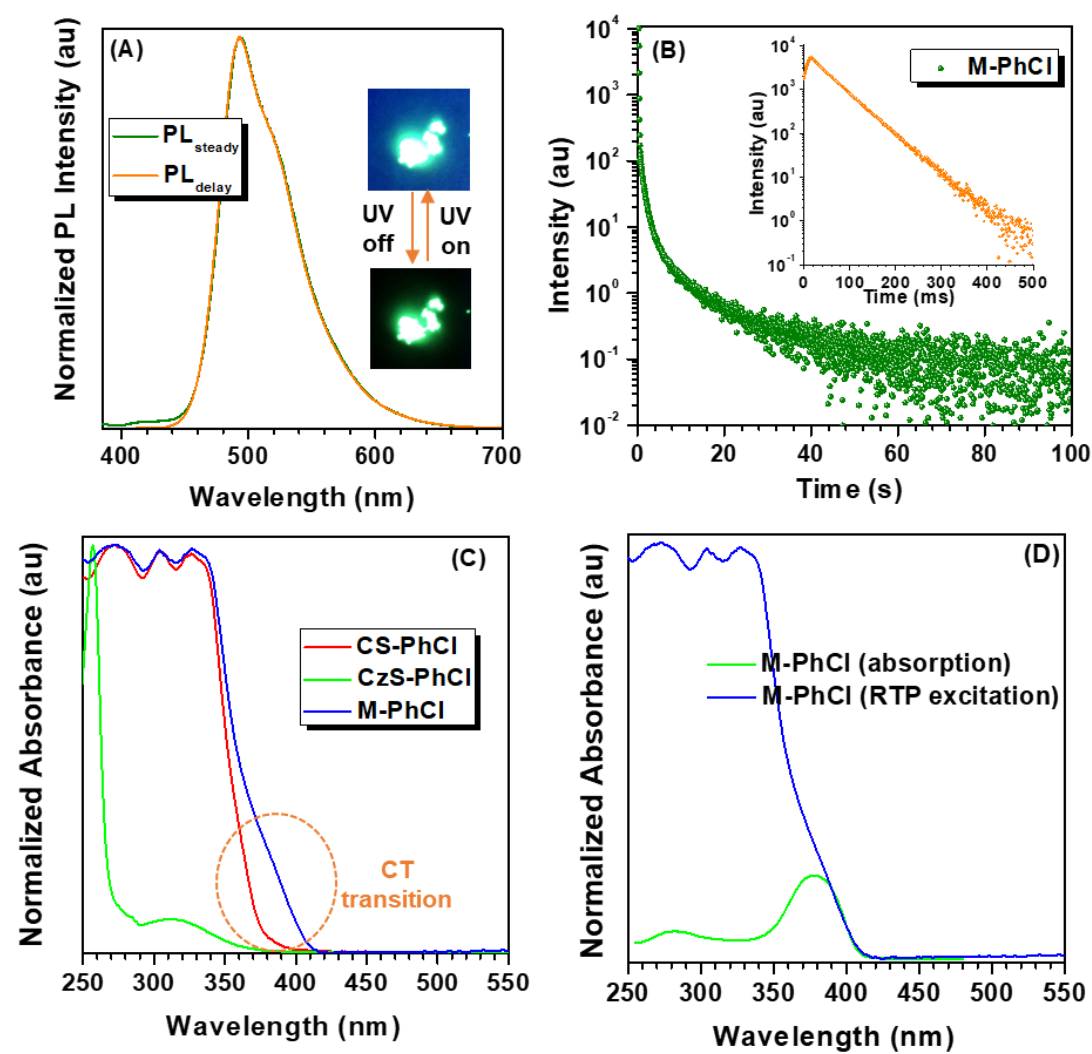

Figure S40 (A) The steady state PL and RTP spectra of co-crystal (M-PhCl) based on CS-PhCl and $\mathrm{CzS}-\mathrm{PhCl}$ with mass ratio of 100:1; (B) The $\mathrm{RTP}$ decay curves of $\mathrm{M}-\mathrm{PhCl}$, in which two components exist, the former one is relatively shorter and later one is ultra-long; (C) UV-vis absorption spectra of $\mathrm{CS}-\mathrm{PhCl}$ (in crystal state), $\mathrm{CzS}-\mathrm{PhCl}$ (in $\mathrm{THF}$ solution) and $\mathrm{M}-\mathrm{PhCl}$ (in crystal state); (B) UV-vis absorption and RTP excitation spectra of $\mathrm{M}-\mathrm{PhCl}$ in crystal state. 

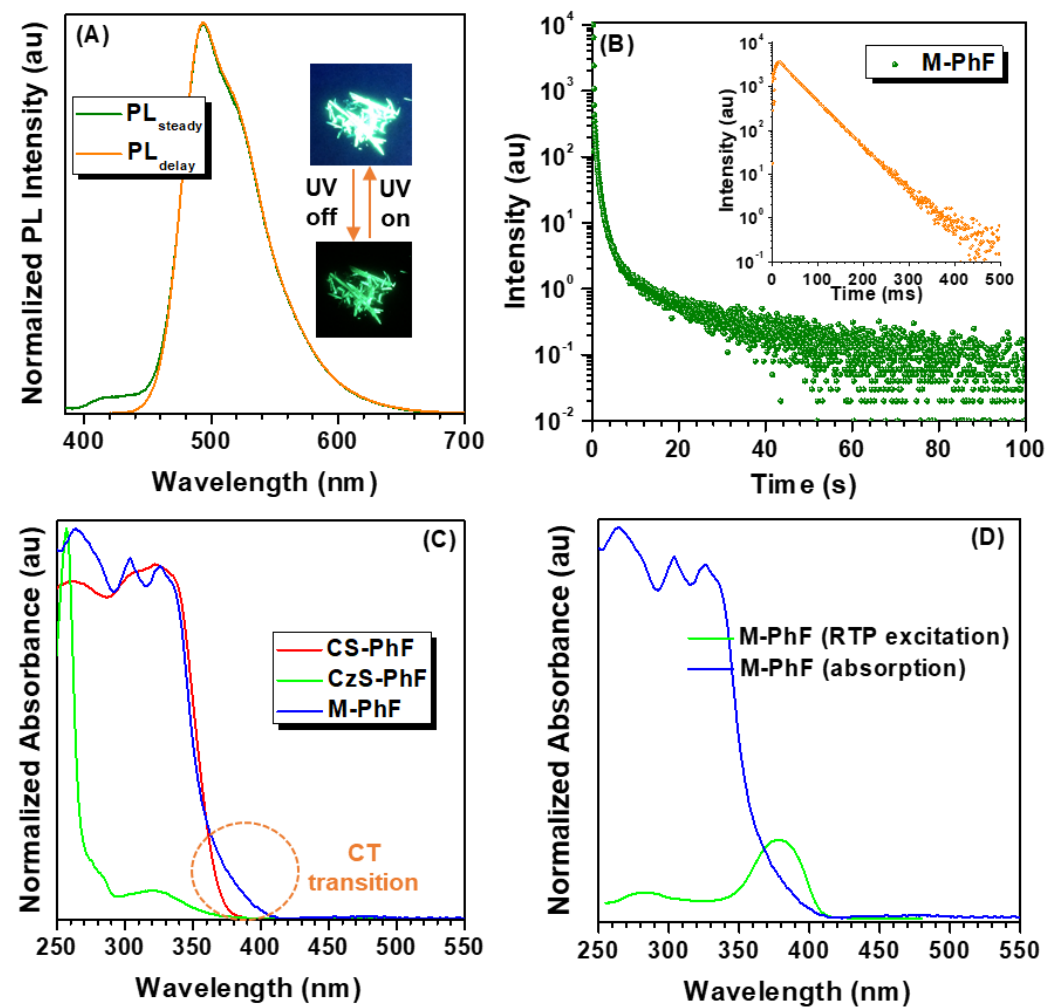

Figure S41 (A) The steady state PL and RTP spectra of co-crystal (M-PhF) based on CS-PhF and CzS-PhF with mass ratio of 100:1; (B) The RTP decay curves of M-PhF, in which two components exist, the former one is relatively shorter and later one is ultra-long; (C) UV-vis absorption spectra of CS-PhF (in crystal state), $\mathrm{CzS}-\mathrm{PhF}$ (in THF solution) and $\mathrm{M}-\mathrm{PhF}$ (in crystal state); (B) UV-vis absorption and RTP excitation spectra of M-PhF in crystal state.

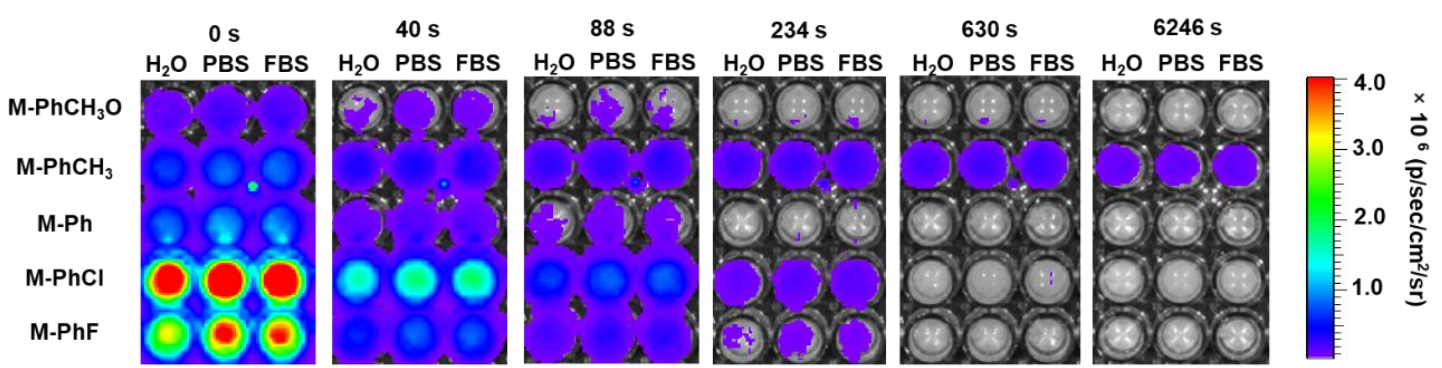

Figure S42 The afterglow imaging of the nanocrystals based on $\mathrm{M}-\mathrm{PhCH}_{3} \mathrm{O}, \mathrm{M}-\mathrm{PhCH}_{3}, \mathrm{M}-\mathrm{Ph}$, $\mathrm{M}-\mathrm{PhCl}$ and $\mathrm{M}-\mathrm{PhF}$. 
Table S3 The photophysical data of CS- $\mathrm{PhCH}_{3} \mathrm{O}, \mathrm{CS}-\mathrm{PhCH}_{3}, \mathrm{CS}-\mathrm{Ph}, \mathrm{CS}-\mathrm{PhCl}$ and $\mathrm{CS}-\mathrm{PhF}$.

\begin{tabular}{llllll}
\hline Sample & $\mathrm{CS}_{-} \mathrm{PhCH}_{3} \mathrm{O}$ & $\mathrm{CS}^{-\mathrm{PhCH}_{3}}$ & $\mathrm{CS}-\mathrm{Ph}$ & $\mathrm{CS}-\mathrm{PhCl}$ & $\mathrm{CS}-\mathrm{PhF}$ \\
\hline$\tau_{\mathrm{F}}$ & $0.35 \mathrm{~ns}$ & $0.34 \mathrm{~ns}$ & $0.29 \mathrm{~ns}$ & $0.66 \mathrm{~ns}$ & $0.40 \mathrm{~ns}$ \\
$\tau_{\mathrm{P}}$ & $88 \mathrm{~ms}$ & $96 \mathrm{~ms}$ & $188 \mathrm{~ms}$ & $256 \mathrm{~ms}$ & $410 \mathrm{~ms}$ \\
$\Phi_{\mathrm{P}}$ & $<1 \%$ & $<1 \%$ & $<1 \%$ & $<1 \%$ & $<1 \%$ \\
\hline
\end{tabular}

Table S4 The photophysical data of $\mathrm{CzS}-\mathrm{PhCH}_{3} \mathrm{O}, \mathrm{CzS}-\mathrm{PhCH}_{3}, \mathrm{CzS}-\mathrm{Ph}, \mathrm{CzS}-\mathrm{PhCl}$ and $\mathrm{CzS}-\mathrm{PhF}$.

\begin{tabular}{llllll}
\hline Sample & $\mathrm{CzS}_{-} \mathrm{PhCH}_{3} \mathrm{O}$ & $\mathrm{CzS}^{-\mathrm{PhCH}_{3}}$ & $\mathrm{CzS}-\mathrm{Ph}$ & $\mathrm{CzS}-\mathrm{PhCl}$ & $\mathrm{CzS}-\mathrm{PhF}$ \\
\hline$\tau_{\mathrm{F}}$ & $3.36 \mathrm{~ns}$ & $2.25 \mathrm{~ns}$ & $4.20 \mathrm{~ns}$ & $2.54 \mathrm{~ns}$ & $2.05 \mathrm{~ns}$ \\
$\tau_{\mathrm{P}}$ & $1.88 \mathrm{~ms}$ & $2.35 \mathrm{~ms}$ & $0.32 \mathrm{~ms}$ & $0.79 \mathrm{~ms}$ & $0.52 \mathrm{~ms}$ \\
$\Phi_{\mathrm{P}}$ & $<1 \%$ & $<1 \%$ & $<1 \%$ & $<1 \%$ & $<1 \%$ \\
\hline
\end{tabular}

Table S5 The photophysical data of $\mathrm{M}-\mathrm{PhCH}_{3} \mathrm{O}, \mathrm{M}-\mathrm{PhCH}_{3}, \mathrm{M}-\mathrm{Ph}, \mathrm{M}-\mathrm{PhCl}$ and $\mathrm{M}-\mathrm{PhF}$.

\begin{tabular}{llllll}
\hline Sample & $\mathrm{M}-\mathrm{PhCH}_{3} \mathrm{O}$ & $\mathrm{M}-\mathrm{PhCH}_{3}$ & $\mathrm{M}-\mathrm{Ph}$ & $\mathrm{M}-\mathrm{PhCl}$ & $\mathrm{M}-\mathrm{PhF}$ \\
\hline$\Phi_{\mathrm{P}}$ & $36.40 \%$ & $37.16 \%$ & $22.22 \%$ & $54.80 \%$ & $23.86 \%$ \\
$\tau_{\mathrm{P} 1}$ & $30 \mathrm{~ms}$ & $45 \mathrm{~ms}$ & $29 \mathrm{~ms}$ & $42 \mathrm{~ms}$ & $40 \mathrm{~ms}$ \\
$\tau_{\mathrm{P} 2}$ & $2.52 \mathrm{~s}$ & $7.12 \mathrm{~s}$ & $9.39 \mathrm{~s}$ & $6.38 \mathrm{~s}$ & $8.15 \mathrm{~s}$ \\
\hline
\end{tabular}



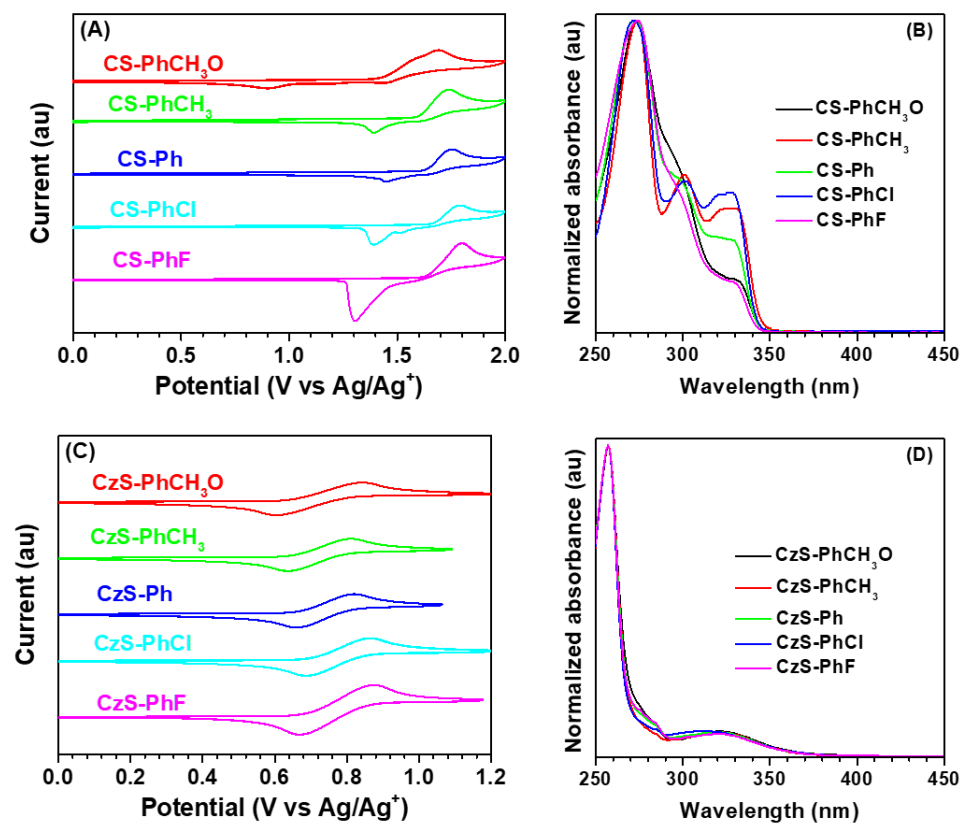

Figure S43 (A) The CV curves of $\mathrm{CS}-\mathrm{PhCH}_{3} \mathrm{O}, \mathrm{CS}-\mathrm{PhCH}_{3}, \mathrm{CS}-\mathrm{Ph}, \mathrm{CS}-\mathrm{PhCl}$ and $\mathrm{CS}-\mathrm{PhF}$; (B) The UV-vis absorption spectra of CS-PhCH $3{ }_{3} \mathrm{O}, \mathrm{CS}-\mathrm{PhCH}_{3}, \mathrm{CS}-\mathrm{Ph}, \mathrm{CS}-\mathrm{PhCl}$ and $\mathrm{CS}-\mathrm{PhF}$ in THF solutions; (C) The CV curves of $\mathrm{CzS}-\mathrm{PhCH}_{3} \mathrm{O}, \mathrm{CzS}-\mathrm{PhCH}_{3}, \mathrm{CzS}-\mathrm{Ph}, \mathrm{CzS}-\mathrm{PhCl}$ and $\mathrm{CzS}-\mathrm{PhF}$; (D) The UV-vis absorption spectra of $\mathrm{CzS}-\mathrm{PhCH}_{3} \mathrm{O}, \mathrm{CzS}-\mathrm{PhCH}_{3}, \mathrm{CzS}-\mathrm{Ph}, \mathrm{CzS}-\mathrm{PhCl}$ and $\mathrm{CzS}-\mathrm{PhF}$ in THF solutions.

Table S6 The HOMO and LUMO date of RTP donors and acceptors.

\begin{tabular}{cccc}
\hline & $\boldsymbol{E}_{\mathbf{g}}(\mathbf{e V})$ & $\boldsymbol{E}_{\text {номо }}(\mathbf{e V})$ & $\boldsymbol{E}_{\mathbf{L u m o}}(\mathbf{e V})$ \\
\hline $\mathrm{CS}-\mathrm{PhCH}_{3} \mathrm{O}$ & 3.60 & -5.75 & -2.15 \\
$\mathrm{CzS}^{-} \mathrm{PhCH}_{3} \mathrm{O}$ & 3.38 & -4.96 & -1.58 \\
$\mathrm{CS}^{-P h C H}{ }_{3}$ & 3.60 & -5.92 & -2.32 \\
$\mathrm{CzS}^{-}-\mathrm{PhCH}_{3}$ & 3.40 & -4.96 & -1.56 \\
$\mathrm{CS}-\mathrm{Ph}$ & 3.63 & -5.95 & -2.32 \\
$\mathrm{CzS}-\mathrm{Ph}$ & 3.38 & -4.99 & -1.61 \\
$\mathrm{CS}-\mathrm{PhCl}$ & 3.64 & -5.99 & -2.35 \\
$\mathrm{CzS}-\mathrm{PhCl}$ & 3.36 & -5.02 & -1.66 \\
$\mathrm{CS}-\mathrm{PhF}$ & 3.63 & -5.95 & -2.32 \\
$\mathrm{CzS}-\mathrm{PhF}$ & 3.40 & -5.00 & -1.60
\end{tabular}




\section{Reference}

15. Yang. J. et al. Elucidating the Excited State of Mechanoluminescence in Organic Luminogens with Room-Temperature Phosphorescence. Angew. Chem. Int. Ed. 56, 15299-15303 (2017).

21. Yang, J. et al. The odd-even effect of alkyl chain in organic room temperature phosphorescence luminogens and the corresponding in vivo imaging. Mater. Chem. Front. 3, 1391-1397 (2019). 